
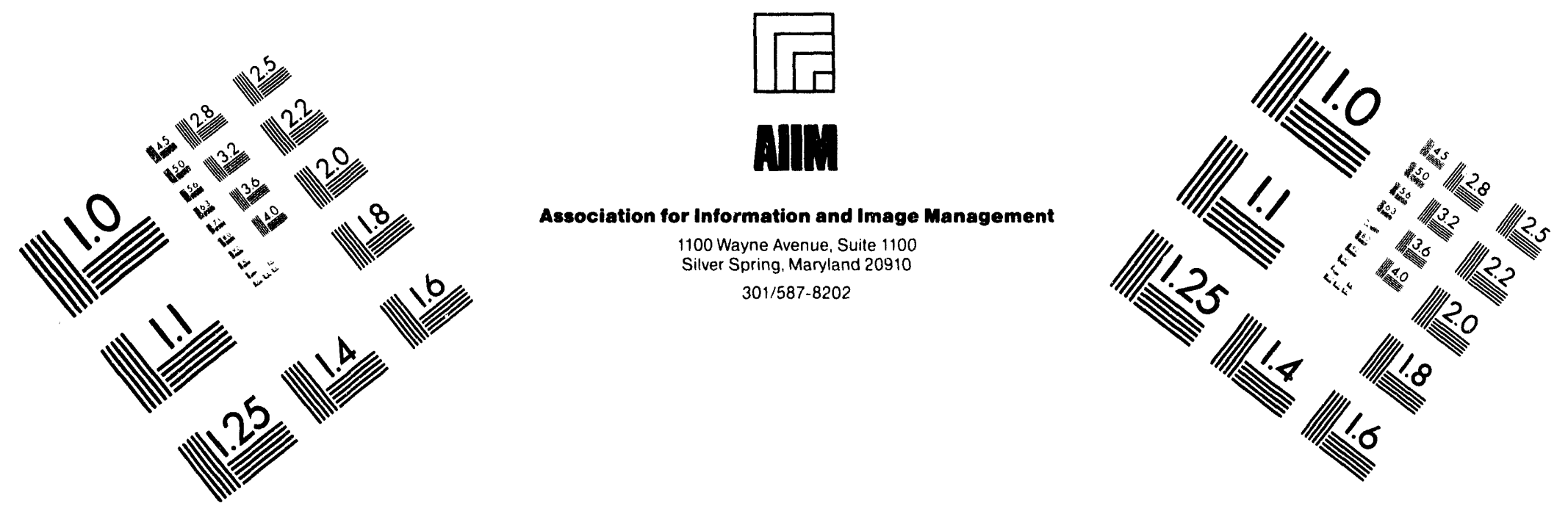

\title{
Centimeter
}

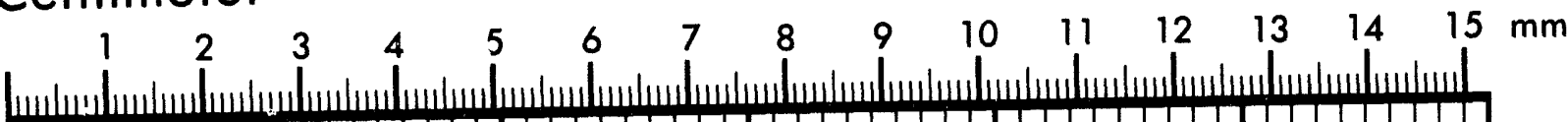

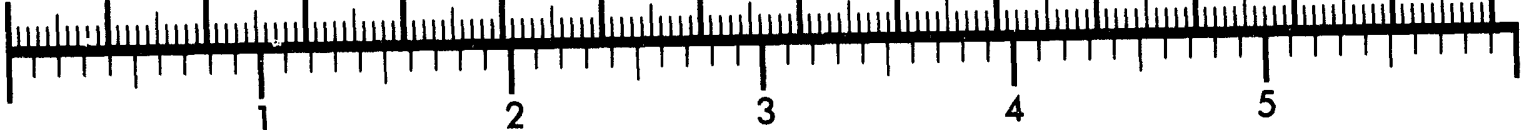
Inches
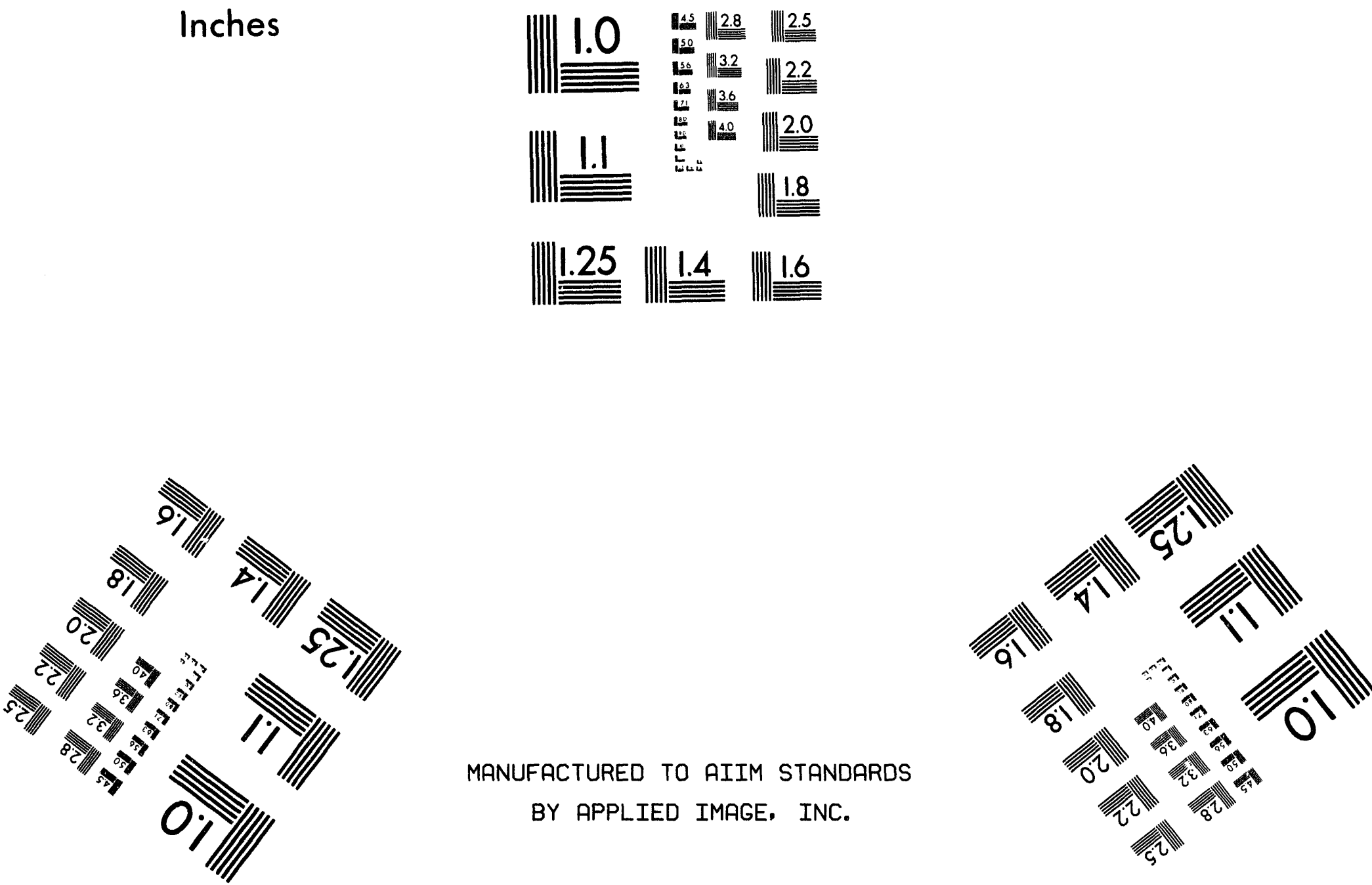

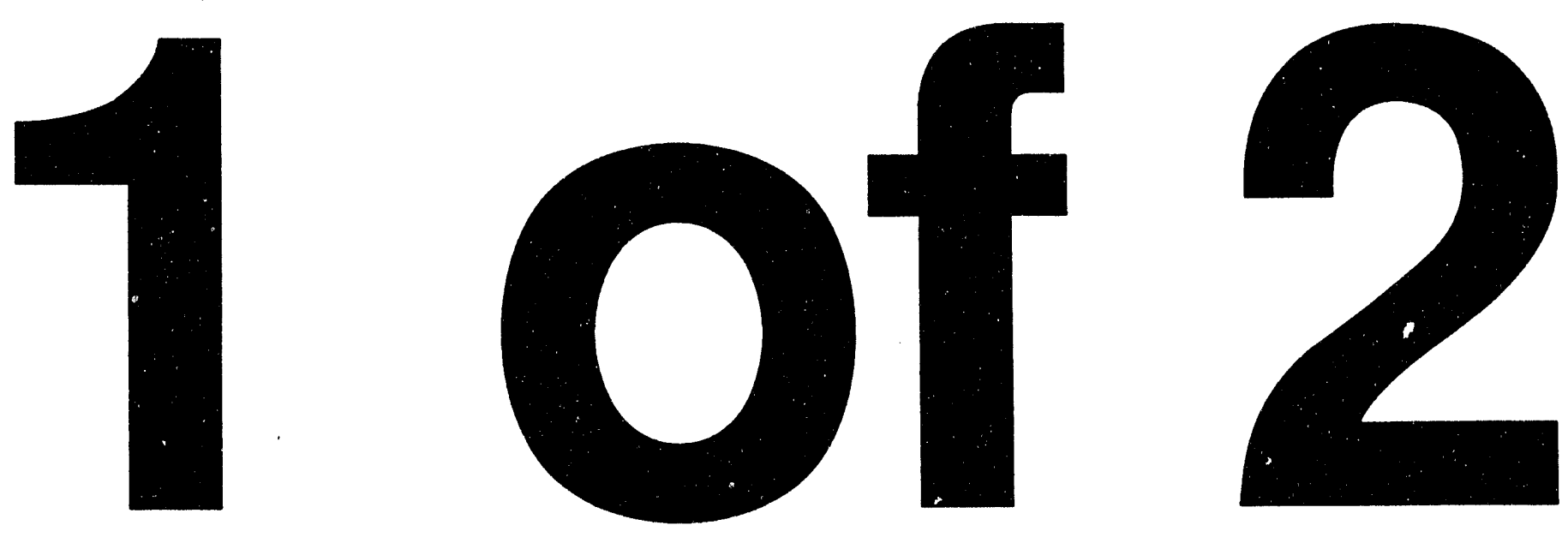
DOE/RL-94-96

UC-630

\section{Hanford Site Pollution Prevention Plan Progress Report, 1993}

Date Published

August 1994

United States

Department of Energy

P.O. Box 550

Richland, Washington 99352

Approved for Public Release 
DOE/RL-94-96

This page left intentionally blank. 


\section{FOREWARD}

This is the Hanford Site annual Pollution Prevention Progress Report for calendar year 1993. This report tracks progress against the goals stated in the Hanford Site 5-year Pollution Prevention Plan. The executive summary of the plan was submitted to the Washington State Department of Ecology (Ecology) in September 1992. The plan, executive summary, and the progress reports are elements of a pollution prevention planning program that is required by Washington Administrative Code (WAC) 173-307 for all hazardous substance users and/or all hazardous waste generators regulated by Ecology. These regulations implement Chapter 70.95C, Revised Code of Washington, an act relating to hazardous waste reduction. The act encourages voluntary efforts to redesign industrial processes to help reduce or eliminate hazardous substances and hazardous waste byproducts, and to maximize the inprocess reuse or reclamation of valuable spent material.

The Hanford Site is voluntarily complying with this state regulatory-mandated program. All treatment, storage, or disposal (TSD) facilities are exempt from participating; the Hanford Site is classified as a TSD.

This is the first year the Hanford Site is submitting a progress report. It covers calendar year 1993 plus the last quarter of 1992, which followed the submittal of the Pollution Prevention Plan.

What is reported, in accordance with WAC 173-307, are reductions in hazardous substance use and hazardous waste generated. The state defines hazardous substances as those pursuant to Section 313 of Title III of the Superfund Amendments and Reauthorization Act and all ozone-depleting compounds as defined by the Montreal Protocol of 1987 and any further updates. The state defines hazardous waste as all dangerous and extremely hazardous wastes, but does not include radioactive or mixed wastes, or any hazardous waste generated because of federal or state remedial action (decontamination and decomissioning work).

A system of Process Waste Assessments (PWA) was chosen to meet the requirements of the program. The PWAs were organized by a physical facility or company organization. Each waste-generating facility/organization performed PWAs to identify, screen, and analyze their own reduction options. Each completed PWA identified any number of reduction opportunities, that are listed individually in the plan and summarized by category in the executive summary. These opportunities were to be implemented or evaluated further over the duration of the 5-year plan. The basis of this progress report is to track action taken on these PWA reduction opportunities in relationship to achieving the goals stated in the Pollution Prevention Plan.

The Executive Summary of the Pollution Prevention Plan combined all similar PWA opportunities and consolidated them into a table (Executive Summary/Table 3). This progress report updates individual opportunities as they are listed in the plan and provides categorization according to the Executive Summary.

Section A discusses progress toward goals that includes some non-PWA reduction opportunities. Section B updates the reduction/recycle/treatment opportunities on the original PWAs that were identified in the 1992 Pollution Prevention Plan. Listed are only opportunities that were implemented or rejected/canceled during the reporting period. Section $C$ identifies new PWAs and the associated opportunities that were conducted after submittal of the executive summary. Section D discusses production levels, problems encountered, and estimation techniques. All sections have been developed using Ecology's suggested worksheets. 
In most cases postimplementation tracking did not occur, and actual reduction amounts are not available. Also, estimated reduction amounts were not always provided on the PWAs; therefore, reduction quantities cannot always be listed on worksheet 4 . Annual reduction amounts reflect actual or estimated reduction quantities for a 12-month duration, regardless of the time of year the opportunity was implemented. Reduction quantitiess used for 1992 data are for the entire year.

At the Hanford Site, not all hazardous waste generation and hazardous substance use reduction result from a formal PWA process. Numerous reductions arise from ideas generated by individuals closely tied to the hazardous waste generating activity and to the hazardous substance procurement process. Table 1 lists numerous non-PWA opportunities that were implemented in 1993 (taken from 1993 waste minimization report) that were not included in the Pollution Prevention Plan. 
Table 1. Summary of 1993 Waste Minimization Opportunities.

Hazardous Waste Stream/Form ANN/L

EDTA/L

HEDTA/L

Hazardous Material Inventory/L \& S

Lead Acid Batteries

Lab 58-325 Operations/L

Lithium Metal Removal from Building 324/S

321 Building Chemicals/L \& $S$

PCB-Contaminated Transformers/S

SST Waste Simulant/S

Used Photographic Fixer/L

Radiography Negatives/S

Unused Products $/ \mathrm{L}$

Building Demolition/L

Sulfuric Acid/L

Sulfuric Acid/L

CFCs/G

Ethylene Glycol/L

Radiography Negatives/S

Onsite Recycle/L \& S

Gel Cell Batteries/S

Synthetic Saltcake/S

Used Photographic Fixer/L

Royalprint Activator/L

Used Fixer Filters/L \& S

Used Fixer/L

Scrap Film \& Paper/S

Spent Solvent (Vehicle)/L

Old, Unused Product/L \& S

Lead Acid Batteries/L \& S

Ethylene Glycol/L

Custodial Sipplies (Aerosols)/L \& S

Old, Unused Product/L \& S

Waste Solvent/L

Solvent Wetted Patches/S

Old, Unused Product/L \& S

Lead Acid Batteries (Auto)/L \& S

Parts Washer Solvent/L

Antifreeze/L

Aerosol Cans/L

General Use Products/L

General Use Products/L

Maintenance Wastes

Painting Preparation Wastes/S

Paint Wastes/L \& S

General Use Products/L

General Use Products/L

Maintenance Painting/L \& S

Spill, Absorptions Wastes/S

Low-Level Waste/S

Batteries/L \& S

Hazardous Waste $/$

Hazardous Waste/L \& S

Hazardous Waste $/ \mathrm{L}$

Hazardous Waste (Lead Acid Battery)/S

Hazardous Waste (Cold Chemical Disposal)/L

Hazardous Waste/L \& S

Hazardous Waste $/ \mathrm{L}$

Excess Chemicals/L,S \& G

bold type denowes a PWA opportunity

Ilsted in the Polhuion Prevention Plan

\section{Process/Method}

Reclassified \& Transferred/R

Reclassified \& Excessed/R

Reclassified \& Excessed/R

Admin./Purchasing Controls-Substitution/SR

Recycled/R

Reclassified \& Transferred/R

Reclassified \& Excessed/R

Transferred/R

Retrofitted \& Reclassified/SR

Reconstituted/R

Sent to Silver Recovery/R

Sent to Silver Recycler/R

Excessed/R

Excessed/R

Excessed/R

Excessed/R

Procedure Modified/SR

Filtered/TT

Sent to Silver Recycler/R

Recycled/R

Recycled/R

Reused/R

Sent for Silver Recovery to $3746 \mathrm{D} / \mathrm{TT}$

Reclassified \& Transferred/SR

Reclaimed \& Excessed/R

Reclaimed \& Excessed/R

Reclaimed \& Excessed/R

Reclamation \& Extend Length of Use/SR

Substitution/SR

Recycled/R

Shipped Off Site \& Recycled/R

Reused/SR

Substitution/SR

Filtered \& Reused/R

Refiltering/R

Substitution/SR

Vendor core exchange/R

Reduced Volume Used/R

Recycled/R

Aerosol Can Puncturing System/R

Reclassified \& Transferred/R

Reclassified \& Transferred/R

Reclassified \& Transferred/R

Replacement with $\mathrm{CO} 2$ Pelletization/SR

Reclassified \& Transferred/R

Reclassified \& Transferred/R

Affirmative Procurement/SR

Affirmative Procurement/SR

Substitute Absorbents/SR

Reduction of Rad. Control Areas/SR

Recycled/R

Reclassified \& Used/R

Transferred \& Used/R

Transferred/R

Recycled/R

Transferred or Excessed/R

Consolidated \& Use/SR

Substitution/SR

Excessed or Recycled/R

GRAND TOTAL:

(SR)/SOURCE REDUCTION TOTAL:

$$
\begin{aligned}
& G=\text { gas } \\
& L=\text { liquid } \\
& S=\text { solid }
\end{aligned}
$$

Weight (lb.)

$122,056.0$

$32,604.0$

$24,244.0$

na

$2,574.0$

360.8

$6,870.6$

360.8

$131,189.9$

897.6

501.6

$8,505.2$

0.0

8.4

$26,516.2$

$68,230.8$

554.4

459.8

363.3

na

49.5

297.0

$1,003.2$

108.7

39.6

$\mathbf{8 , 5 1 8 . 8}$

$4,804.5$

$1,914.0$

na

2,178.0

$14,713.6$

$9,900.0$

na

40.0

180.4

na

73,396.6

$9,028.8$

$15,219.6$

167.2

16.5

50.6

59.4

242.0

209.0

$5,999.4$

$11,598.4$

622.6

$18,997.0$

$5,016.0$

$8,498.6$

200.6

9,719.6

255.0

$5,075.4$

$189,094.8$

na

297.0

$823,858.3$

$175,126.9$

$647,268.4$

$1,463.0$
Weight (kg.)

$55,480.0$

$14,820.0$

$11,020.0$

na

$1,170.0$

164.0

$3,123.0$

164.0

$59,631.8$

408.0

228.0

$3,866.0$

0.0

3.8

$12,052.8$

$31,014.0$

252.0

209.0

165.2

na

22.5

135.0

456.0

49.4

18.0

$3,872.2$

$2,183.9$

870.0

na

990.0

$6,688.0$

$4,500.0$

na

18.2

82.0

na

33,362.1

$4,104.0$

$6,918.0$

76.0

7.5

23.0

27.0

110.0

95.0

$2,727.0$

$5,272.0$

283.0

$8,635.0$

$2,280.0$

$3,863.0$

91.2

4,418.0

115.9

$2,307.0$

$85,952.2$

na

na

135.0

374,481 .0

$79,603.2$

$294,212.9$

665.0 
DOE/RL-94-96

This page left intentionally blank. 


\section{TABLE OF CONTENTS}

SECTION A: PROGRESS TOWARD GOALS $\ldots \ldots \ldots \ldots \ldots \ldots \ldots \ldots \ldots$

SECTION B: IMPLEMENTED OPPORTUNITIES $\ldots \ldots \ldots \ldots \ldots \ldots \ldots \ldots \ldots$

SECTION C: NEWLY IDENTIFIED OPPORTUNITIES $\ldots \ldots \ldots \ldots \ldots \ldots \ldots \ldots$

SECTION D: PRODUCTION LEVELS, PROBLEMS, AND ESTIMATION TECHNIQUES . D-1

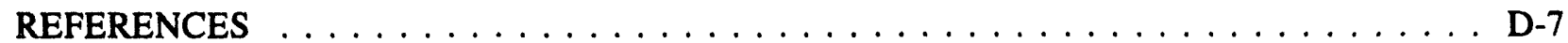

\section{TABLES}

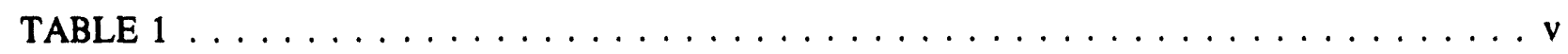

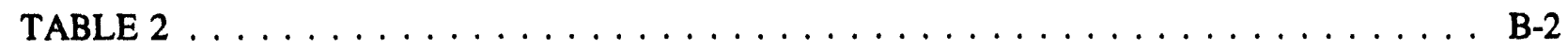

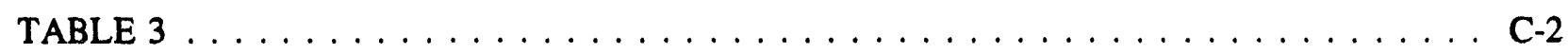


DOE/RL-94-96

This page left intentionally blank. 
DOE/RL-94-96

\section{SECTION A}

\section{PROGRESS TOWARD GOALS}




\section{Worksheet 1}

\section{Facility Identification, Progress Toward Goals}

Facility Name: Hanford Site

State/EPA Identification number(s): WA7890008967

Reporting Year(s): October 1, 1992 - December 31, 1993

\section{Progress Toward Goals -080(1)(a)}

If you established numeric goals in your plan, you need to discuss your progress towards meeting those goals. First, write the original goals established in your plan in the table below to help put the discussion into context. If numeric goals have not been established, leave the table blank. Ecology is most interested in your progress towards the goals established for the five year life of your plan. You might include an estimated percentage of each goal that has been achieved through this reporting year.

\begin{tabular}{|l|l|l|l||}
\hline $\begin{array}{c}\text { Hazardous Substance } \\
\text { Use Reduction }\end{array}$ & \multicolumn{1}{|c|}{$\begin{array}{c}\text { Hazardous Waste } \\
\text { Reduction }\end{array}$} & \multicolumn{1}{|c|}{$\begin{array}{c}\text { Hazardous Waste } \\
\text { to be Recycled }\end{array}$} & \multicolumn{1}{c|}{$\begin{array}{c}\text { Hazardous Waste } \\
\text { to be Treated }\end{array}$} \\
\hline $\begin{array}{l}\text { Goal: } 25 \% \\
\text { (b91) }\end{array}$ & $\begin{array}{l}\text { Goal: } 30 \% \text { thru '95 } \\
\text { (b90) } 15 \% \text { thru } 9 / 93\end{array}$ & Goal: no goal set & Goal: no goal set \\
\hline Achlevement: $31 \%$ & Achievement: $61 \%$ & Achievement: $\mathrm{n} / \mathrm{a}$ & Achievement: $\mathrm{n} / \mathrm{a}$ \\
\hline
\end{tabular}

Discussion: The use of hazardous substances has declined significantly in the last two years despite the growing list of eligiable chemicals (new additions to the EPCRA list). The following data are from the Hazardous Material Inventory Database (HMID2) that shows the annual usage of hazardous substances (1991 is used as baseline):

$$
\begin{array}{llll}
1991- & 147,149 \mathrm{lb} & (66886 \mathrm{~kg}) \\
1993- & 100,783 \mathrm{lb} & (45810 \mathrm{~kg})
\end{array}
$$

Total usage from the base year declined by $31 \%$ for $1993^{*}$, which exceeds the 5 -year goal of $25 \%$. Already the intended goal has been met with still 3 years remaining. A portion of this reduction is attributable to a reduction in Hanford Site activities. One example is the reduced need for potable water which results in a reduction in the amount of chlorine used for treatment. The balance of reduction can be attributed to a heightened awareness by the users of products containing hazardous substances. This awareness has led to reduced usage. Many of these reduction successes do not have a directly identifiable cause and have gone unreported by the facility.

Procurement control programs, implemented both at the facility and contractor levels, have been effective in reducing both the quantities and variety of products containing hazardous substances that are purchased. This has been accomplished through exchange of surplus chemicals and identification of alternative nonhazardous products.

\footnotetext{
Measured weights are only for the chemical constituent, not the weight of the entire product(s) used.
} 
Hazardous waste reduction measurement is based on hazardous waste generation data. The following data are taken from the Solid Waste Information Tracking System (SWITS) database. The following figures represent annual non-D\&D hazardous waste generation for the Hanford Site based on shipment date of the waste (1990 is used as baseline):

$$
\begin{array}{lrl}
1990- & 1,448,040 \mathrm{lb} & (658200 \mathrm{~kg}) \\
1993- & 558,976 \mathrm{lb} & (254080 \mathrm{~kg})
\end{array}
$$

This is a significant $61 \%$ reduction that doubles the reduction goal in less than one half the expected time period.

No goals were established in the plan for recycling or treatment of hazardous wastes.

If you have revised your goals or have newly established goals, display them in the table below.

\begin{tabular}{||l|l|l|l|}
\hline $\begin{array}{c}\text { Hazardous Substance } \\
\text { Use Reduction }\end{array}$ & \multicolumn{1}{|c|}{$\begin{array}{c}\text { Hazardous Waste } \\
\text { Reduction }\end{array}$} & \multicolumn{1}{|c|}{$\begin{array}{c}\text { Hazardous Waste } \\
\text { to be Recycled }\end{array}$} & \multicolumn{1}{c|}{$\begin{array}{c}\text { Hazardous Waste } \\
\text { to be Treated }\end{array}$} \\
\hline New Goal: & New Goal: & New Goal: & New Goal: \\
\hline
\end{tabular}

Discuss your progress towards meeting these revised or newly established goals. If numeric goals have not been established, please discuss your progress toward setting them.

Discussion: Although the procurement control programs are intended to reduce purchasing of . all products containing hazardous chemicals, additional goals have been established on the reduction of certain toxic chemicals. These goals are as follows:

1. A reduction of $50 \%$ by 1999 for the 17 chemicals identified in EPA $33 / 50$ program.

2. Total elimination of Class | ozone-depleting substances by 1995 .

If you established any non-numeric goals in your plan, e.g. establishment of employee training programs, please discuss your progress in meeting these non-numeric goals.

Discussion: $n / a$ 
DOE/RL-94-96

This page left intentionally blank.

A-4 
DOE/RL-94-96

\section{SECTION B}

\section{IMPLEMENTED OPPORTUNITIES}

B-1 
The following table is an update of Table 3 in the Executive Summary, which summarized reduction opportunities selected for implementation. This table categorizes the implemented PWA opportunities into 22 categories and lists each opportunity number in the appropriate opportunity category. This updated table combines similar categories from the original table.

Table 2. Opportunities Selected for Implementation.

\begin{tabular}{|c|c|c|c|}
\hline & $\begin{array}{l}\text { OPPORTUNITY } \\
\text { CATEGORY } \\
\end{array}$ & PROCESS & OPPORTUNITY NUMBERS \\
\hline 1 & Electroric ballasts & Lighting of facilities & \\
\hline 2 & Turn off lights & $\begin{array}{l}\text { Lighting of inactive } \\
\text { facilities }\end{array}$ & \\
\hline 3 & Product substitution & $\begin{array}{l}\text { PCB light ballasts; PCB } \\
\text { capacitors; light bulbs; } \\
\text { batteries; paint and paint } \\
\text { waste; DOP saturated rags; } \\
\text { cleaning }\end{array}$ & $\begin{array}{l}\text { FOT 1-2; FOT } 4-1 \text {; KEH 1-1; } \\
\text { GAS } 7-1 \text {; EFS } 1-1\end{array}$ \\
\hline 4 & Water treatment center & Sodium bulbs & \\
\hline 5 & New purge units & Refrigerant/chillers & \\
\hline 6 & Solvent recovery & Paint waste & $\mathrm{KEH} \mathrm{2-4}$ \\
\hline 7 & $\begin{array}{l}\text { Electrostatic spray } \\
\text { painting }\end{array}$ & Paint waste & KEH 2-3 \\
\hline 8 & $\begin{array}{l}\text { Eliminate use of poison } \\
\text { baits }\end{array}$ & Waste pesticides & EFS 2-1 \\
\hline 9 & Training/awareness & Gasoline spill & \\
\hline 10 & $\begin{array}{l}\text { Storage facility } \\
\text { inspections }\end{array}$ & Spill residue cleanup & \\
\hline 11 & $\begin{array}{l}\text { Inventory/procurement } \\
\text { control }\end{array}$ & $\begin{array}{l}\text { Chemical products use; } \\
\text { surveillance, maintenance, } \\
\text { \& cleanup }\end{array}$ & $\begin{array}{l}\text { FOT } 6-1 \text {; FOT } 6-2 \text {; FOT } 6-3 \text {; } \\
\text { TPT } 1-1 \text { TPT } 1-3 \text { FFT } 7-1 ; \\
\text { FFT } 7-3 \text {; GAS } 4-3 \text {; GAS } 7-2 \text {; } \\
\text { GAS } 9-2 \text {; EFS } 5-2\end{array}$ \\
\hline 12 & Recycle coolant & Liquid coolant & FFT 1-1; FAB 2-1 \\
\hline 13 & Segregate & Solvent cleaning rags & \\
\hline 14 & Job control & $\begin{array}{l}\text { Surveillance, maintenance, } \\
\& \text { cleanup }\end{array}$ & TPT $1-2 ;$ GAS $4-2 ;$ GAS 9-1 \\
\hline 15 & Material tracking & $\begin{array}{l}\text { Surveillance, maintenance, } \\
\& \text { cleanup }\end{array}$ & GAS 4-4 \\
\hline 16 & Use material exchanges & $\begin{array}{l}\text { Surveillance, maintenance, } \\
\& \text { cleanup; chemical } \\
\text { products use }\end{array}$ & TPT 1-4; GAS 4-6; EFS 5-1 \\
\hline
\end{tabular}


DOE/RL-94-96

\begin{tabular}{||l||l|l||l||}
\hline 17 & Improve housekeeping & Maintenance; clean-outs & EFS 4-1 \\
\hline 18 & Recycling & Maintenance; construction & GAS 4-5 \\
\hline 19 & Procedure change & $\begin{array}{l}\text { Maintenance; construction; } \\
\text { lighting; operations }\end{array}$ & FOT 5-1; GAS 7-3; GAS 9-3 \\
\hline 20 & Design changes & Maintenance; operations & \\
\hline 21 & $\begin{array}{l}\text { Recover } \\
\text { refrigerants/CFCs }\end{array}$ & Refrigeration & \\
\hline 22 & Process modification & Fabrication; construction & GAS 4-1 \\
\hline
\end{tabular}

PCB - Polychlorinated biphenyl

DOP - Dioctyl phthalate

CFC - Chlorinated fluorocarbon 


\section{Worksheet 2 \\ Opportunity Descriptions - 080(1)(i)}

Briefly describe the reduction opportunities you have implemented during the past reporting year; or reference the section and page number where the opportunities are described in your Executive Summary for plan submitted in lieu of an Executive Summary). In either case, provide the following information:

- A short name and number for each opportunity. If you did this in your plan or Executive Summary, use the same name and number. Transfer the short name and/or code number to Worksheet 4.

- A discussion on any reduction opportunities that have changed from the original plan or prior progress reports.

- A description of any new opportunities you have identified and selected for implementation.

Facility name: Hanford

Reporting Year(s): October 1, 1992 - December 31, 1993

Number: FFT 1-1

Short name: Recycle/filter

Description: Liquid coolant drained from systems during maintenance and testing is to be filtered and returned to the system.

\section{Worksheet 3 \\ Processes Impacted - 080(1)(a)(ii)}

Briefly describe the processes affected by your reduction opportunities; or reference the section and page number where they are described in your Executive Summary (or plan submitted in lieu of an Executive Summary). In either case, provide the following information:

- A short name and number for each process. If you did this for your plan or Executive Summary, use the same name and number. Transfer the short name and/or code number to Worksheet 4.

- $\quad$ A discussion on the processes affected by your reduction opportunities.

Facility name: Hanford

Reporting Year(s): October 1, 1992 - December 31, 1993

Number: $\quad$ FFT-1

Short name: Liquid coolant

Description: Ethylene glycol is used for coolant for equipment and temperature control for the plant and interim examination and maintenance (IEM) cell. Ethylene glycol is drained from the system during maintenance activities. This same glycol is filtered and returned to the system as much as possible. Waste glycol is collected from pump seal leaks. Glycol-wetted rags are also handled as hazardous waste. 


\section{Worksheet 2}

Opportunity Descriptions - 080(1)(i)

Briefly describe the reduction opportunities you have implemented during the past reportins ar; or reference the section and page number where the opportunities are described in ycur Executive Summary for plan submitted in lieu of an Executive Summary). In either case, provide the following information:

- A shor name and number for each opportunity. If you did this in your plan or Executive Summary, use the same name and number. Transfer the shor name and/or code number to Worksheet 4.

- $A$ discussion on any reduction opportunities that have changed from the original plan or prior progress reports.

- A description of any new opportunities you have identified and selected for implementation.

Facility name: Hanford

Reporting Year(s): October 1, 1992 - December 31, 1993

Number: $\quad$ FFT 7-1

Short name: Process review

Description: Ongoing review by reduction opportunities identification team for potential waste minimization and recycle.

Number: $\quad$ FFT $7-3$

Short name: Ordering process

Description: Need to reevaluate the ordering process to minimize the amount purchased.

\section{Worksheet 3}

\section{Processes Impacted - 080(1)(a)(ii)}

Briefly describe the processes affected by your reduction opportunities; or reference the section and page number where they are described in your Executive Summary (or plan submitted in lieu of an Executive Summary). In either case, provide the following information:

- $\quad$ A sho.7 name and number for each process. If you did this for your plan or Executive Summary, use the same name and number. Transfer the shor name and/or code number to Worksheet 4.

- $\quad$ A discussion on the processes affected by your reduction opportunities.

Facility name: Hanford

Reporting Year(s): October 1, 1992 - December 31, 1993

Number: $\quad$ FFT-7

Short name: Outdated materials

Description: Excessive material ordered and not used in a timely manner. 


\section{Worksheet 2}

\section{Opportunity Descriptions - 080(1)(i)}

Briefly describe the reduction opportunities you have implemented during the past reporting year; or reference the section and page number where the opportunities are described in your Executive Summary (or plan submitted in lieu of an Executive Summary). In either case, provide the following information:

- A short name and number for each opportunity. If you did this in your plan or Executive Summary, use the same name and number. Transfer the short name and/or code number to Worksheet 4.

- $A$ discussion on any reduction opportunities that have ihanged from the original plan or prior progress reports.

- A description of any new opportunities you have identified and selected for implementation.

Facility name: Hanford

Reporting Year(s): October 1, 1992 - December 31, 1993

Number: FFT 8-1 CANCELED

Short name: Process review

Description: Ongoing review by reduction opportunities identification team for potential waste minimization and recycle.

Number: FFT 8-2 CANCELED

Short name: Technology review

Description: When new technology becomes available, the team will evaluate for potential waste reduction.

Number: FFT 8-3 CANCELED

Short name: Ordering process

Description: Need to reevaluate the ordering process to minimize the amount purchased.

Number: FFT 8-4 CANCELED

Short name: Longer shelf life

Description: Look for material with a longer shelf life.

Number: FFT 8-5 CANCELED

Short name: Substitution

Description: Find a nonhazardous product to replace the chemical hazard.

Number: FFT 8-6 CANCELED

Short name: Treatment

Description: Treat the product creating a nonhazardous waste. 


\section{Worksheet 3}

\section{Processes Impacted - 080(1)(a)(ii)}

Briefly describe the processes affected by your reduction opportunities; or reference the section and page number where they are described in your Executive Summary (or plan submitted in lieu of an Executive Summary). In either case, provide the following information:

- A shor name and number for each process. If you did this for your plan or Executive Summary, use the same name and number. Transfer the shor name and/or code number to Worksheet 4.

- $\quad A$ discussion on the processes affected by your reduction opportunities.

Facility name: Hanford

Reporting Year(s): October 1, 1992 - December 31, 1993

Number: FFT-8

Short name: Sodium bulbs

Description: Burned out lightbulbs are replaced as part of routine maintenance. Process generates waste mercury. 


\section{Worksheet 2 \\ Opportunity Descriptions - 080(1)(i)}

Briefly describe the reduction opportunities you have implemented during the past reporting year; or reference the section and page number where the opportunities are described in your Executive Summary for plan submitted in lieu of an Executive Summary). In either case, provide the following information:

- $\quad A$ short name and number for each opportunity. If you did this in your plan or Executive Summary, use the same name and number. Transfer the shor name and/or code number to Worksheet 4.

- A discussion on any reduction opportunities that have changed from the original plan or prior progress reports.

- A description of any new opportunities you have identified and selected for implementation.

Facility name: Hanford

Reporting Year(s): October 1, 1992 - December 31, 1993

Number: $\quad$ FOT 1-2

Short name: Baking soda battery cleaner

Description: Replace aerosol battery cleaners with baking soda cleaner.

\section{Worksheet 3 \\ Processes Impacted - 080(1)(a)(ii)}

Briefly describe the processes affected by your reduction opportunities; or reference the section and page number where they are described in your Executive Summary (or plan submitted in lieu of an Executive Summary). In either case, provide the following information:

- $\quad A$ shorn name and number for each process. If you did this for your plan or Executive Summary, use the same name and number. Transfer the shor name and/or code number to Worksheet 4.

- $\quad A$ discussion on the processes affected by your reduction opportunities.

Facility name: Hanford

Reporting Year(s): October 1, 1992 - December 31, 1993

Number: $\quad$ FOT-1

Short name: Aerosol products

Description: Aerosol products are used in all phases of automotive vehicle maintenance.

Results in waste streams of rags, gloves, and cans. 


\section{Worksheet 2}

\section{Opportunity Descriptions - 080(1)(i)}

Briefly describe the reduction opportunities you have implemented during the past reporting year; or reference the section and page number where the opportunities are described in your Executive Summary (or plan submitted in lieu of an Executive Summary). In either case, provide the following information:

- A short name and number for each opportunity. If you did this in your plan or Executive Summary, use the same name and number. Transfer the shor name and/or code number to Worksheet 4.

- A discussion on any reduction opportunities that have changed from the original plan or prior progress reports.

- $\quad A$ description of any new opportunities you have identified and selected for implementation.

Facility name: Hanford

Reporting Year(s): October 1, 1992 - December 31, 1993

Number: $\quad$ FOT 4-1

Short name: Rechargeable flashlights

Description: Use rechargeable alkaline flashlights.

Number: FOT 4-2 CANCELED

Short name: Rechargeable flashlights

Description: Use rechargeable zinc-carbon flashlights.

\section{Worksheet 3}

Processes Impacted - 080(1)(a)(ii)

Briefly describe the processes affected by your reduction opportunities; or reference the section and page number where they are described in your Executive Summany (or plan submitted in lieu of an Executive Summary). In either case, provide the following information:

- $\quad$ A short name and number for each process. If you did this for your plan or Executive Summary, use the same name and number. Transfer the short name and/or code number to Worksheet 4.

A discussion on the processes affected by your reduction opportunities.

Facility name: Hanford

Reporting Year(s): October 1, 1992 - December 31, 1993

Number: $\quad$ FOT-4

Short name: Flashlight batteries

Description: Flashlight batteries are used in all of our maintenance activities (vehicle, road, grounds, track, etc.). 


\section{Worksheet 2}

\section{Opportunity Descriptions - 080(1)(i)}

Briefly describe the reduction opportunities you have implemented during the past reporting year; or reference the section and page number where the opportunities are described in your Executive Summary (or plan submitted in lieu of an Executive Summary). In either case, provide the following information:

- A short name and number for each opportunity. If you did this in your plan or Executive Summary, use the same name and number. Transfer the short name and/or code number to Worksheet 4.

- A discussion on any reduction opportunities that have changed from the original plan or prior progress reports.

- A description of any new opportunities you have identified and selected for implementation.

Facility name: Hanford

Reporting Year(s): October 1, 1992 - December 31, 1993

Number: FOT 5-1

Short name: Better procurement and maintenance

Description: Increase the life of the battery by ordering a better grade of battery, better maintenance, and check the condition of the battery to see if it can be recharged rather than changed out.

\section{Worksheet 3}

\section{Processes Impacted - 080(1)(a)(ii)}

Briefly describe the processes affected by your reduction opportunities; or reference the section and page number where they are described in your Executive Summary (or plan submitted in lieu of an Executive Summary). In either case, provide the following information:

- $\quad$ A short name and number for each process. If you did this for your plan or Executive Summary, use the same name and number. Transfer the short name and/or code number to Worksheet 4.

- $\quad A$ discussion on the processes affected by your reduction opportunities.

Facility name: Hanford

Reporting Year(s): October 1, 1992 - December 31, 1993

Number: FOT-5

Short name: Automotive lead acid batteries

Description: Automotive vehicle electrical system maintenance. 


\section{Worksheet 2 \\ Opportunity Descriptions - 080(1)(i)}

Briefly describe the reduction opportunities you have implemented during the past reporting year; or reference the section and page number where the opportunities are described in your Executive Summary (or plan submitted in lieu of an Executive Summary). In either case, provide the following information:

- $\quad$ short name and number for each opportunity. If you did this in your plan or Executive Summary, use the same name and number. Transfer the shor name and/or code number to Worksheet 4.

- A discussion on any reduction opportunities that have changed from the original plan or prior progress reports.

- $\quad A$ description of any new opportunities you have identified and selected for implementation.

Facility name: Hanford

Reporting Year(s): October 1, 1992 - December 31, 1993

Number: FOT 6-1

Short name: Inventory control

Description: Strict inventory control for lightly used products and aerosol cans.

Number: FOT 6-2

Short name: Just-in-time delivery

Description: Check for vendor availability for different products. If the local vendors have a product on hand at all times and can deliver in a reasonable time frame, then we could reduce our onhand inventory and avoid shelf-life problems.

Number: FOT 6-3

Short name: Return off specification/old products

Description: Return unopen off specification/out-of-date products to the manufacturer, instead of disposing of them as hazardous waste.

\section{Worksheet 3 \\ Processes Impacted - 080(1)(a)(ii)}

Briefly describe the processes affected by your reduction opportunities; or reference the section and page number where they are described in your Executive Summary (or plan submitied in lieu of an Executive Summary). In either case, provide the following information:

- A short name and number for each process. If you did this for your plan or Executive Summary, use the same name and number. Transfer the shor name and/or code number to Worksheet 4.

- $\quad A$ discussion on the processes affected by your reduction opportunities.

Facility name: Hanford

Reporting Year(s): October 1, 1992 - December 31, 1993

Number: FOT-6

Short name: Off specification/out-of-date products

Description: Routine vehicle maintenance and removing unwanted products from vacated maintenance shops. Substitutes less hazardous products for more hazardous products. 


\title{
Worksheet 2
}

Opportunity Descriptions - 080(1)(i)

\begin{abstract}
Briefly describe the reduction opportunities you have implemented during the past reporting year; or reference the section and page number where the opportunities are described in your Executive Summary (or plan submitted in lieu of an Executive Summary). In either case, provide the following information:

- A short name and number for each opportunity. If you did this in your plan or Executive Summary, use the same name and number. Transfer the short name and/or code number to Worksheet 4.

- $\quad A$ discussion on any reduction opportunities that have changed from the original plan or prior progress reports.

- A description of any new opportunities you have identified and selected for implementation.
\end{abstract}

Facility name: Hanford

Reporting Year(s): October 1, 1992 - December 31, 1993

Number: KEH 1-1

Short name: Replace blueprint machines

Description: The whiteprint duplicating machine does not use ammonia chemicals, toners, or absorbers during operations. It does use a nonhazardous activator. If more technical data is needed it can be obtained.

Number: KEH 2-1 CANCELED

Short name: Paint stripper

Description: A particular brand of paint stripper has been specifically designed for the removal of lead based paint on all types of steel structures. This stripper has no toxic fumes and no flammable solvents, and will remove multilayers of paint in one application. The product is sprayed onto the surface and will adhere to all irregular surfaces. It is self-sealing within an hour; therefore, the paste is working in a sealed environment without any evaporation taking place. After the paste and paint is removed, the steel is protected from initial corrosion by the alkalinity of the product.

A similar product is a solvent-based paste designed specifically for removal of high-strength, two-part epoxy coatings, urethanes, elastomerics, chlorinated rubber mastics, nonskid coatings, automobile paints, floor coatings, rubberized membrane coatings and other chemically resistant coatings, and most graffiti paints. The paste is brushed, troweled, or sprayed over the surface to be stripped and is then covered with a fibrous laminated material and left until the coatings are ready to be removed. The cloth covering allows the paste to work in a sealed environment with a minimum of evaporation taking place and acts as a carrier of the paste and paint that become part of the cloth upon removal. The product can be used on almost all surfaces except fiberglass and hardwoods.

Number: KEH 2-2 CANCELED

Short name: Steel grit abrasive blasting agent

Description: Usually disposable abrasives that crumble during use are employed for industrial painting projects. Sand is a very common disposable abrasive and it has been used for this purpose for so many years that the painting industry is having a difficult time changing from the archaic term "sand blasting" to the technically correct expression of "abrasive blasting." Other disposable one-time-use only abrasives include slags of coal and copper as well as low silica minerals. 
The biggest problem with disposal abrasives is getting rid of the huge pile of spent materials when the job has been completed. A rule of thumb for abrasive consumption is that about ten pounds of sand or coal slag is needed to abrasively clean one square foot of painted or rusted steel. Recyclable steel grit abrasives are a better alternative. Spent steel grit is collected by a vacuum system that transports the grit and the paint chips to a classifier. This unit separates the steel from the paint. The steel grit is returned to the abrasive blasting pot for reuse and the paint chips flowed into sealed drums.

\section{Number: KEH 2-3}

Short name: Electrostatic spraying system

Description: The principal advantage of electrostatic spraying is the savings in material and labor. This is accomplished by placing a high voltage electric charge on each atomized particle of paint. The object to be coated is an electrically conductive ground. Some of the paint particles that would normally miss the work will now be attracted to the edges and back side of the work. This effect is commonly referred to as the "wrap around" effect.

\section{Number: KEH 2-4}

Short name: Solvent recovery system

Description: Employing a solvent recovery system to recycle paint solvent used in cleanup of painting activities. 


\section{Worksheet 3}

\section{Processes Impacted - 080(1)(a)(ii)}

Briefly describe the processes affected by your reduction opportunities; or reference the section and page number where they are described in your Executive Summary (or plan submitted in lieu of an Executive Summary). In either case, provide the following information:

- A short name and rumber for each process. If you did this for your plan or Executive Summary, use the same naml: and number. Transfer the shor name andlor code number to Worksheet 4.

- $\quad A$ discussion on the processes affected by your reduction opportunities.

Facility name: Hanford

Reporting Year(s): October 1, 1992 - December ¿1, 1993

Number: KEH-1

Shor name: Amınonium hydroxide from duplicating services

Description: Aminonium hydroxide $\left(\mathrm{NH}_{3} \mathrm{OH}\right)$ vapors facilitate blueprint imaging for the proisuction of engineering and architectural blueprints. A 1-gallon container of aminonium hydroxide solution, connected by hoses in a closed system, is circlulated through the blueprint machine. As the solution vaporizes, it reacts chemically with the blueprint paper creating an image on the paper. When the solution gets weak, fewer vapors are emitted and the image begins to fade. The gallon container is then replaced with a fresh one leaving approximately one-half gallion of spent ammonium hydroxide to be disposed of as hazardous waste.

Number: KEH-2

Short name: Paint waste/related waste from paint operations

Description: Painting operations are extremely diverse. Therefore, using an example paint operation to describe the process that generates hazardous waste seems to be an appropriate method of explanation.

Preparation of the substrate, or the surface of the object to be painted, is the initial step in a painting operation. If the substrate is newly constructed bare steel, it may be wiped down with acetone or another solvent to cut any oil or grease that may be on the surface. It is then etched with an etching medium, such as copper sulfate or a sulfuric acid mix. The etching process is used to better prepare the substrate to accept paint by actually eroding away most foreign material adhering to the surface. The hazardous wastes generated to this point would be rags, cloths, brushes, and other things used to apply the solvents and etchings and to clean up after their use.

Preparation could also require sandblasting to ready the substrate for painting. A nonregulated blasting agent is now used for this process. Blasting a previously unpainted surface prepares this surface exceptionally well and generates very little, if arly, waste. However, if blasting a previously painted surface, the old paint could contain lead, asbestos, or other hazardous material, therefore, creating a hazardous waste stream that includes the now contaminated blasting agent. 
Painting is the second step. There are many variables involved in this process: (1) the surface to be painted may require one or more coats of primer to be applied before applications of one or more coats of the regular paint; and (2) paint can be applied by brush, roller, spray gun, spray can or all of these, once again depending upon the job requirements. Whether or not the paint used contains hazardous material (i.e., heavy metals, solvents, etc.) or not depends upon a myriad of variables. Most notably, what protective qualities must the coating offer and what elements of the environment is the coating required to withstand. Other than leftover or excess paint, any waste streams generated from this point forward come from cleanup operations.

Cleanup, after the painting operation is completed, generates the greatest quantity of waste during the painting process. Brushes, rollers, rags, spray guns and most other reusable equipment is cleaned in the triple brush wash (see worksheet 3). Drop cloths are reused, but masking tape and paper, plastic coverings, and empty paint cans are discarded. 


\section{Worksheet 2 \\ Opportunity Descriptions - 080(1)(i)}

Briefly describe the reduction opportunities you have implemented during the past reporting year; or reference the section and page number where the opportunities are described in your Executive Summary (or plan submitted in lieu of an Executive Summary). In either case, provide the following information:

- $\quad$ A shor name and number for each opportunity. If you did this in your plan or Executive Summary, use the same name and number. Transfer the short name and/or code number to Worksheet 4.

- A discussion on any reduction opportunities that have changed from the original plan or prior progress reports.

- A description of any new opportunities you have identified and selected for implementation.

Facility name: Hanford

Reporting Year(s): October 1, 1992 - December 31, 1993

Number: $\quad$ TPT 1-1

Short name: Procurement restrictions

Description: All chemicals will require approval of the facility hazardous waste coordinator before purchase.

Number: TPT 1-2

Short name: Job control

Description: Packages involving use of chemicals will require review and approval by the hazardous waste coordinator.

Number: TPT 1-3

Short name: Material tracking/inventory

Description: Routine surveillances and housekeeping inspections will be periodically conducted.

Number: TPT 1-4

Short name: Use material exchanges

Description: All unused and partially used containers of chemicals will be made available for SCE or excess.

Number: TPT 1-5 CANCELED

Short name: Improve housekeeping

Description: Complete facility cleanup of old, unknown chemicals, and maintain using the methods listed above. 


\section{Worksheet 3 \\ Processes Impacted - 080(1)(a)(ii)}

Briefly describe the processes affected by your reduction opportunities; or reference the section and page number where they are described in your Executive Summary (or plan submitted in lieu of an Executive Summary). In either case, provide the following information:

- A short name and number for each process. If you did this for your plan or Executive Summary, use the same name and number. Transfer the shor name and/or code number to Worksheet 4.

- $\quad A$ discussion on the processes affected by your reduction opportunities.

Facility name: Hanford

Reporting Year(s): October 1, 1992 - December 31, 1993

Number: TPT-1

Short name: Surveillance/maintenance/cleanup

Description: Product from routine maintenance/operation/janitorial work are not completely spent or are abandoned. The products are discovered during routine surveillance of the facilities. If no immediate use is identified for these products, they are declared a waste. 


\section{Worksheet 2 \\ Opportunity Descriptions - 080(1)(i)}

Briefly describe the reduction opportunities you have implemented during the past reporting year; or reference the section and page number where the opportunities are described in your Executive Summary for plan submitted in lieu of an Executive Summary). In either case, provide the following information:

- A short name and number for each opportunity. If you did this in your plan or Executive Summary, use the same name and number. Transfer the short name and/or code number to Worksheet 4.

- $A$ discussion on any reduction opportunities that have changed from the original plan or prior progress reports.

- A description of any new opportunities you have identified and selected for implementation.

Facility name: Hanford

Reporting Year(s): October 1, 1992 - December 31, 1993

Number: $\quad F A B$ 2-1

Short name: Recycle unit

Description: Purchase recycling unit to recover coolant.

\section{Worksheet 3}

Processes Impacted - 080(1)(a)(ii)

Briefly describe the processes affected by your reduction opportunities; or reference the section and page number where they are described in your Executive Summary (or plan submitted in lieu of an Executive Summary). In either case, provide the following information:

- A shor name and number for each process. If you did this for your plan or Executive Summary, use the same name and number. Transfer the short name and/or code number to Worksheet 4.

- $\quad A$ discussion on the processes affected by your reduction opportunities.

Facility name: Hanford

Reporting Year(s): October 1, 1992 - December 31, 1993

Number: $\quad F A B-2$

Short name: Liquid coolant

Description: Coolant is used to protect the friction bearing parts of shop equipment. It is nonregulated in the concentrations used. There is a problem of the coolant picking up small concentrations of lead as it circulates through the equipment. 


\section{Worksheet 2}

\section{Opportunity Descriptions - 080(1)(i)}

Briefly describe the reduction opportunities you have implemented during the past reporting year; or reference the section and page number where the opportunities are described in your Executive Summary (or plan submitted in lieu of an Executive Summary). In either case, provide the following information:

- A short name and number for each opportunity. If you did this in your plan or Executive Summary, use the same name and number. Transfer the short name and/or code number to Worksheet 4.

- A discussion on any reduction opportunities that have changed from the original plan or prior progress reports.

- A description of any new opportunities you have identified and selected for implementation.

Facility name: Hanford

Reporting Year(s): October 1, 1992 - December 31, 1993

Number: GAS 1-1 CANCELED

Short name: Lighting controls

Description: Use programmable/automatic lighting controls to ensure lights are on only when and where needed.

Number: GAS 1-2 CANCELED

Short name: Group re-lamping

Description: Use group re-lamping to reduce labor costs.

Number: GAS 1-3 CANCELED

Short name: Energy saving lamps

Description: Replace standard fluorescent lamps with energy saving lamps all at one time.

\section{Worksheet 3}

\section{Processes Impacted - 080(1)(a)(ii)}

Briefty describe the processes affected by your reduction opportunities; or reference the section and page number where they are described in your Executive Summary (or plan submitted in lieu of an Executive Summary). In either case, provide the following information:

- $\quad$ A short name and number for each process. If you did this for your plan or Executive Summary, use the same name and number. Transfer the shor name and/or code number to Worksheet 4.

- $\quad$ A discussion on the processes affected by your reduction opportunities.

Facility name: Hanford

Reporting Year(s): October 1, 1992 - December 31, 1993

\section{Number: GAS-1}

Short name: Filters from tube crusher

Description: Fluorescent tubes are crushed in drum crushers. Filters for the drum crushers are hazardous waste due to the accumulation of mercury from the vapor caused by the crushing activity. 


\section{Worksheet 2}

\section{Opportunity Descriptions - 080(1)(i)}

Briefly describe the reduction opportunities you have implemented during the past reporting year; or reference the section and page number where the opportunities are described in your Executive Summary (or plan submitted in lieu of an Executive Summary). In either case, provide the following information:

- A short name and number for each opportunity. If you did this in your plan or Executive Summary, use the same name and number. Transfer the shor name and/or code number to Worksheet 4.

- $\quad A$ discussion on any reduction opportunities that have changed from the original plan or prior progress reports.

- A description of any new opportunities you have identified and selected for implementation.

Facility name: Hanford

Reporting Year(s): October 1, 1992 - December 31, 1993

Number: GAS 3-1 CANCELED

Short name: Label machinery

Description: Label machinery to identify the type of grease or oil used to maintain machinery.

Number: GAS 3-2 CANCELED

Short name: Standardize lubricants

Description: Standardize oil and grease.

\section{Worksheet 3 \\ Processes Impacted - 080(1)(a)(ii)}

Briefty describe the processes affected by your reduction opportunities; or reference the section and page number where they are described in your Executive Summary (or plan submitted in lieu of an Executive Summary). In either case, provide the following information:

- $\quad$ A shor name and number for each process. If you did this for your plan or Executive Summary, use the same name and number. Transfer the shor name and/or code number to Worksheet 4.

- $\quad A$ discussion on the processes affected by your reduction opportunities.

Facility name: Hanford

Reporting Year(s): October 1, 1992 - December 31, 1993

Number:

GAS-3

Short name: Oily rags

Description: Oil is put into machinery to maintain it. The old oil is removed/drained and now oil put in. Old pieces of equipment are drained of any oils upon removal. 


\section{Worksheet 2}

\section{Opportunity Descriptions - 080(1)(i)}

Briefly describe the reduction opportunities you have implemented during the past reporting year; or reference the section and page number where the opportunities are described in your Executive Summary (or plan submitted in lieu of an Executive Summany). In either case, provide the following information:

- A short name and number for each opportunity. If you did this in your plan or Executive Summary, use the same name and number. Transfer the short name and/or code number to Worksheet 4.

- $A$ discussion on any reduction opportunities that have changed from the original plan or prior progress reports.

- A description of any new opportunities you have identified and selected for implementation.

Facility name: Hanford

Reporting Year(s): October 1, 1992 - December 31, 1993

Number: GAS 4-1

Short name: Drop cloths reused

Description: All drop cloths are currently being reused.

Number: GAS 4-2

Short name: Evaluate repainting requests

Description: Better work planning and scheduling could eliminate the need to paint room by room. It is feasible to paint an entire floor of offices, section of a building versus individual requests.

Number: GAS 4-3

Short name: Standardize paints and colors

Description: Standardize all paints and colors that come on the Hanford Site. Currently stores has in place a stores systems contract the guarantees 24 hour turn around time from the time the order is placed to delivery. Make it mandatory that all paints and paint products are ordered through this system.

\section{Number: $\quad$ GAS 4-4}

Short name: Document paint applications

Description: In the Job Control System (JCS) if we could incorporate a checklist in the work packages which would include the material safety data sheet (MSDS) numbers, product name and manufacturer we could eliminate costly sampling we are now having to do when we sandblast the exterior of buildings. Currently there is no past documentation of paints that were used. Also the JCS system would have to have the capability to sort by building to retrieve the information needed.

Number: GAS 4-5

Short name: Plastic paint buckets

Description: WHC establish and implement a contract to recycle plastics.

Number: $\quad$ GAS 4-6

Short name: Material exchanges

Description: Use the exchange of painting materials across the site. 


\section{Worksheet 3 \\ Processes Impacted - 080(1)(a)(ii)}

Briefly describe the processes affected by your reduction opportunities; or reference the section and page number where they are described in your Executive Summary (or plan submitted in lieu of an Executive Summary). In either case, provide the following information:

- A short name and number for each process. If you did this for your plan or Executive Summary, use the same name and number. Transfer the shor name and/or code number to Worksheet 4.

- $\quad A$ discussion on the processes affected by your reduction opportunities.

Facility name: Hanford

Reporting Year(s): October 1, 1992 - December 31, 1993

Number: $\quad$ GAS -4

Short name: Paint/paint related material (latex)

Description: Preparatory work for building painting of interior and exterior consists of scraping, cleaning, and patching. Sealing or priming maybe applied in some cases. One or two coats of finished material will be applied for a finished coat. 


\section{Worksheet 2 \\ Opportunity Descriptions - 080(1)(i)}

Briefly describe the reduction opponunities you have implemented during the past reporting year; or reference the section and page number where the opportunities are described in your Executive Summary (or plan submitted in lieu of an Executive Summary). In either case, provide the following information:

- A shor name and number for each opportunity. If you did this in your plan or Executive Summary, use the same name and number. Transfer the shor name andlor code number to Worksheet 4.

- A discussion on any reduction opportunities that have changed from the original plan or prior progress reports.

- $\quad A$ description of any new opportunities you have identified and selected for implementation.

Facility name: Hanford

Reporting Year(s): October 1, 1992 - December 31, 1993

Number: GAS 6-2 CANCELED

Short name: Distillation unit

Description: Use a distillation to recover solvents in liquid waste.

\section{Worksheet 3}

Processes Impacted - 080(1)(a)(ii)

Briefly describe the processes affected by your reduction opportunities; or reference the section and page number where they are described in your Executive Summary (or plan submitted in lieu of an Executive Summary). In either case, provide the following information:

- A shor name and number for each process. If you did this for your plan or Executive Summary, use the same name and number. Transfer the shor name and/or code number to Worksheet 4.

- $\quad$ A discussion on the processes affected by your reduction opportunities.

Facility name: Hanford

Reporting Year(s): October 1, 1992 - December 31, 1993

\section{Number: GAS-6}

Short name: Solvent/solvent rags

Description: A positive is made on the computer out of vinyl. The positive is transferred to the screen by using film and activators. The screen is then placed on the screen printing press. The image is transferred through the silk screen on to the metal sign blanks by using a squeegee pulled across the screen forcing the inks through the open portion of the screen. The screening is used when a large quantity oi the same sign is required. One positive can generate several signs in a fraction of time it would take to make on the computer. 


\section{Worksheet 2}

Opportunity Descriptions - 080(1)(i)

Briefly describe the reduction opportunities you have implemented during the past reporting year; or reference the section and page number where the opportunities are described in your Executive Summary (or plan submitted in lieu of an Executive Summary). In either case, provide the following information:

- A short name and number for each opportunity. If you did this in your plan or Executive Summary, use the same name and number. Transfer the shor name andlor code number to Worksheet 4.

- $\quad A$ discussion on any reduction opportunities that have changed from the original plan or prior progress reports.

- A description of any new opportunities you have identified and selected for implementation.

Facility name: Hanford

Reporting Year(s): October 1, 1992 - December 31, 1993

Number: GAS 7-1

Short name: Material substitution

Description: Use less hazardous or nonhazardous materials that will provide a quality job.

Number: $\quad$ GAS $7-2$

Short name: Procurement controls

Description: Procurement controls/management avoid over-purchasing.

Number: GAS 7-3

Short name: Puncture aerosol cans

Description: Puncture aerosol cans.

Number: GAS 7-4 CANCELED

Short name: Distillation unit

Description: Use distillation to recover solvents in liquid cleanup waste. 


\section{Worksheet 3}

Processes Impacted - 080(1)(a)(ii)

Briefly describe the processes affected by your reduction opportunities; or reference the section and page number where they are described in your Executive Summary (or plan submitted in lieu of an Executive Summary). In either case, provide the following information:

- A short name and number for each process. If you did this for your plan or Executive Summary, use the same name and number. Transfer the shor name and/or code number to Worksheet 4.

- $\quad A$ discussion on the processes affected by your reduction opportunities.

Facility name: Hanford

Reporting Year(s): October 1, 1992 - December 31, 1993

Number: GAS-7

Short name: Paint/paint related material

Description: Spray painting in a paint booth is done on pieces of equipment brought into the shop that require a smooth finish. By using a spray paint booth the air around is clean because of the air vacuum system in the booth. Turning on the exhaust fan and water pump in the spray booth creates a waterfall of water which is used to filter the overspray of paint. By filtering out all the paints, the air that exits out the vent is clean air.

Shop paint work (painting done by brushes) is done when it doesn't matter if the paint brush strokes show up. 


\section{Worksheet 2 \\ Opportunity Descriptions - 080(1)(i)}

Briefly describe the reduction opportunities you have implemented during the past reporting year; or reference the section and page number where the opportunities are described in your Executive Summary (or plan submitted in lieu of an Executive Summary). In either case, provide the following information:

- A shorn name and number for each opportunity. If you did this in your plan or Executive Summary, use the same name and number. Transfer the shor name and/or code number to Worksheet 4.

- A discussion on any reduction opportunities that have changed from the original plan or prior progress reports.

- $A$ description of any new opportunities you have identified and selected for implementation.

Facility name: Hanford

Reporting Year(s): October 1, 1992 - December 31, 1993

Number: GAS 9-1

Short name: Dispensary control

Description: Dispense the product in an orderly fashion so that partially used containers are reused before new products are circulated.

Number: $\quad$ GAS 9-2

Short name: Procurement control

Description: Procurement restriction (avoid over-purchasing).

Number: $\quad$ GAS 9-3

Short name: Procedure control

Description: Control use of products through procedures.

\section{Worksheet 3}

Processes Impacted - 080(1)(a)(ii)

Briefly describe the processes affected by your reduction opportunities; or reference the section and page number where they are described in your Executive Summary (or plan submitted in lieu of an Executive Summary). In either case, provide the following information:

- A short name and number for each process. If you did this for your plan or Executive Summary, use the same name and number. Transfer the short name and/or code number to Worksheet 4.

- $\quad A$ discussion on the processes affected by your reduction opportunities.

Facility name: Hanford

Reporting Year(s): October 1, 1992 - December 31, 1993

Number: GAS-9

Short name: Surplus chemicals (out-of-date material)

Description: Products from routine maintenance work are not completely spent or are abandoned. The products were discovered during a major housekeeping effort of the facilities. If no immediate use is identified for these products or if the shelf life has expired they are declared a waste. 


\section{Worksheet 2}

\section{Opportunity Descriptions - 080(1)(i)}

Briefly describe the reduction opportunities you have implemented during the pant reporting year; or reference the section and page number where the opportunities are described in your Executive Summary for plan submitted in lieu of an Executive Summary). In either case, provide the following information:

- A short name and number for each opportunity. If you did this in your plan or Execusive Summary, use the same name and number. Transfer the short name and/or code number to Worksheet 4.

- A discussion on any reduction opportunities that have changed from the original plan or prior progress reports.

- A description of any new opportunities you have identified and selected for implementation.

Facility name: Hanford

Reporting Year(s): October 1, 1992 - December 31, 1993

\section{Number: $\quad$ EFS 1-1}

Short name: Extraction and disposal of capacitors

Description: This option will eventually eliminate capacitors potentially contaminated with PCBs from all site groundwater well pumps. The quantity and location of the pre-1980 groundwater pumps is an unknown. Since PCB contamination has not been indicated per the site groundwater analytical data, concern regarding leaking capacitors is negligible.

When the pumps are removed for maintenance purposes, pre-1980 pumps are disassembled, the capacitors are extracted and disposed as PCB. waste. Post 1980 pumps (PCB free) are placed in service to replace the pre-1980 pumps. The pre-1980 pumps will then undergo dismantel in a special purpose cubitainer where the capacitors are tested for PCBs. Only the PCB-containing capacitors will be segregated as regulated waste. 


\section{Worksheet 3}

\section{Processes Impacted - 080(1)(a)(ii)}

Briefly describe the processes affected by your reduction opportunities; or reference the section and page number where they are described in your Executive Summary (or plan submitted in lieu of an Executive Summary). In either case, provide the following information:

- A short name and number for each process. If you did this for your plan or Executive Summary, use the same name and number. Transfer the short name and/or code number to Worksheet 4.

- $\quad A$ discussion on the processes affected by your reduction opportunities.

Facility name: Hanford

Reporting Year(s): October 1, 1992 - December 31, 1993

Number: EFS-1

Short name: Small capacitors

Description: Electrical submersible pumps are used to pump groundwater from Site Groundwater Wells. The pumps manufactured prior to 1980 may contain electric capacitors potentially contaminated with elevated levels of PCBs. When pre-1980 pumps are removed from Site wells as a normal maintenance function, the capacitors are extracted and disposed as PCB waste. The replacement pumps are manufactured after 1980 and do not have the potential to contain capacitors with regulated levels of PCBs. 


\section{Worksheet 2 \\ Opportunity Descriptions - 080(1)(i)}

Briefly describe the reduction opportunities you have implemented during the past reporting year; or reference the section and page number where the opportunities are described in your Executive Summary (or plan submitted in lieu of an Executive Summary). In either case, provide the following information:

- A short name and number for each opportunity. If you did this in your plan or Executive Summary, use the same name and number. Transfer the short name and/or code number to Worksheet 4.

- A discussion on any reduction opportunities that have changed from the original plan or prior progress reports.

- A description of any new opportunities you have identified and selected for implementation.

Facility name: Hanford

Reporting Year(s): October 1, 1992 - December 31, 1993

Number: $\quad$ EFS 2-1

Short name: Material substitution

Description: Various means of controlling undesirable bird populations are available and currently in use on the site. Control methods include trapping, applications of bird repellents, placement of roosting site access barriers, etc. These methods do not pose a significant threat to non target species as do the avicides. Eliminating procurement of poison bait type avicides will help minimize this waste stream without adversely affecting bird population control.

\section{Worksheet 3}

\section{Processes Impacted - 080(1)(a)(ii)}

Briefly describe the processes affected by your reduction opportunities; or reference the section and page number where they are described in your Executive Summary (or plan submitted in lieu of an Executive Summary). In either case, provide the following information:

- A shor name and number for each process. If you did this for your plan or Executive Summary, use the same name and number. Transfer the short name and/or code number to Worksheet 4.

- $\quad A$ discussion on the processes affected by your reduction opportunities.

Facility name: Hanford

Reporting Year(s): October 1, 1992 - December 31, 1993

Number: EFS-2

Short name: Waste pesticides (avicides)

Description: Pesticides (herbicides, insecticides, rodenticides, avicides) are used to control undesirable vegetation and animal (insects, rodents, spiders, etc.) populations on site. Pesticide applications are conducted by Site personnel as well as contract vendors. There is a concern regarding poisoning of nontarget species. 


\title{
Worksheet 2
}

\section{Opportunity Descriptions - 080(1)(i)}

\begin{abstract}
Briefly describe the reduction opportunities you have implemented during the past reporting year; or reference the section and page number where the opportunities are described in your Executive Summary (or plan submitted in lieu of an Executive Summary). In either case, provide the following information:

- A short name and number for each opportunity. If you did this in your plan or Executive Summary, use the same name and number. Transfer the shor name and/or code number to Worksheet 4.

- $\quad A$ discussion on any reduction opportunities that have changed from the original plan or prior progress reports.

- $\quad A$ description of any new opportunities you have identified and selected for implementation.
\end{abstract}

Facility name: Hanford

Reporting Year(s): October 1, 1992 - December 31, 1993

Number: EFS 3-1 CANCELED

Short name: Extend usage of respirator cartridges

Description: Respirator cartridges are currently used for the period of time required to complete a job specific activity (not to exceed one day). The cartridge would be used for an extended period before disposing as waste.

Number: EFS 3-2 CANCELED

Short name: Non-cartridge type respirators

Description: Fresh air type respirators would replace the MSA type cartridge respirators for use as respiratory protection during pesticide application.

\section{Worksheet 3}

\section{Processes Impacted - 080(1)(a)(ii)}

Briefly describe the processes affected by your reduction opportunities; or reference the section and page number where they are described in your Executive Summary (or plan submitted in lieu of an Executive Summary). In either case, provide the following information:

- $\quad$ A short name and number for each process. If you did this for your plan or Executive Summary, use the same name and number. Transfer the short name and/or code number to Worksheet 4.

- $\quad$ A discussion on the processes affected by your reduction opportunities.

Facility name: Hanford

Reporting Year(s): October 1, 1992 - December 31, 1993

Number: EFS-3

Short name: Respirator cartridges

Description: Pesticides (herbicides, insecticides, rodenticides, avicides) are used to control undesirable vegetation and animal (insects, rodents, spiders, etc.) populations on site. Pesticide applications are conducted by Hanford Site personnel as well as contract vendors. Respirators are worn when handling/applying the pesticides. 


\section{Worksheet 2}

\section{Opportunity Descriptions - 080(1)(i)}

Briefly describe the reduction opportunities you have implemented during the past reporting year; or reference the section and page number where the opportunities are described in your Executive Summary (or plan submitted in lieu of an Executive Summary). In either case, provide the following information:

- $\quad$ A short name and number for each opportunity. If you did this in your plan or Executive Summary, use the same name and number. Transfer the short name and/or code number to Worksheet 4.

- $\quad$ discussion on any reduction opportunities that have changed from the original plan or prior progress reports.

- $\quad$ A description of any new opportunities you have identified and selected for implementation.

Facility name: Hanford

Reporting Year(s): October 1, 1992 - December 31, 1993

Number: $\quad$ EFS 4-1

Short name: Mandatory maintenance for equipment

Description: This option would require that known pieces of problem equipment (drill rigs, generators, etc.) requiring secondary containment to avoid leakage of hazardous substances to the soil/environment, be placed out of service until appropriate maintenance is complete. 


\section{Worksheet 3 \\ Processes Impacted - 080(1)(a)(ii)}

Briefly describe the processes affected by your reduction opportunities; or reference the section and page number where they are described in your Executive Summary (or plan submitted in lieu of an Executive Summary). In either case, provide the following information:

- A short name and number for each process. If you did this for your plan or Executive Summary, use the same

name and number. Transfer the shor name and/or code number to Worksheet 4.

- $\quad$ A discussion on the processes affected by your reduction opportunities.

Facility name: Hanford

Reporting Year(s): October 1, 1992 - December 31, 1993

Number: $\quad$ EFS -4

Short name: Investigation derived wastes

Description: Hanford Site Investigative Drilling Operations are conducted in order to monitor or obtain sample characterization data from suspected hazardous waste sites as required to facilitate eventual waste site remediation. The drilling activity generates large volumes of investigation/derived waste (IDW) comprised primarily of drill cuttings (soils and slurries) which are sampled and analyzed for contaminants. Unless field monitoring instruments indicate otherwise, the IDW is labeled as "unknown" pending receipt of the analytical sample results. Purgewater/groundwater generated during the process is either disposed to the ground or sent to Nodutanks for evaporation depending upon analytical sample results. Miscellaneous waste (personal protective equipment, tools, etc.) is also generated during investigative drilling activities, but is unlikely to receive a hazardous designation due to incidental contact with IDW. Decontamination fluids are managed in a manner similar to other IDW and would only receive a hazardous designation if so indicated by analytical sample results. 


\section{Worksheet 2}

\section{Opportunity Descriptions - 080(1)(i)}

Briefly describe the reduction opportunities you have implemented during the past reporting year; or reference the section and page number where the opportunities are described in your Executive Summary (or plan submitted in lieu of an Executive Summary). In either case, provide the following information:

- A short name and number for each opportunity. If you did this in your plan or Executive Summary, use the same name and number. Transfer the shor name and/or code number to Worksheet 4.

- A discussion on any reduction opportunities that have changed from the original plan or prior progress reports.

- A description of any new opportunities you have identified and selected for implementation.

Facility name: Hanford

Reporting Year(s): October 1, 1992 - December 31, 1993

Number: EFS 5-1

Short name: Use site surplus chemical exchange database

Description: Identify the current inventory of surplus chemical products and offer to other site organizations via the site surplus chemical exchange database.

Number: EFS 5-2

Short name: Establish a chemical products procurement system

Description: Perform an analysis of current chemical product inventory. Determine actual chemical product process needs. Eliminate inventory of marginally useful chemical products. Research alternate substitute products for those chemicals deemed necessary to the process. Establish a listing of chemicals approved for procurement for this process and incorporate a formal authorization system for procurement of any chemical products not listed. 


\section{Worksheet 3}

\section{Processes Impacted - 080(1)(a)(ii)}

Briefly describe the processes affected by your reduction opportunities; or reference the section and page number where they are described in your Executive Summary (or plan submitted in lieu of an Executive Summary). In either case, provide the following information:

- $\quad A$ short name and number for each process. If you did this for your plan or Executive Summary, use the same name and number. Transfer the short name and/or code number to Worksheet 4.

- $\quad A$ discussion on the processes affected by your reduction opportunities.

Facility name: Hanford

Reporting Year(s): October 1, 1992 - December 31, 1993

Number: EFS-5

Short name: Paint/paint related material

Description: Hanford Site Investigative Drilling Operations are conducted in order to monitor or obtain sample characterization data from suspected hazardous waste sites as required to facilitate eventual waste site remediation. Spilled or leaking vehicle and equipment fluids as well as surplus chemical products are other sources of hazardous waste streams associated with the investigative drilling process. 


\section{Worksheet 4}

\section{Quantities of Hazardous Substances and Wastes \\ Reduced by Each Opportunity - 080(1)(a)(iii)}

Facility Name: Hanford

State/EPA Identification number(s): WA7890008967

Reporting Year(s): October 1, 1992 - December 31, 1993

Production Factor (from worksheet 5): 1

Use this worksheet to show reductions and other results from implementing the opportunities listed on Worksheet 2. Report quantities in pounds, not normalized for production.

\begin{tabular}{|c|c|c|c|c|}
\hline $\begin{array}{c}\text { Substances/ } \\
\text { Wastes Affected } \\
\end{array}$ & \multicolumn{3}{|c|}{$\begin{array}{l}\text { Implemented Reduction Opportunities } \\
1992-1993 \\
\end{array}$} & \multirow{2}{*}{$\begin{array}{c}\text { Reduction } \\
\text { Quantities } \\
\text { (in ib.) } \\
\text { unless noted } \\
\text { otherwise }\end{array}$} \\
\hline Name & $\begin{array}{l}\text { Opportunity } \\
\text { Name/Code }\end{array}$ & $\begin{array}{l}\text { Impacted } \\
\text { Process } \\
\text { Name/Code }\end{array}$ & $\begin{array}{l}\text { Reduction } \\
\text { Code }\end{array}$ & \\
\hline Glycol & $\begin{array}{l}\text { Filtered/recycled coolant } \\
\text { (FFT 1-1) }\end{array}$ & 1 & $D$ & 55 gal. \\
\hline Fire barrier caulk & $\begin{array}{l}\text { Work package review-process } \\
\text { review (FFT 7-1) }\end{array}$ & 7 & $A$ & NT \\
\hline Solvents & $\begin{array}{l}\text { Surplus chemical exchange-- } \\
\text { ordering process (FFT 7-3) }\end{array}$ & 7 & C & NT \\
\hline Aerosol cans & $\begin{array}{l}\text { Baking soda battery cleaner } \\
\text { (FOT 1-2) }\end{array}$ & 1 & $A$ & NT \\
\hline Batteries & $\begin{array}{l}\text { Rechargeable flashlights } \\
\text { (FOT 4-1) }\end{array}$ & 4 & C & NT \\
\hline Lead acid batteries & $\begin{array}{l}\text { Better procurement and } \\
\text { maintenance (FOT } 5-1 \text { ) }\end{array}$ & 5 & $\mathrm{C}$ & NT \\
\hline Dated products & $\begin{array}{l}\text { Inventory control } \\
\text { (FOT 6-1) }\end{array}$ & 6 & $\mathrm{C}$ & NT \\
\hline Dated products & $\begin{array}{l}\text { Just-in-time delivery } \\
\text { (FOT 6-2) }\end{array}$ & 6 & C & NT \\
\hline Dated products & $\begin{array}{l}\text { Return off spec./old products } \\
\text { (FOT 6-3) }\end{array}$ & 6 & $D$ & NT \\
\hline Ammonia hydroxide & $\begin{array}{l}\text { Replace blueprint machines } \\
\text { (KEH 1-1) }\end{array}$ & 1 & $A$ & 1265 \\
\hline Paint waste & $\begin{array}{l}\text { Electrostatic spraying system } \\
\text { (KEH 2-3) }\end{array}$ & 2 & c & 1175 \\
\hline Paint related waste & $\begin{array}{l}\text { Solvent recovery system } \\
\text { (KEH 2-4) }\end{array}$ & 2 & $D$ & 6464 \\
\hline
\end{tabular}




\begin{tabular}{|c|c|c|c|c|}
\hline $\begin{array}{l}\text { Batteries, paint waste, } \\
\text { spill, clean up }\end{array}$ & $\begin{array}{l}\text { Procurement restrictions } \\
\text { (TPT 1-1) }\end{array}$ & 1 & A & 220 \\
\hline $\begin{array}{l}\text { Batteries, paint waste, } \\
\text { spill, clean up }\end{array}$ & $\begin{array}{l}\text { Job control } \\
\text { (TPT 1-2) }\end{array}$ & 1 & $A$ & 60 \\
\hline $\begin{array}{l}\text { Batteries, paint waste, } \\
\text { spill, clean up }\end{array}$ & $\begin{array}{l}\text { Material tracking/inventory } \\
\text { (TPT 1-3) }\end{array}$ & 1 & C & 60 \\
\hline $\begin{array}{l}\text { Batteries, paint waste, } \\
\text { spill, clean up }\end{array}$ & $\begin{array}{l}\text { Use material exchanges } \\
\text { (TPT 1-4) }\end{array}$ & 1 & D & 297 \\
\hline Glycol & $\begin{array}{l}\text { Recycle unit } \\
\text { (FAB 2-1) }\end{array}$ & 2 & $D$ & $1000 \mathrm{gal}$. \\
\hline Glycol & $\begin{array}{l}\text { Recycle unit } \\
\text { (FAB 2-1) }\end{array}$ & 2 & $\mathrm{C}$ & 200 gal. \\
\hline Paint related waste & $\begin{array}{l}\text { Drop cloths reused } \\
\text { (GAS 4-1) }\end{array}$ & 4 & C & NT \\
\hline Paint related waste & $\begin{array}{l}\text { Evaluate repainting requests } \\
\text { (GAS 4-2) }\end{array}$ & 4 & $A$ & NT \\
\hline Paint related waste & $\begin{array}{l}\text { Evaluate repainting requests } \\
\text { (GAS 4-2) }\end{array}$ & 4 & C & NT \\
\hline Paint related waste & $\begin{array}{l}\text { Standardize paints and colors } \\
\text { (GAS 4-3) }\end{array}$ & 4 & C & NT \\
\hline Paint related waste & $\begin{array}{l}\text { Document paint applications } \\
\text { (GAS 4-4) }\end{array}$ & 4 & C & NT \\
\hline Paint related waste & $\begin{array}{l}\text { Plastic paint buckets } \\
\text { (GAS 4-5) }\end{array}$ & 4 & $D$ & NT \\
\hline Paint related waste & $\begin{array}{l}\text { Material exchanges } \\
\text { (GAS 4-6) }\end{array}$ & 4 & C & NT \\
\hline Paint related waste & $\begin{array}{l}\text { Material substitution } \\
\text { (GAS 7-1) }\end{array}$ & 7 & A & NT \\
\hline Paint related waste & $\begin{array}{l}\text { Material substitution } \\
\text { (GAS 7-1) }\end{array}$ & 7 & $\mathrm{C}$ & NT \\
\hline Paint related waste & $\begin{array}{l}\text { Procurement controls } \\
\text { (GAS 7-2) }\end{array}$ & 7 & $\mathrm{C}$ & NT \\
\hline Paint related waste & $\begin{array}{l}\text { Puncture aerosol cans } \\
\text { (GAS 7-3) }\end{array}$ & 7 & $\mathrm{C}$ & NT \\
\hline $\begin{array}{l}\text { Surplus chemicals (out-of- } \\
\text { date material) }\end{array}$ & $\begin{array}{l}\text { Dispensary control } \\
\text { (GAS 9-1) }\end{array}$ & 9 & $\mathrm{C}$ & NT \\
\hline $\begin{array}{l}\text { Surplus chemicals (out-of- } \\
\text { date material) }\end{array}$ & $\begin{array}{l}\text { Procurement control } \\
\text { (GAS 9-2) }\end{array}$ & 9 & $\mathrm{C}$ & NT \\
\hline $\begin{array}{l}\text { Surplus chemicals (out-of- } \\
\text { date material) }\end{array}$ & $\begin{array}{l}\text { Procedure control } \\
\text { (GAS 9-3) }\end{array}$ & 9 & A & NT \\
\hline
\end{tabular}




\begin{tabular}{|c|c|c|c|c|}
\hline $\begin{array}{l}\text { Surplus chemicals (out-of- } \\
\text { date material) }\end{array}$ & $\begin{array}{l}\text { Procedurt control } \\
\text { (GAS 9-3) }\end{array}$ & 9 & $\mathrm{C}$ & NT \\
\hline Small capacitors & $\begin{array}{l}\text { Extraction and disposal of } \\
\text { capacitors (EFS 1-1) }\end{array}$ & 1 & B & 6.6 \\
\hline Small capacitors & $\begin{array}{l}\text { Extraction and disposal of } \\
\text { capacitors (EFS 1-1) }\end{array}$ & 1 & $\mathrm{C}$ & NT \\
\hline Waste pesticides & $\begin{array}{l}\text { Material substitution } \\
\text { (EFS 2-1) }\end{array}$ & 2 & A & NT \\
\hline Waste pesticides & $\begin{array}{l}\text { Material substitution } \\
\text { (EFS 2-1) }\end{array}$ & 2 & C & 5 \\
\hline $\begin{array}{l}\text { Investigation derived } \\
\text { wastes }\end{array}$ & $\begin{array}{l}\text { Mandatory maintenance for } \\
\text { equipment (EFS 4-1) }\end{array}$ & 4 & B & NT \\
\hline $\begin{array}{l}\text { Investigation derived } \\
\text { wastes }\end{array}$ & $\begin{array}{l}\text { Mandatory maintenance for } \\
\text { equipment (EFS 4-1) }\end{array}$ & 4 & C & NT \\
\hline Surplus chemical products & $\begin{array}{l}\text { Use site surplus chemical } \\
\text { exchange database (EFS 5-1) }\end{array}$ & 5 & C & NT \\
\hline Surplus chemical products & $\begin{array}{l}\text { Establish a chemical products } \\
\text { procurement system (EFS 5-2) }\end{array}$ & 5 & A & NT \\
\hline Surplus chemical products & $\begin{array}{l}\text { Establish a chemical products } \\
\text { procurement system (EFS } 5-2 \text { ) }\end{array}$ & 5 & C & NT \\
\hline
\end{tabular}

* Use the following codes to indicate reduction classification (only one code may be used per reporting line):

A - Reduction of haz. substances used
B - Reduction of haz. substances released
C - Reduction of haz. waste generased
D - Haz. waste recycled

$E$-- Haz. waste treated

NT - Not tracked 
DOE/RL-94-96

This page left intentionally blank. 
DOE/RL-94-96

SECTION C

NEWLY IDENTIFIED OPPORTUNITIES 
This table categorizes all the new PWA opportunities into 22 categories and lists each opportunity number in the appropriate opportunity category.

Table 3. New Opportunities Selected for Implementation.

\begin{tabular}{|c|c|c|c|}
\hline & $\begin{array}{l}\text { OPPORTUNITY } \\
\text { CATEGORY } \\
\end{array}$ & PROCESS & OPPORTUNITY NUMBERS \\
\hline 1 & Electronic ballasts & Lighting of facilities & PNL 2-2; PNL 5-1 \\
\hline 2 & Turn off lights & $\begin{array}{l}\text { Lighting of inactive } \\
\text { facilities }\end{array}$ & PNL 2-4 \\
\hline 3 & Product substitution & $\begin{array}{l}\text { PCB light ballasts; PCB } \\
\text { capacitors; light bulbs; } \\
\text { paint and paint waste; DOP } \\
\text { saturated rags }\end{array}$ & $\begin{array}{l}\text { FFT 10-1; FFT 15-1; PFP 2-1; } \\
\text { PFP 2-3; PFP 2-4; PFP 3-1; } \\
\text { PFP 3-2; PFP 3-6; PFP 7-4; } \\
\text { PFP 9-4; PFP 11-13; PFP 12-15; } \\
\text { PFP 14-3; PFP 15-4; PNL 2-1; } \\
\text { PNL 4-3; PUR 4-1; PUR 6-1; } \\
\text { PUR 7-2; PUR 8-3; UOX 6-1; } \\
\text { UOX 7-1; UOX 7-2 }\end{array}$ \\
\hline 4 & Water treatment center & Sodium bulbs & \\
\hline 5 & New purge units & Refrigerant/chillers & \\
\hline 6 & Solvent recovery & Paint waste & FFT 14-1; PFP 12-10; PNL 4-1 \\
\hline 7 & $\begin{array}{l}\text { Electrostatic spray } \\
\text { painting }\end{array}$ & Paint waste & \\
\hline 8 & $\begin{array}{l}\text { Eliminate use of poison } \\
\text { baits }\end{array}$ & Waste pesticides & \\
\hline 9 & Training/awareness & Gasoline spill & PFP 8-6; PFP 12-11; PFP 12-12 \\
\hline 10 & $\begin{array}{l}\text { Storage facility } \\
\text { inspections }\end{array}$ & Spill residue cleanup & . \\
\hline 11 & $\begin{array}{l}\text { Inventory/procurement } \\
\text { control }\end{array}$ & $\begin{array}{l}\text { Chemical products use; } \\
\text { surveillance, maintenance, } \\
\text { and cleanup }\end{array}$ & $\begin{array}{l}\text { PFP 1-1; PFP 1-2; PFP 4-1; } \\
\text { PFP 4-2; PFP 5-2; PFP 6-1; } \\
\text { PFP 6-2; PFP 8-4; PFP 8-5; } \\
\text { PFP 9-2; PFP 10-2; PFP 11-2; } \\
\text { PFP 11-6; PFP 11-7; PFP 12-2; } \\
\text { PFP 12-7; PFP 12-14; PFP 13-5; } \\
\text { PFP 13-8; PFP 14-2; PFP 14-7; } \\
\text { PFP 15-5; PUR 2-2; PUR 3-1; } \\
\text { PUR 5-1; PUR 7-1; PUR 8-1; } \\
\text { UOX 2-2; UOX 3-1; UOX 4-1; } \\
\text { UOX 5-1; }\end{array}$ \\
\hline 12 & Recycle coolant & Liquid coolant & FFT $11-1$ \\
\hline 13 & Segregate & Solvent cleaning rags & $\begin{array}{l}\text { PFP 3-3; PFP 4-3; PFP 6-3; } \\
\text { PFP 8-2; PNL 3-1; PUR 8-2 }\end{array}$ \\
\hline
\end{tabular}


DOE/RL-94-96

\begin{tabular}{|c|c|c|c|}
\hline 14 & Job control & $\begin{array}{l}\text { Surveillance, maintenance, } \\
\text { and cleanup }\end{array}$ & \\
\hline 15 & Material tracking & $\begin{array}{l}\text { Surveillance, maintenance, } \\
\text { and cleanup }\end{array}$ & \\
\hline 16 & Use material exchanges & $\begin{array}{l}\text { Surveillance, maintenance, } \\
\text { and cleanup; chemical } \\
\text { products use }\end{array}$ & $\begin{array}{l}\text { PFP 7-5; PFP 8-7; PFP 8-8; } \\
\text { PUR 8-4 }\end{array}$ \\
\hline 17 & Improve housekeeping & Maintenance; clean-outs & \\
\hline 18 & Recycling & Maintenance; construction & $\begin{array}{l}\text { FFT 9-1; FFT 12-1; FFT 12-2; } \\
\text { PFP 1-4; PFP 1-5; PFP 1-6; } \\
\text { PFP 1-7; PFP 1-8; PFP 3-4; } \\
\text { PFP 4-4; PFP 4-5; PFP 4-6; } \\
\text { PFP 4-7; PFP 4-8; PFP 6-4; } \\
\text { PFP 7-1; PFP 7-2; PFP 9-1; } \\
\text { PFP 9-3; PFP 15-1; PFP 15-2; } \\
\text { PNL 1-1; PNL 1-3; PUR 2-1; } \\
\text { PUR 4-2; PUR 5-2; PUR 5-3; } \\
\text { UOX 2-1; UOX 4-2; UOX 5-2; } \\
\text { UOX 5-3 }\end{array}$ \\
\hline 19 & Procedure change & $\begin{array}{l}\text { Maintenance; construction; } \\
\text { lighting; operations }\end{array}$ & $\begin{array}{l}\text { PFP 1-10; PFP 3-7; PFP 4-10; } \\
\text { PFP } 7-3 ; \text { PFP 8-1; PFP 11-1; } \\
\text { PFP 11-4; PFP 11-5; PFP 12-1; } \\
\text { PFP 12-13; PFP 13-6; PFP 13-7; } \\
\text { PFP 14-1; PFP 15-3; PNL } 1-2 ; \\
\text { PNL 3-2 }\end{array}$ \\
\hline 20 & Design changes & Maintenance; operations & PFP $5-4 ;$ PFP $10-4 ;$ PNL 2-3 \\
\hline 21 & $\begin{array}{l}\text { Recover } \\
\text { refrigerants/CFCs }\end{array}$ & Refrigeration & $\begin{array}{l}\text { FFT 13-1; FFT 13-2; PFP 5-1; } \\
\text { PFP 10-1 }\end{array}$ \\
\hline 22 & Process modification & Fabrication; construction & $\begin{array}{l}\text { PFP 1-9; PFP 4-9; PFP 5-3; } \\
\text { PFP 8-3; PFP 8-9; PFP 9-5; } \\
\text { PFP 10-3; PFP 12-3; PFP 12-4; } \\
\text { PFP 12-5; PFP 12-6; PFP 12-8; } \\
\text { PFP 12-9; PFP 13-1; PFP 13-2; } \\
\text { PFP 13-3; PFP 13-4; PFP 13-9; } \\
\text { PFP 14-4; PFP 14-5; PFP 14-6; } \\
\text { PNL 4-4; PUR 6-2; PUR 8-5; } \\
\text { UOX 6-2 }\end{array}$ \\
\hline
\end{tabular}




\section{Worksheet 2 \\ Opportunity Descriptions - 080(1)(i)}

Briefly describe the reduction opportunities you have implemented during the past reporting year; or reference the section and page number where the opportunities are described in your Executive Summary (or plan submitted in lieu of an Executive Summary). In either case, provide the following information:

- A short name and number for each opportunity. If you did this in your plan or Executive Summary, use the same name and number. Transfer the short name and/or code number to Worksheet 4.

- A discussion on any reduction opportunities that have changed from the original plan or prior progress reports.

- A description of any new opportunities you have identified and selected for implementation.

Facility name: Hanford

Reporting Year(s): October 1, 1992 - December 31, 1993

Number: $\quad$ FFT 9-1

Short name: Battery recycling

Description: Continue current recycling of these batteries; also continue to look for opportunities to recycle more types of batteries.

\section{Worksheet 3}

Processes Impacted - 080(1)(a)(ii)

Briefly describe the processes affected by your reduction opportunities; or reference the section and page number where they are described in your Executive Summary (or plan submitted in lieu of an Executive Summary). In either case, provide the following information:

- $\quad$ A short name and number for each process. If you did this for your plan or Executive Summary, use the same name and number. Transfer the short name and/or code number to Worksheet 4.

- $\quad A$ discussion on the processes affected by your reduction opportunities.

Facility name: Hanford

Reporting Year(s): October 1, 1992 - December 31, 1993

Number: FFT-9

Short name: Emergency equipment process and backup equipment

Description: Emergency equipment process and backup equipment is in normal use throughout the plant. Normal usage creates waste lead and sulfuric acid. 


\title{
Worksheet 2
}

\section{Opportunity Descriptions - 080(1)(i)}

\begin{abstract}
Briefly describe the reduction opportunities you have implemented during the past reporting year; or reference the section and page number where the opportunities are described in your Executive Summary (or plan submitted in lieu of an Executive Summary). In either case, provide the following information:

- A shorn name and number for each opportunity. If you did this in your plan or Executive Summary, use the same name and number. Transfer the shor name and/or code number to Worksheet 4.

- A discussion on any reduction opportunities that have changed from the original plan or prior progress reports.

- A description of any new opportunities you have identified and selected for implementation.
\end{abstract}

Facility name: Hanford

Reporting Year(s): October 1, 1992 - December 31, 1993

Number: FFT 10-1

Short name: Obtain manufacturer certification that ballasts are non-PCB before purchase.

Description: PCB light ballasts have not been manufactured since 1977. However, manufacturers are not required to place a label on the new ballasts that specify it contains no PCBs. Therefore, all ballasts without adequate labeling and documentation must be treated as suspected PCB ballasts.

Verified non-PCB ballasts will be color-coded with a green stick on dot when received from the vendor. When the ballast fails, the electrician can immediately know what, if any, handling precautions and disposal requirements are needed.

\section{Worksheet 3}

\section{Processes Impacted - 080(1)(a)(ii)}

Briefly describe the processes affected by your reduction opportunities; or reference the section and page number where they are described in your Executive Summary (or plan submitted in lieu of an Executive Summary). In either case, provide the following information:

- A shor name and number for each process. If you did this for your plan or Executive Summary, use the same name and number. Transfer the short name and/or code number to Worksheet 4.

- $\quad A$ discussion on the processes affected by your reduction opportunities.

Facility name: Hanford

Reporting Year(s): October 1, 1992 - December 31, 1993

Number: FFT-10

Short name: Light ballasts

Description: Light ballasts a required for fluorescent lights. During routine plant and supporting facilik : maintenance, these ballasts are changed out. The leaking suspect PCB balli ts are disposed of as Toxic Substance Control Act (TSCA) waste. The nonleaning ballasts are disposed of in the landfill. 


\section{Worksheet 2}

Opportunity Descriptions - 080(1)(i)

Briefly describe the reduction opportunities you have implemented during the past reporting year; or reference the section and page number where the opportunities are described in your Executive Summary (or plan submined in lieu of an Executive Summary). In either case, provide the following information:

- A shor name and number for each opportunity. If you did this in your plan or Executive Summary, use the same name and number. Transfer the short name and/or code number to Worksheet 4.

- $A$ discussion on any reduction opportunities that have changed from the original plan or prior progress reports.

- $A$ description of any new opporturities you have identified and selected for implementation.

Facility name: Hanford

Reporting Year(s): October 1, 1992 - December 31, 1993

Number: FFT 11-1

Short name: Recycle ethylene glycol

Description: Filtration tests were conducted with a borrowed filtration unit on used glycol. This portable unit successfully filtered waste glycol from plant systems to the point where that glycol could be retumed to system use. Initiated the fabrication of a portable filtration unit to further recycle the glycol.

\section{Worksheet 3}

\section{Processes Impacted - 080(1)(a)(ii)}

Briefly describe the processes affected by your reduction opportunities; or reference the section and page number where they are described in your Executive Summary (or plan submitied in lieu of an Executive Summary). In either case, provide the following information:

- A short name and number for each process. If you did this for your plan or Executive Summary, use the same name and number. Transfer the shor name andlor code number to Worksheet 4.

- $A$ discussion on the processes affected by your reduction opportunities.

Facility name: Hanford

Reporting Year(s): October 1, 1992 - December 31, 1993

Number: FFT-11

Short name: Liquid coolant

Description: Ethylene glycol is used as coolant to maintain equipment and temperature control for the plant and the IEM Cell. The glycol is drained from the system during maintenance activities. The same glycol is then filtered and returned to the system as much as possible. Waste glycol is collected from pump seal leaks. Glycol wetted rags are also handled as hazardous waste. 


\title{
Worksheet 2 \\ Opportunity Descriptions - 080(1)(i)
}

\begin{abstract}
Briefly describe the reduction opportunities you have implemented during the past reporting year; or reference the section and page number where the opportunities are described in your Executive Summary for plan subminted in lieu of an Executive Summary). In either case, provide the following information:

- A short name and number for each opportunity. If you did this in your plan or Executive Summary, use the same name and number. Transfer the short name andlor code number to Worksheet 4.

- $A$ discussion on any reduction opportunities that have changed from the original plan or prior progress reports.

- $\quad A$ description of any new opportunities you have identified and selected for implementation.
\end{abstract}

Facility name: Hanford

Reporting Year(s): October 1, 1992 - December 31, 1993

Number: FFT 12-1

Short name: Reuse used oil

Description: The current procedure of reusing oil wherever possible is the first alternative. This method provides the most cost-effective reduction method.

Number: $\quad$ FFT 12-2

Short name: Recycle used oil

Description: The recycling of oil through an outside vendor also prevents off-specification oil from becoming a hazardous waste.

\section{Worksheet 3}

Processes Impacted - 080(1)(a)(ii)

Briefly describe the processes affected by your reduction opportunities; or reference the section and page number where they are described in your Executive Summary (or plan submitted in lieu of an Execurive Summary). In either case, provide the following information:

- A short name and number for each process. If you did this for your plan or Executive Summary, use the same name and number. Transfer the short name and/or code number to Worksheet 4.

- $\quad A$ discussion on the processes affected by your reduction opportunities.

Facility name: Hanford

Reporting Year(s): October 1, 1992 - December 31, 1993

Number: FFT-12

Short name: Maintenance

Description: When maintenance is performed on pumps and rotating equipment, oil is removed from the equipment. The oil is sampled, and if it meets specifications can be reused without treatment. However, oil containing heavy metals or other analytes of concern cannot be directly returned to the system without treatment. 


\section{Worksheet 2}

Opportunity Descriptions - 080(1)(i)

Briefly describe the reduction opportunities you have implemented during the past reporting year; or reference the section and page number where the opportunities are described in your Executive Summary (or plan submitted in lieu of an Executive Summary). In either case, provide the following information:

- A short name and number for each opportunity. If you did this in your plan or Executive Summary, use the same name and number. Transfer the shor name and/or code number to Worksheet 4.

- $\quad A$ discussion on any reduction opportunities that have changed from the original plan or prior progress reports.

- A description of any new opportunities you have identified and selected for implementation.

Facility name: Hanford

Reporting Year(s): October 1, 1992 - December 31, 1993

Number: FFT 13-1

Short name: Better maintenance procedures

Description: New maintenance procedures require the use of a collection system to collect freon so it is not vented to the atmosphere.

Number: FFT 13-2

Short name: Operate fewer machines when not required

Description: An engineering evaluation has been completed to determine how many compressors are required, at a minimum, for plant operations. A change is in progress to remove two chillers from service within the plant. This action will be implemented wheri the documentation is completed.

\section{Worksheet 3}

Processes Impacted - 080(1)(a)(ii)

Briefly describe the processes affected by your reduction opportunities; or reference the section and page number where they are described in your Executive Summary (or plan submitted in lieu of an Executive Summary). In either case, provide the following information:

- A short name and number for each process. If you did this for your plan or Executive Summary, use the same name and number. Transfer the shor name and/or code number to Worksheet 4.

- $A$ discussion on the processes affected by your reduction opportunities.

Facility name: Hanford

Reporting Year(s): October 1, 1992 - December 31, 1993

Number: FFT-13

Short name: Refrigerants/CFCs

Description: The plant chillers feed primarily heating and ventilation systems and cell cooling. Cooling water is a different system. The plant operates large refrigeration compressors to provide this cooling. Normal maintenance and freon leakage from the machines comprises this waste stream. 


\section{Worksheet 2}

\section{Opportunity Descriptions - 080(1)(i)}

Briefly describe the reduction opportunities you have implemented during the past reporting year; or reference the section and page number where the opportunities are described in your Executive Summary lor plan submitted in lieu of an Executive Summary). In either case, provide the following information:

A short name and number for each opportunity. If you did this in your plan or Execurive Summary, use the same name and number. Transfer the short name and/or code number to Worksheet 4.

- A discussion on any reduction opportunities that have changed from the original plan or prior progress reports.

- $\quad A$ description of any new opportunities you have identified and selected for implemensation.

Facility name: Hanford

Reporting Year(s): October 1, 1992 - December 31, 1993

Number: FFT 14-1

Short name: Recycle, reuse solvent

Description: Recycle solvent with solvent filtration equipment.

\section{Worksheet 3}

\section{Processes Impacted - 080(1)(a)(ii)}

Briefly describe the processes affected by your reduction opportunities; or reference the section and page number where they are described in your Executive Summary (or plan submitted in lieu of an Executive Summary). In either case, provide the following information:

- A shor name and number for each process. If you did this for your plan or Executive Summary, use the same name and number. Transfer the shor name and/or code number to Worksheet 4.

- $\quad A$ discussion on the processes affected by your reduction opportunities.

Facility name: Hanford

Reporting Year(s): October 1, 1992 - December 31, 1993

Number: FFT-14

Short name: Maintenance

Description: Equipment repair requires that oil/grease and dirt be moved for equipment repair. This cleaning process generates dirty, spent solvent. 


\section{Worksheet 2}

Opportunity Descriptions - 080(1)(i)

Briefly describe the reduction opportunities you have implemented during the past reporting year; or reference the section and page number where the opportunities are described in your Executive Summary (or plan submitted in lieu of an Executive Summary). In either case, provide the following information:

- A short name and number for each opportunity.' If you did this in your plan or Executive Summary, use the same name and number. Transfer the shor name andior code number to Worksheet 4.

- A discussion on any reduction opportunities that have changed from the original plan or prior progress reports.

- $\quad A$ description of any new opportunities you have identified and selected for implementation.

Facility name: Hanford

Reporting Year(s): October 1, 1992 - December 31, 1993

Number: FFT 15-1

Short name: Substitute nonhazardous lighting

Description: Replace low-pressure sodium fixtures on plant buildings with mercury vapor lighting. This will eliminate the low-pressure sodium bulbs as a waste stream.

\section{Worksheet 3}

Processes Impacted - 080(1)(a)(ii)

Briefly describe the processes affected by your reduction opportunities; or reference the section and page number where they are described in your Executive Summary (or plan submitted in lieu of an Executive Summary). In either case, provide the following information:

- A short name and number for each process. If you did this for your plan or Executive Summary, use the same name and number. Transfer the shor name and/or code number to Worksheet 4.

- $\quad A$ discussion on the processes affected by your reduction opportunities.

Facility name: Hanford

Reporting Year(s): October 1, 1992 - December 31, 1993

Number: FFT-15

Short name: Lighting of facilities

Description: In normal operations, burned-out bulbs are replaced. 


\section{Worksheet 2 \\ Opportunity Descriptions - 080(1)(i)}

Briefly describe the reduction opportunities you have implemented during the past reporting year; or reference the section and page number where the opportunities are described in your Executive Summary (or plan submitted in lieu of an Executive Summary). In either case, provide the following information:

- A shor name and number for each opportunity. If you did this in your plan or Executive Summary, use the same name and number. Transfer the short name and/or code number to Worksheet 4.

- $A$ discussion on any reduction opportunities that have changed from the original plan or prior progress reports.

- A description of any new opportunities you have identified and selected for implementation.

Facility name: Hanford (MIEHOO4, FHWOO2)

Reporting Year(s!: October 1, 1992 - December 31, 1993

Number: PFP 1-1

Short name: Use Hazardous Material Management Plan

Description: Use the Hazardous Material Management Plan, controlled chemical inventory, and product application matrix to reduce unnecessary purchases, and encourage product substitutes for hazardous products.

Number: PFP 1-2

Short name: Recycled batteries

Description: Purchase only recycled batteries.

Number: PFP 1-3

Short name: Segregation

Description: Separate nonregulated from regulated batteries during disposal.

Number: PFP 1.4

Short name: Recycle alkaline

Description: Recycle all Alkaline batteries.

Number: PFP 1-5

Short name: Recycle nickel-cadmium

Description: Recycle all nickel-cadmium batteries.

Number: PFP 1-6

Short name: Recycle lead acid

Description: Recycle all lead acid and gel cell batteries.

Number: PFP $1-7$

Short name: Use nickel-cadmium

Description: Use nickel-cadmium rechargeable batteries when possible.

Number: PFP 1-8

Short name: Use alkaline

Description: Purchase and use alkaline rechargeable batteries. 
Number: PFP 1-9

Short name: Hand-held equipment

Description: Use hand-held equipment that can be AC operated versus battery operated.

Number: PFP 1-10

Short name: Use battery tester

Description: Use battery tester to verify battery is dead before disposal.

\section{Worksheet 3}

\section{Processes Impacted - 080(1)(a)(ii)}

Briefly describe the processes affected by your reduction opportunities; or reference the section and page number where they are described in your Executive Summary (or plan submitted in lieu of an Executive Summary). In either case, provide the following information:

- A shor name and number for each process. If you did this for your plan or Executive Summary, use the same name and number. Transfer the shor name and/or code number to Worksheet 4.

- $\quad A$ discussion on the processes affected by your reduction opportunities.

Facility name: Hanford

Reporting Year(s): October 1, 1992 - December 31, 1993

Number: PFP-1

Short name: Maintenance/instrument/electrical batteries

Description: Batteries are used in flashlights, pagers, air purifying systems, emergency lights, and small hand held equipment. Various makes and models exist.

Number: PFP-4

Short name: Office Waste Batteries

Description: Batteries are used in flashlights, pagers, air purifying systems, emergency lights, (covered under PWA MIEHOO4), and small hand-held equipment. Various makes and models exist. 


\section{Worksheet 2}

Opportunity Descriptions - 080(1)(i)

Briefly describe the reduction opporturities you have implemented during the past reporting year; or reference the section and page number where the opportunities are described in your Executive Summary for plan submitted in lieu of an Executive Summary). In either case, provide the following information:

- A short name and number for each opportunity. If you did this in your plan or Execurive Summary, use the same name and number. Transfer the shorn name and/or code number to Worksheet 4.

- $\quad A$ discussion on any reduction opportunities that have changed from the original plan or prior progress reports.

- $\quad A$ description of any new opportunities you have identified and selected for implementation.

Facillty name: Hanford (MIEH001)

Reporting Year(s): October 1, 1992 - December 31, 1993

Number: PFP 2-1

Short name: Rapid start fixtures

Description: Use rapid start fixtures rather than ballast start fixtures to save on life of bulb.

Number: PFP 2-3

Short name: Use citric-based cleaner

Description: Use citric-based cleaner to clean all fixtures instead of solvents and normal paraffin hydrocarbon (NPH).

Number: PFP 2-4

Short name: Florescent lighting

Description: Switch overhead lighting to compact florescent lighting, where feasible.

\section{Worksheet 3}

Processes Impacted - 080(1)(a)(ii)

Briefly describe the processes affected by your reduction opportunities; or reference the section and page number where they are described in your Executive Summary (or plan submitted in lieu of an Executive Summary). In either case, provide the following information:

- A short name and number for each process. If you did this for your plan or Executive Summary, use the same name and number. Transfer the shor name andlor code number to Worksheet 4.

- $\quad A$ discussion on the processes affected by your reduction opportunities.

Facility name: Hanford

Reporting Year(s): October 1, 1992 - December 31, 1993

Number: PFP-2

Short name: Maintenance/electricians/ballasts

Description: Ballasts and fixtures are changed out as needed in the facility or when they are detected leaking. This requires the electrician to handle the entire waste as PCB contaminated, if applicable, generating rags, and cleanup in addition to the ballast. 


\section{Worksheet 2}

Opportunity Descriptions - 080(1)(i)

Briefly describe the reduction opportunities you have implemented during the past reporting year; or reference the section and page number where the opportunities are described in your Executive Summary lor plan submitted in lieu of an Executive Summany). In either case, provide the following information:

- A shor name and number for each opportunity. If you did this in your plan or Executive Summary, use the same name and number. Transfer the shor name andlor code number to Worksheet 4.

- A discussion on any reduction opportunities that have changed from the original plan or prior progress reports.

- A description of any new opporrunities you have identified and selected for implementation.

Facillty name: Hanford (MIEHOO2)

Reporting Year(s): October 1, 1992 - December 31, 1993

Number: PFP $3-1$

Short name: Use the Green Lights manual

Description: Use the Green Lights manual from EPA to determine the best lighting for an area or application.

Number: PFP 3-2

Short name: Use compact florescent lighting

Description: Use compact florescent lighting when possible to replace standard florescent and incandescent bulbs.

Number: PFP 3-3

Short name: Use solder remover

Description: Use solder remover to remove lead bead from bulbs.

Number: PFP $3-4$

Short name: Recycle florescent tubes

Description: Recycle all florescent tubes through a recycling company.

Number: PFP $3-6$

Short name: Use rapid start fixtures

Description: Use rapid start fixtures rather than ballast start fixtures to save on life of bulb.

Number: PFP 3-7

Short name: Section and change all lights

Description: Section and change all lights within an area instead of changing as they go out. 


\section{Worksheet 3}

Processes Impacted - 080(1)(a)(ii)

Briefly describe the processes affected by your reduction opportunities; or reference the section and page number where they are described in your Executive Summary (or plan submitted in lieu of an Executive Summary). In either case, provide the following information:
A short name and number for each process. If you did this for your plan or Execurive Summary, use the same name and number. Transfer the short name and/or code number to Worksheet 4. $A$ discussion on the processes affected by your reduction opportunities.

-

Facillty name: Hanford

Reporting Year(s): October 1, 1992 - December 31, 1993

Number: PFP-3

Short name: Maintenance/electricians/lighting

Description: Lights are changed on an as-needed basis throughout the facility. 


\section{Worksheet 2}

\section{Opportunity Descriptions - 080(1)(i)}

Briefly describe the reduction opportunities you have implemented during the past reporting year; or reference the section and page number where the opportunities are described in your Execurive Summary (or plan submitted in lieu of an Executive Summary). In either case, provide the following information:

A short name and number for each opportunity. If you did this in your plan or Executive Summary, use the same name and number. Transfer the shor name andior code number to Worksheet 4.

- A discussion on any reduction opportunities that have changed from the original plan or prior progress reports.

- A description of any new opportunities you have identified and selected for implementation.

Facillty name: Hanford (CNMHOO1)

Reporting Year(s): October 1, 1992 - December 31, 1993

Number: PFP 5-1

Short name: Reclaim freon

Description: Reclaim freon through recovery units rather than discharging to the environment.

Number: PFP 5-2

Short name: Use Hazardous Material Management Plan

Description: Use Hazardous Material Management Plan and material life cycling analysis to evaluate all procurement.

Number: PFP 5-3

Short name: Use hot drain system

Description: Use hot drain system for draining all oil filters and sending filters out as scrap metal instead of regulated oil waste.

Number: PFP 5-4

Short name: Design capacity

Description: Design facility equipment for smaller capacity fluid cavities. 


\section{Worksheet 3}

Processes Impacted - 080(1)(a)(ii)

Briefly describe the processes affected by your reduction opportunities; or reference the section and page number where they are described in your Executive Summary (or plan submined in lieu of an Executive Summary). In either case, provide the following information:

- A shor name and number for each process. If you did this for your plan or Executive Summary, use the same name and number. Transfer the shor name and/or code number 10 Worksheet 4.

- $\quad A$ discussion on the processes affected by your reduction opportunities.

Facility name: Hanford

Reporting Year(s): October 1, 1992 - December 31, 1993

Number: PFP.5

Short name: Construction/modification: lubricants

Description: Miscellaneous equipment includes the following: emergency turbines, vacuum pumps, ancillary equipment, and miscellaneous process equipment not evaluated under other process waste assessments for a specific process.

During the changing of lubricating fluids for preventative and corrective maintenance activities, various wastes are produced. The amount of waste generated is dependent upon the type of activity, the scope of work being performed, and the total amount of fluid to be drained. In addition, rags and adsorbents are used to cleanup any spills or residues generated. 


\section{Worksheet 2}

\section{Opportunity Descriptions - 080(1)(i)}

Briefly describe the reduction opportunities you have implemented during the past reporting year; or reference the section and page number where the opportunities are described in your Executive Summary (or plan submitted in lieu of an Executive Summary). In either case, provide the following information:

- $\quad$ A shorn name and number for each opportunity. If you did this in your plan or Executive Summary, use the same name and number. Transfer the short name andlor code number to Worksheet 4.

- $A$ discussion on any reduction opportunities that have changed from the original plan or prior progress reports.

- $\quad A$ description of any new opportunities you have identified and selected for implementation.

Facility name: Hanford (FHWO01)

Reporting Year(s): October 1, 1992 - December 31, 1993

Number: PFP 6-1

Short neme: Use the Hazardous Material Management Plan

Description: Use the Hazardous Material Management Plan, controlled chemical and product application matrix to reduce unnecessary purchases, and encourage product substitutes for hazardous products.

Number: PFP 6-2

Short name: Recycled toners

Description: Purchase only recycled toners.

Number: PFP 6-3

Short name: Segregate

Description: Separate nonregulated from regulated toners and cartridges.

Number: PFP 6-4

Short name: Recycle toners

Description: Recycle all toners. 


\section{Worksheet 3}

Processes Impacted - 080(1)(a)(ii)

Briefly describe the processes affected by your reduction opportunities; or reference the section and page number where they are described in your Executive Summary (or plan submitted in lieu of an Executive Summary). In either case, provide the following information:

- A short name and number for each process. If you did this for your plan or Executive Summary, use the same name and number. Transfer the short name and/or code number to Worksheet 4.

- $\quad A$ discussion on the processes affected by your reduction opportunities.

Facility name: Hanford

Reporting Year(s): October 1, 1992 - December 31, 1993

Number: PFP-6

Short name: Office wastes copier toners

Description: When copy machines and printers require changing of the toner, the toner is collected in nonrecyclable and recyclable drums or containers. Toners are changed when an alarm or light indicates the toner is low.

Rags and empty containers are generated during the use of these products. 


\section{Worksheet 2}

\section{Opportunity Descriptions - 080(1)(i)}

Briefly describe the reduction opportunities you have implemented during the past reporting year; or reference the section and page number where the opportunities are described in your Executive Summary (or plan submitted in lieu of an Executive Summary). In either case, provide the following information:

- A shor name and number for each opportunity. If you did this in your plan or Executive Sumnary, use the same name and number. Transfer the shor name and/or code number to Worksheet 4.

- $\quad A$ discussion on any reduction opportunities that have changed from the original plan or prior progress reports.

- $A$ description of any new opportunities you have identified and selected for implementation.

Facility name: Hanford (MMH0O4, CNMH0O4)

Reporting Year(s): October 1, 1992 - December 31, 1993

Number: PFP 7-1

Short name: Recycle nonradioactive hydraulic fluids

Description: Controlling the amount and toxicity of material has already been accomplished through the implementation of the Hazardous Material Management Plan and the Product Application Matrix. Only approved materials may be ordered, and only in "just in time" inventory amounts, through the Hazardous Material Specialists.

Number: PFP 7-2

Short name: Recycle fluid through a filtering system

Description: Recycling the solution through filters would reduce handling and transportation of containers; however, additional issues such as housekeeping and where the recycling would be done would require evaluation. In addition, suitable micron filters and corrosion inhibitors would have to be procured to recycle the material.

Number: PFP 7-3

Short name: Increase the length of time between changes

Description: Increasing the length of time between changes would reduce the amount of waste; however, additional evaluations must be done to ensure equipment failure or malfunctions would not occur because of the change in fluid change our frequency.

Number: $\quad$ PFP $7-4$

Short name: Substitute with vegetable oil-based fluid

Description: Suitable substitutes are available. Process and Maintenance engineering will need to assess the suitability of the fluid.

Number: PFP $7-5$

Short name: Use the controlled chemical inventory procedure

Description: Recycling of material through offsite vendor or supplier would allow the facility. to set up a contract in which material would be sent out once samples had determined no contamination was present. Transportation and additional handling of the material would be disadvantages of this method. 


\section{Worksheet 3}

Processes Impacted - 080(1)(a)(ii)

Briefly describe the processes affected by your reduction opportunities; or reference the section and page number where they are described in your Executive Summary (or plan submitted in lieu of an Executive Summary). In either case, provide the following information:

- $\quad$ A short name and number for each process. If you did this for your plan or Executive Summary, use the same name and number. Transfer the short name and/or code number to Worksheet 4.

- $\quad A$ discussion on the processes affected by your reduction opportunities.

Facility name: Hanford

Reporting Year(s): October 1, 1992 - December 31, 1993

Number: PFP-7

Short name: Mechanical maintenance hydraulic systems

Description: Mechanical maintenance hydraulic fluid changes occur from routine, scheduled preventative maintenance performed on elevator and hydraulic lift systems throughout the facility. In addition, leaks or other corrective maintenance activities increase the frequency of the fluid changes and, therefore, the waste generated.

Waste absorbents contaminated with hydraulic fluids result from spill cleanup and maintenance housekeeping during fluid changes. These absorbents have historically been diatomaceous earth or universal absorbent.

Number: PFP-7

Short name: New/modified construction hydraulic systems

Description: Newly constructed, or modified, hydraulic fluid systems are installed to upgrade or replace old systems, or are part of a new facility. These include hydraulic lifts, scissor lifts, cranes, and elevators. In addition, leaks or other corrective maintenance activities increase the frequency of the fluid changes and, therefore, the waste generated.

Waste absorbents contaminated with hydraulic fluids result from spill cleanup and maintenance housekeeping during fluid changes. These absorbents have historically been diatomaceous earth or universal absorbent. 


\section{Worksheet 2 \\ Opportunity Descriptions - 080(1)(i)}

Briefly describe the reduction opportunities you have implemented during the past reporting year; or reference the section and page number where the opportunities are described in your Executive Summary (or plan submitted in lieu of an Executive Summary). In either case, provide the following information:

- A short name and number for each opportuniny. If you did this in your plan or Executive Summary, use the same name and number. Transfer the shorn name and/or code number to Worksheet 4.

- A discussion on any reduction opportunities that have changed from the original plan or prior progress reports.

- A description of any new opportunities you hove identified and selected for implementation.

Facility name: Hanford (PRFH002, RMCH002, MMH007, MIEH007, JANH001)

Reporting Year(s): October 1, 1992 - December 31, 1993

Number: PFP 8-1

Short name: Resolve moratorium waste issues

Description: Resolve moratorium waste issues to reduce mixed waste and controlled wastes from excess or partially spent products generation.

Number: PFP 8-2

Short name: Control all containers entering the surface contamination areas

Description: Control all containers entering the surface contamination areas, to reduce the need to buy products for both nonradioactive and surface contamination Areas.

Number: PFP 8-3

Short name: Use a managed care system with Health Physics seals or tags

Description: Use a managed care system with Health Physics seals or tags on items entering zones to ensure they can be sealed and taken out of zone areas once the job is completed.

Number: PFP 8-4

Short name: Use the Hazardous Material Management Plan

Description: Use the Hazardous Material Management Plan, controlled chemical inventory, and product application matrix to reduce unnecessary purchases.

Number: PFP 8-5

Short name: Barcode all hazardous materials

Description: Barcode all hazardous materials to keep better track and realtime inventories throughout the facility.

Number: PFP 8-6

Short name: Provide a pollution prevention-lessons leamed course

Description: Provide a pollution prevention-lessons leamed course for hazardous material management in PFP.

Number: PFP 8-7

Short name: Chemical exchange

Description: Transfer products through the chemical exchange. 
Number: PFP 8-8

Short name: Public auction

Description: Sell excess and overstocked products through the public auction.

Number: PFP 8-9

Short name: Plant redeployment program

Description: Set up a central Plant Redeployment program-buy bulk chemicals and distribute through all laboratories, maintenance, and operations.

\section{Worksheet 3}

Processes Impacted - 080(1)(a)(ii)

Briefty describe the processes affected by your reduction opportunities; or reference the section and page number where they are described in your Executive Summary (or plan submitted in lieu of an Executive Summary). In either case, provide the following information:

- A shor name and number for each process. If you did this for your plan or Executive Summary, use the same name and number. Transfer the short name and/or code number to Worksheet 4.

- $\quad A$ discussion on the processes affected by your reduction opportunities.

Facility name: Hanford

Reporting Year(s): October 1, 1992 - December 31, 1993

Number: PFP-8

Short name: General use products

Description: General use products are commonly used cleaners. In addition, they include decon agents. Instrument technicians and electricians also use solvents in the cleaning of circuit boards, poppy probes, and other items. Historically, these solvents were 1,1,1 trichlorethane, and perchlorethane-based cleaners; however, the plant switched to nonflammable and noncarcinogenic citrus terpene in 19891990.

Janitorial staff uses these products for cleaning of fixtures, walls, desks, windows, and floors throughout the facility. Rags and empty containers are generated during the use of these products. 


\title{
Worksheet 2
}

Opportunity Descriptions - 080(1)(i)

\begin{abstract}
Briefty describe the reduction opportunities you have implemented during the past reporting year; or reference the section and page number where the opportunities are described in your Executive Summary for plan submitted in lieu of an Execurive Summary). In either case, provide the following information:

- A shor name and number for each opportunity. If you did this in your plan or Executive Summary, use the same name and number. Transfer the short name and/or code number to Worksheet 4.

- $A$ discussion on any reduction opportunities that have changed from the original plan or prior progress reports.

- A description of any new opportunities you have identified and selected for implementation.
\end{abstract}

Facility nome: Hanford (MMH002)

Reporting Year(s): October 1, 1992 - December 31, 1993

Number: PFP 9-1

Short name: Recycle used cutting fluids

Description: Recycling cutting fluids in house through a five micron particulate filter(s) would lengthen the life of the fluid. The filters could be disposed of as waste, with the rinsed fluid being reused many times.

Number: PFP 9-2

Short name: Use Hazardous Material Management Plan

Description: The Hazardous Material Management Plan ensures that all fluids and oils are evaluated against regulatory concerns and life-cycling analysis. Controlled chemical inventory ensures that a Hazardous Material Specialist verifies the need for the new product to be ordered before authorizing the purchase.

Number: PFP 9-3

Short name: Recycle all scrap metal

Description: Recycling all scrap metal provides a renewable resource to industry-this option has been used for most of the metal scrap generated at Plutonium Finishing Plant (PFP) in nonradiological areas.

Number: PFP $9-4$

Short name: Use water-soluble cutting fluid

Description: A particular product has been used with success at the Kansas City Allied Signal shop for several years. The product has a pleasant cinnamon odor that disappears as the product begins to "spoil" and needs changing. The material is recyclable throughout the vendors filtration system and reduces the amount of fluid required in metal machining operations.

\section{Number: PFP 9-5}

Short name: Rinse metal turnings

Description: Metal turnings, removed immediately from the lathe, drill press, or other machine operation area, would be rinsed in a clean cutting fluid, reducing the time spent leaching into the equipments fluid bath or bed. This would reduce the amount of metal fines or turnings from sitting in the fluid, and would allow the fluid to be recyclable or filtered more easily. 


\section{Worksheet 3}

Processes Impacted - 080(1)/a)(ii)

Briefly describe the processes affected by your reduction opportunities; or reference the section and page number where they are described in your Executive Summary (or plan submined in lieu of an Executive Summary). In either case, provide the following information:

- A short name and number for each process. If you did this for your plan or Executive Summary, use the same name and number. Transfer the short name and/or code number to Worksheet 4.

- $\quad A$ discussion on the processes affected by your reduction opportunities.

Facility name: Hanford

Reporting Year(s): October 1, 1992 - December 31, 1993

Number: PFP-9

Short name: Pipe machining: fluids, turnings, and metal

Description: Pipe, sheeting, and miscellaneous equipment pieces are cut, tumed, lathed, and polished for maintenance activities within the PFP complex. As a result, a variety of small metal fines, turnings, and fluids are generated.

The fluids are changed out as they become visibly contaminated by metal fines and particulate. Often all wastes are treated as hazardous because of the metal and organic toxicity of the tumings/fluid matrix. Rigid fluid is recycled as soluble oils.

Scrap metal is surveyed and released for excess or recycled. 


\section{Worksheet 2}

\section{Opportunity Descriptions - 080(1)(i)}

Briefly describe the reduction opportunities you have implemented during the past reporting year; or reference the section and page number where the opportunities are described in your Executive Summary (or plan submitted in lieu of an Executive Summary). In either case, provide the following information:

- A short name and number for each opportunity. If you did this in your plan or Executive Summary, use the same name and number. Transfer the shor name and/or code number to Worksheet 4.

- A discussion on any reduction opportunities that have changed from the original plan or prior progress reports.

- A description of any new opportunities you have identified and selected for implementation.

Facility name: Hanford (CNMHOO2)

Reporting Year(s): October 1, 1992 - December 31, 1993

Number: PFP 10-1

Short name: Reclaim freon

Description: Reclaim freon through recovery units rather than discharging to the environment.

Number: PFP 10-2

Short name: Use Hazardous Material Management Plan

Description: Use Hazardous Material Management Plan and material life-cycling analysis to evaluate all procurement.

Number: PFP 10-3

Short name: Use hot drain system

Description: Use hot drain system for draining all oil filters, and sending filters out as scrap metal instead of regulated oil waste.

Number: PFP 10-4

Short name: Design capacity

Description: Design facility equipment for smaller capacity fluid cavities. 


\section{Worksheet 3}

Processes Impacted - 080(1)(a)(ii)

Briefly describe the processes affected by your reduction opportunities; or reference the section and page number where they are described in your Executive Summary (or plan submitted in lieu of an Executive Summary). In either case, provide the following information:

- A short name and number for each process. If you did this for your plan or Executive Summary, use the same name and number. Transfer the short name and/or code number to Worksheet 4.

- $\quad A$ discussion on the processes affected by your reduction opportunities.

Facillty name: Hanford

Reporting Year(s): October 1, 1992 - December 31, 1993

Number: PFP-10

Short name: Construction/modification: oils/pipe machine

Description: Miscellaneous equipment includes the following: emergency turbines, vacuum pumps, ancillary equipment, and miscellaneous process equipment being installed in the facility as a new item or modification of a current safety system.

During the changing of lubricating fluids for preventative and corrective maintenance activities, various wastes are produced. The amount of waste generated is dependent upon the type of activity, the scope of work being performed, and the total amount of fluid to be drained. In addition, rags and absorbents are used to clean up any spills or residues generated. 


\section{Worksheet 2}

\section{Opportunity Descriptions - 080(1)(i)}

Brigfy describe the reduction opportunities you have implemented during the past reporting year; or reference the section and page number where the opportunities are described in your Execusive Summary for plan submitted in lieu of an Execurive Sumnary). In either case, provide the following information:

- A shor name and number for each opporturity. If you did this in your plan or Execurive Summary, use the same name and number. Transfer the short name and/or code number to Wortsheet 4.

- A discussion on any reduction opporturities that have changed from the original plan or prior progress reports.

- A description of any new opporturities you have identified and selected for implementation.

Facility mame: Hanford (CNMH003A, CRWH001B, MMH003A)

Reporting Year(s): October 1, 1992 - December 31, 1993

Number: PFP 11-1

Short name: Proceduralize HP hold point

Description: Proceduralize Health Physics (HP) hold point to allow HP personnel to follow craft in surface contamination areas to release material upon job completion.

Number: PFP 11-2

Short name: Standardize epoxy and paint order

Description: Standardize epoxy and paint orders site wide-use stores to stock base coats and primers/epoxies to eliminate over ordering and streamline variety.

Number: PFP 11-3

Short name: Use of latex epoxy

Deacription: Use latex-based epoxy instead of 2 or 3 part epoxies.

Number: PFP 11-4

Short name: Planning process

Description: Include painters in preplanning work packages.

Number: PFP 11-5

Short name: Create coating engineer position

Description: Create coating engineer position to provide technical support and on-the-job training to painters.

Number: PFP 11-6

Short name: Use epoxies only when necessary

Description: Use epoxies only when necessary-evaluate use in comparison with waste.

Number: PFP 11-7

Short name: Use Product Application Matrix

Description: Use Product Application Matrix (controlled purchase system) to identify less toxic materials and reduce volumes purchased. 


\section{Worksheet 3}

Processes Impacted - 080(1)(a)(ii)

Briefly describe the processes affected by your reduction opportunities; or reference the section and page number where they are described in your Executive Summary (or plan submined in lieu of an Executive Summary). In either case, provide the following information:

- A shor name and number for each process. If you did this for your plan or Executive Summary, use the same name and number. Transfer the short name and/or code number to Worksheet 4.

- $\quad A$ discussion on the processes affected by your reduction opportunities.

Facillty name: Hanford

Reporting Year(): October 1, 1992 - December 31, 1993

Number: PFP-11

Short name: New/modified construction painting

Description: Hew/modified construction painting process includes the following: painting of pumps, supply fans, walls, floors, valves, and safety lanes, etc.

Number: $\quad P=P-11$

Short name: Construction remediation painting

Description: Construction remediation painting process includes the following: painting of pumps, supply fans, walls, floors, valves, and safety lanes, etc.

Number: PFP-11

Short name: Mechanical maintenance painting

Description: Mechanical maintenance painting process includes: painting of pumps, supply fans, walls, floors, valves, and safety lanes, etc. 


\section{Worksheet 2}

\section{Opportunity Descriptions - 080(1)(i)}

Briefly describe the reduction opportunities you have implemented during the past reporting year; or reference the section and page number where the opportunities are described in your Executive Summary (or plan submitted in lieu of an Executive Summary). In either case, provide the following information:

- A shor name and number for each opportunity. If you did this in your plan or Executive Summary, use the same name and number. Transfer the short name and/or code number to Worksheet 4.

- A discussion on any reduction opportunities that have changed from the original plan or prior progress reports.

- A description of any new oppornunities you have identified and selected for implemensation.

Facility name: Hanford (MMH003C, CNMH003B, CRW001A)

Reporting Year(s): October 1, 1992 - December 31, 1993

Number: PFP 12-1

Short name: Use painter in planning process

Description: Use painter in planning process to determine correct sign finishes and if work is still required (check with requester before starting signs).

Number: PFP $12-2$

Short name: Use Product Application Matrix

Description: Use Product Application Matrix in material selection before ordering for job.

Number: PFP 12-3

Short name: Install paint booths

Description: Install paint booths with high efficiency particulate air (HEPA) filtration for onsite painting.

Number: PFP 12-4

Short name: Use experienced painter

Description: Use experienced painter as the person in charge of painting and coating jobs.

Number: PFP $12-5$

Short name: Discard all brushes

Description: Discard all brushes instead of rinsing with thinner or water.

Number: PFP 12-6

Short name: Install controlled temperature storage units

Description: Install controlled temperature storage units for outside storage of paints.

Number: PFP 12-7

Short name: Control life cycle of paint

Description: Control life cycle of paint using Hazardous Material Management Plan for analysis of inventory and type of paint to be used.

Number: PFP 12-8

Short name: Use seal system

Description: Use seal system to seal bags with brushes-refrigerate to keep pliable. 
Number: PFP $12-9$

Short name: Place tools in plastic bags

Description: Place tools in plastic bags-don't seal, but refrigerate.

Number: PFP 12-10

Short name: Install solvent distiller

Description: Install solvent distiller to recover spent solvents.

Number: PFP 12-11

Short name: Hold sitewide, quality circle meetings

Description: Hold sitewide, quality circle meetings with vendors and other painters to discuss new techniques and equipment.

Number: PFP 12-12

Short name: Provide training to all painters

Description: Provide training to all painters on techniques and material management.

Number: PFP 12-13

Short name: Create a coating engineer position

Description: Create a coating engineer position for the Hanford Site.

Number: PFP 12-14

Short name: Use high-quality paints

Description: Use high-quality paints instead of low-bid paints to gain durability and reduce frequency of painting.

Number: PFP 12-15

Short name: Use waterborne products

Description: Use waterborne products and acrylic enamels instead of oil-based paints when possible. 


\section{Worksheet 3 \\ Processes Impacted - 080(1)(a)(ii)}

Briefly describe the processes affected by your reduction opportunities; or reference the section and page number where they are described in your Executive Summary (or plan submitied in lieu of an Execurive Summary). In either case, provide the following information:

- A short name and number for each process. If you did this for your plan or Executive Summary, use the same name and number. Transfer the shor name and/or code number to Worksheet 4.

- $\quad A$ discussion on the processes affected by your reduction opportunities.

Facility name: Hanford

Reporting Year(s): October 1, 1992 - December 31, 1993

Number: PFP-12

Short name: Mechanical maintenance painting

Description: Mechanical maintenance painting process includes the following: painting of pumps, supply fans, walls, floors, valves, and safety lanes, etc.

Number: PFP-12

Short name: New/modified construction painting

Description: New/modified construction painting process includes the following: painting of pumps, supply fans, walls, floors, valves, and safety lanes, etc.

Number: PFP-12

Short name: Construction remediation painting

Description: New/modified construction facility painting process includes the following: painting of pumps, supply fans, walls, floors, valves, and safety lanes, etc. 


\section{Worksheet 2}

\section{Opportunity Descriptions - 080(1)(i)}

Briefly describe the reduction opportunities you have implemented during the past reporting year; or reference the section and page number where the opportunities are described in your Executive Summary lor plan submitted in lieu of an Executive Summary). In either case, provide the following information:

- A short name and number for each oppornunity. If you did this in your plan or Executive Summary, use the same name and number. Transfer the short name and/or code number to Worksheet 4.

- A discussion on any reduction opportunities that have changed from the original plan or prior progress reports.

- $\quad A$ description of any new opportunities you have identified and selected for implementation.

Facility name: Hanford (CNMHO03, CRWHO01)

Reporting Year(s): October 1, 1992 - December 31, 1993

Number: PFP 13-1

Short name: Do not strip-abrade

Description: Do not strip surface, abrade instead.

Number: PFP 13-2

Short name: Use needle gun

Description: Use needle gun with vacuum attachment to remove surface coatings.

Number: PFP 13-3

Short name: Use $\mathrm{CO} 2$ pellets

Description: Use $\mathrm{CO} 2$ pellets to remove coating on surfaces.

Number: PFP $13-4$

Short name: Use vacuum blasters

Description: Use vacuum blasters to prepare and remove surface.

Number: PFP 13-5

Short name: Control amount of chemical stripper used

Description: Control amount of chemical stripper used on the job/stored at facility.

Number: PFP 13-6

Short rame: Include painters in preplanning

Description: Include painters in preplanning work packages.

Number: PFP 13-7

Short name: Make painters person in charge (PIC) on jobs

Description: Make painters PICs on jobs; they are more knowledgeable.

Number: PFP 13-8

Short name: Use Product Application Matrix

Deacription: Use Product Application Matrix to identify less toxic materials.

Number: PFP 13-9

Short name: Sandblast

Description: Sandblast instead of chemical strippers for paint removal. 


\section{- Worksheet 3}

Processes Impacted - 080(1)(a)(ii)

Briefly describe the processes affected by your reduction opportunities; or reference the section and page number where they are described in your Executive Summary (or plan submitred in lieu of an Executive Summary). In either case, provide the following information:

- A short name and number for each process. If you did this for your plan or Executive Summary, use the same name and number. Transfer the short name and/or code number to Worksheet 4.

- $\quad A$ discussion on the processes affected by your reduction opporturities.

Facility name: Hanford

Reporting Year(s): October 1, 1992 - December 31, 1993

Number: PFP-13

Short name: New/modified construction painting

Description: New/modified construction facility painting process includes the following: painting of pumps, supply fans, walls, floors, valves, and safety lanes, etc. 


\section{Worksheet 2}

\section{Opportunity Descriptions - 080(1)(i)}

Briefly describe the reduction opportunities you have implemented during the past reporting year; or reference the section and page number where the opportunities are described in your Executive Summary for plan submitted in lieu of an Executive Summary). In either case, provide the following information:

- A short name and number for each opportunity. If you did this in your plan or Executive Summary, use the same name and number. Transfer the shor name and/or code number to Worksheet 4.

- A discussion on any reduction opportunities that have changed from the original plan or prior progress reports.

- A description of any new oppornunities you have identified and selected for implementation.

Facility name: Hanford (MMH003B)

Reporting Year(s): October 1, 1992 - December 31, 1993

Number: PFP 14-1

Short name: Use painter in planning process

Description: Use painter in planning process to determine correct sign finishes and if work is still required (check with requestor before starting signs).

Number: PFP 14-2

Short name: Use Product Application Matrix

Description: Use Product Application Matrix select the materials before ordering. Control life cycle of paint using Hazardous Material Management Plan for analysis of inventory and type of paint to be used.

Number: PFP 14-3

Short name: Use vinyl for signs

Description: Use vinyl instead of oil-based paints for signs.

Number: PFP 14-4

Short name: Use labelizers

Description: Use labelizers or computer-assisted, sign fabrication systems instead of silk screen or stencils.

Number: PFP 14-5

Short name: Discard all brushes

Description: Discard all brushes instead of rinsing with thinner or water.

Number: PFP 14-6

Short name: Install controlled temperature storage units

Description: Install controlled temperature storage units for outside storage of paints.

Number: PFP 14-7

Short name: Control life cycle of paint

Description: Control life cycle of paint using Hazardous Material Management Plan for analysis of inventory and type of paint to be used. 


\section{Worksheet 3}

Processes Impacted - 080(1)(a)(ii)

Briefly describe the processes affected by your reduction opportunities; or reference the section and page number where they are described in your Executive Summary (or plan submitred in lieu of an Executive Summary). In either case, provide the following information:

- A short name and number for each process. If you did this for your plan or Executive Summary, use the same name and number. Transfer the short name and/or code number to Worksheet 4.

- $\quad A$ discussion on the processes affected by your reduction opportunities.

Facility name: Hanford

Reporting Year(s): October 1, 1992 - December 31, 1993

Number: PFP-14

Short name: Mechanical maintenance painting

Description: Mechanical maintenance painting process includes the following: painting of pumps, supply fans, walls, floors, valves, and safety lanes, etc. 


\section{Worksheet 2 \\ Opportunity Descriptions - 080(1)(i)}

Briefly describe the reduction opportunities you have implemented during the past reporting year; or reference the section and page number where the opportunities are described in your Executive Summary (or plan submined in lieu of an Executive Summary). In either case, provide the following information:

- A shor name and number for each opportunity. If you did this in your plan or Executive Summary, use the same name and number. Transfer the shor name and/or code number to Worksheet 4.

- $\quad A$ discussion on any reduction opportunities that have changed from the original plan or prior progress reports.

- A description of any new opportunities you have identified and selected for implementation.

Facility name: Hanford (MMH005)

Reporting Year(s): October 1, 1992 - December 31, 1993

Number: PFP 15-1

Short name: Recycle nonradioactive hydraulic fluids

Description: Recycle nonradioactive hydraulic fluids through vendor/supplier, if possible.

Number: PFP 15-2

Short name: Recycle the fluid through a filtering system

Description: Recycle the fluid through a filtering system within the facility.

Number: PFP 15-3

Short name: Increase the length of time between changes

Description: Increase the length of time between changes through sampling for viscosity, corrosion, and wear.

Number: PFP 15-4

Short name: Substitute with a vegetable oil-based fluid

Description: Substitute the present fluids with a vegetable oil-based fluid that is known to be nonregulated after use.

Number: PFP 15-5

Short name: Use the controlled chemical inventory procedures

Description: Use the controlled chemical inventory and material life cycling procedures to ensure all procurement of hydraulic fluids are kept as low as reasonably achievable (ALARA). 


\section{Worksheet 3}

Processes Impacted - 080(1)(a)(ii)

Briefly describe the processes affected by your reduction opportunities; or reference the section and page number where they are described in your Executive Summary (or plan submined in lieu of an Executive Summary). In either case, provide the following information:

- A short name and number for each process. If you did this for your plan or Executive Summary, use the same name and number. Transfer the short name and/or code number to Worksheet 4.

- $\quad$ A discussion on the processes affected by your reduction opportunities.

Facility name: Hanford

Reporting Year(s): October 1, 1992 - December 31, 1993

Number: PFP-15

Short name: Mechanical maintenance hydraulic systems

Description: Mechanical maintenance hydraulic fluid changes occur because of routine, scheduled preventative maintenance performed on elevator and hydraulic lift systems throughout the facility. In addition, leaks or other corrective maintenance activities increase the frequency of the fluid changes and therefore, the waste generated.

Waste absorbents contaminated with hydraulic fluids result from spill cleanup and maintenance housekeeping during fluid changes. These absorbents have historically been diatomaceous earth or universal absorbent.

The type of hydraulic fluid currently in use is an ethylene glycol-based fluid. It is considered toxic (WTO2) in Washington State. 


\section{Worksheet 2}

Opportunity Descriptions - 080(1)(i)

Briefly describe the reduction opportunities you have implemented during the past reporting year; or reference the section and page number where the opportunities are described in your Executive Summary (or plan submitted in lieu of an Executive Summary). In either case, provide the following information:

- A short name and number for each opportunity. If you did this in your plan or Executive Summary, use the same name and number. Transfer the short name and/or code number to Worksheet 4.

- A discussion on any reduction opportunities that have changed from the original plan or prior progress reports.

- A description of any new opporturities you have identified and selected for implementation.

Facility name: Hanford

Reporting Year(s): October 1, 1992 - December 31, 1993

Number: PNL 1-1

Short name: Investigate using rechargeable batteries

Description: PNL has and will continue to investigate applications for rechargeable batteries for use in equipment throughout the laboratory.

Number: PNL 1-2

Short name: Investigate preventative maintenance (PM) schedules to determine if usable life can be extended

Description: The Pacific Northwest Laboratory (PNL) will evaluate PM schedules to ensure that batteries are not changed out before their useful life is exceeded. At this time, it is unknown which, if any, PM schedules involve opportunities for improvement.

Number: PNL 1-3

Short name: Contract with vendors to take back spent batteries

Description: As indicated above, vendors have been contacted to discuss return/reclaim programs for spent batteries. Thus far, no such programs have been identified. However, this will continue to be a high priority for waste reduction purposes. 


\section{Worksheet 3}

Briefly describe the processes affected by your reduction opportunities; or reference the section and page number where they are described in your Executive Summary (or plan submitted in lieu of an Executive Summary). In either case, provide the following information:

- A shon name and number for each process. If you did this for your plan or Executive Summary, use the same name and number. Transfer the shor name andlor code number to Worksheet 4.

- $\quad$ A discussion on the processes affected by your reduction opportunities.

Facility name: Hanford

Reporting Year(s): October 1, 1992 - December 31, 1993

Number: PNL-1

Short name: Batteries

Description: Used batteries are generated from a variety of sources. One of the single largest contributors to the battery waste stream is the large number of used alkaline batteries from PNL's portable radiation survey equipment. Other batteries entering the waste stream include nickel-cadmium batteries from portable radios: batteries (carbon zinc, alkaline) from flashlights, and lithium batteries from computers. Lead acid batteries from automobiles and heavy equipment also contribute to this waste stream. 


\section{Worksheet 2}

\section{Opportunity Descriptions - 080(1)(i)}

Briefly describe the reduction opportunities you have implemented during the past reporting year; or reference the section and page number where the opporthunities are described in your Executive Summary (or plan submitted in lieu of an Executive Summary). In either case, provide the following information:

- A shor name and number for each opportunity. If you did this in your plan or Executive Summary, use the same name and number. Transfer the shor name and/or code number to Worksheet 4.

- A discussion on any reduction oppormunities that have changed from the original plan or prior progress reports.

- $A$ description of any new opportunities you have identified and selected for implementation.

Facility name: Hanford

Reportiug Year(s): October 1, 1992 - December 31, 1993

Number: PNL 2-1

Short name: Product substitution

Description: Literature from Lighting Design Laboratory in Seattle, Washington indicates that the replacement of T-12 fluorescent tubes will result in greater energy efficiency and luminary efficiency, with no added cost. By itself, this does not imply a reduction in this waste stream. However, greater energy efficiency does imply decreased use of scarce resources.

\section{Number: PNL 2-2}

Short name: Electronic ballasts/higher efficiency tubes

Description: Literature from the Lighting Design Laboratory also indicates that electronic ballasts have a life expectancy several times greater than conventional magnetic ballasts. Furthermore, electronic ballasts will likely increase the life expectancy of fluorescent tubes through more efficient operation. As light ballasts at PNL are either pre-1978 PCB containing ballasts (disposed to a chemical land-fill) or magnetic ballasts (disposed as Washington State dangerous waste), longer life expectancy will yield considerable waste reduction opportunities for both ballasts and tubes.

Number: PNL 2-3

Short name: For new facilities/renovations of existing facilities

Description: An up-front evaluation of energy-efficient, design schema in new and renovated facilities would yield substantial energy efficiency benefits and would provide a mechanism for ensuring the installation of electronic ballasts and energy efficiency lamps.

Number: PNL 2-4

Short name: Install motion sensors/infrared light switches

Description: Installation of motion sensors and infrared light switches would greatly reduce overall consumption of energy and extend the life of lamps and ballasts through decreased use. 
Worksheet 3

Processes Impacted - 080(1)(a)(ii)

Briefty describe the processes affected by your reduction opportunities; or reference the section and page number where they are described in your Executive Summary (or plan submitted in lieu of an Executive Summary). In either case, provide the following information:

-

A short name and number for each process. If you did this for your plan or Executive Summary, use the same name and number. Transfer the short name and/or code number to Worksheet 4.

- $\quad$ A discussion on the processes affected by your reduction opportunities.

Facility name: Hanford

Reporting Year(s): October 1, 1992 - December 31, 1993

Number: PNL-2

Short name: Fluorescent tubes

Description: PNL regularly purchases fluorescent tubes for replacement in existing facilities or installation in new facilities. Tubes are replaced as needed when they burn out. Used tubes are then crushed to minimize volume and then disposed of as Washington State dangerous waste. 


\section{Worksheot 2}

\section{Opportunity Descriptions - 080(1)(i)}

Briefly describe the reduction opportunities you have implemented during the past reporting year; or reference the section and page number where the opportunities are described in your Executive Summary for plan submitted in lieu of an Executive Summary). In either case, provide the following information:

- A shor name and number for each opportunity. If you did this in your plan or Execusive Summary, use the same name and number. Transfer the shon name and/or code number to Worksheet 4.

- A discussion on any reduction opportunities that have changed from the original plan or prior progress reports.

- 1 description of any new opportunities you have identified and selected for implementation.

Facility name: Hanford

Reporting Year(s): October 1, 1992 - December 31, 1993

Number: PNL 3-1

Short name: Continue segregating used oils

Description: Continue segregating used oils by type to prevent cross contamination and allow for recycling opportunities.

Number: PNL 3-2

Short name: Evaluate routine maintenance/possibilities

Description: Evaluate routine maintenance for possibilities to extend period between change out of oil.

\section{Worksheet 3}

\section{Processes Impacted - 080(1)(a)(ii)}

Briefly describe the processes affected by your reduction opportunities; or reference the section and page number where they are described in your Executive Summary (or plan submined in lieu of an Executive Summary). In either case, provide the following information:

- A short name and number for each process. If you did this for your plan or Executive Summary, use the same name and number. Transfer the short name and/or code number to Worksheet 4.

- A discussion on the processes affected by your reduction opportunities.

Facility name: Hanford

Reporting Year(s): October 1, 1992 - December 31, 1993

Number: PNL-3

Short name: Oil

Description: Used oil is generated from change out of oils in motors, refrigeration units, compressors, vacuum pumps, and other mechanical devices. Primarily, used oils are generated from removal through routine maintenance. 
Worksheet 2

Opportunity Descriptions - 080(1)(i)

Briefly describe the reduction oppormunities you have implemented during the past reporting year; or reference the section and page number where the opportunities are described in your Executive Summany (or plan submitted in lieu of an Executive Summary). In either case, provide the following information:

- A shor name and number for each opportunity. If you did this in your plan or Execurive Sumuary, use the same name and number. Transfer the short name and/or code number to Worksheet 4.

- A discussion on any reduction opportunities that hove changed from the original plan or prior progress reports.

- A description of any new oppormunities you have idensified and selected for implementation.

Facillty name: Hanford

Reporting Year(s): October 1, 1992 - December 31, 1993

Number: PNL 4-1

Short name: Purchase and install a solvent reclaiming unit

Description: Purchase of a solvent recovery system has been evaluated and budgeted. Manufacturers of these units claim a 65 to $95 \%$ reduction in waste volumes, depending on the application.

Number: PNL 4-3

Short name: Procure less hazardous/nonhazardous paints

Description: Procurement of less hazardous paints has been emphasized to paint shop personnel. However, revising procurement policies and procedures to account for less hazardous substitutes is being pursued. For example. PNL has recently instituted a Chemical Management System that will eventually be tied in to the procurement system to greatly reduce the purchase of unnecessarily hazardous products when less hazardous products are available.

Number: PNL 4-4

Short name: Label properly

Description: Labeling paint cans as either hazardous or nonhazardous will allow painters to segregate empty cans so that cans containing nonhazardous residues will not be disposed of with empty cans containing hazardous residues. This should significantly reduce paint waste associated with empty cans. 


\section{Worksheet 3 \\ Processes Impacted - 080(1)(a)(ii)}

Briffly describe the processes affected by your reduction opportunities; or reference the section and page number where they are described in your Executive Summary (or plan subminted in lieu of an Executive Summary). In either case, provide the following information:

- A shor name and number for each process. If you did this for your plan or Executive Summary, use the same name and number. Transfer the short name and/or code number to Worksheet 4.

- A discussion on the processes affected by your reduction opportunities.

Paclity name: Hanford

Reporting Year(8): October 1, 1992 - December 31, 1993

Number: PNL 4

Short name: Paint waste

Description: Solid paint waste consists of brushes, rollers, crushed empty paint can, drop clothes, masking tape, spray booth ventilation filters, and spray booth floor paper, etc. generated from routine painting operations. Liquid paint waste consists mainly of paint solvents that are used in cleanup activities and a small amount of liquid paint. 

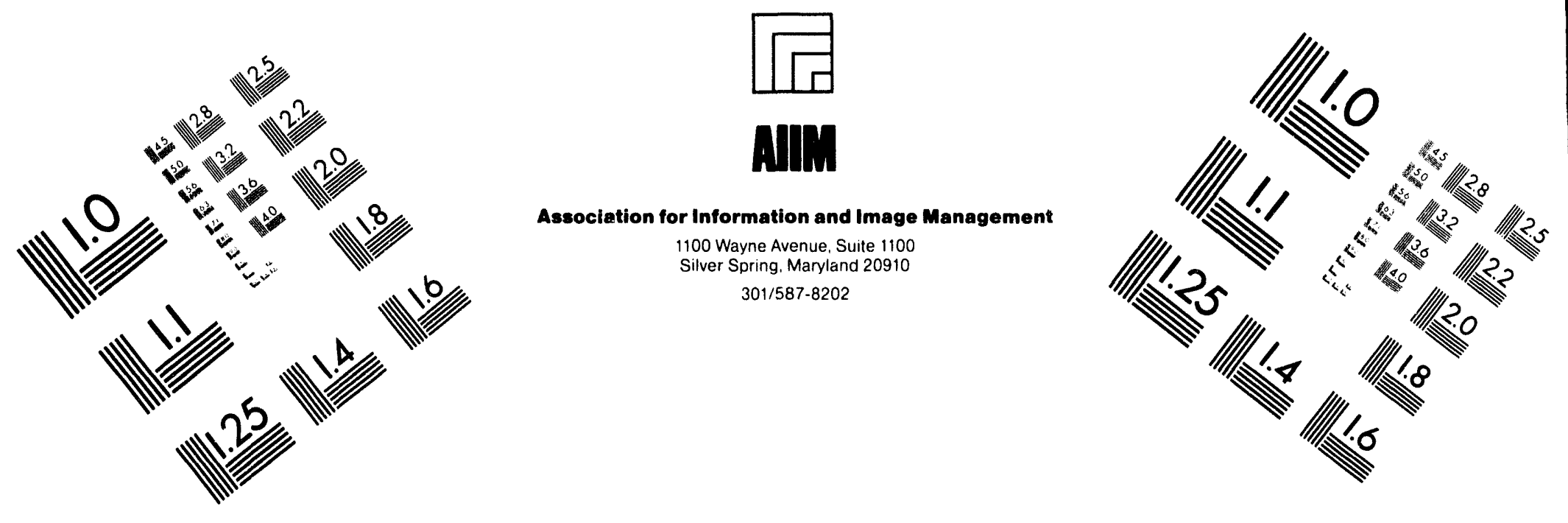

\section{Centimeter}

$\begin{array}{llllllllllllllll}1 & 2 & 3 & 4 & 5 & 6 & 7 & 8 & 9 & 10 & 11 & 12 & 13 & 14 & 15 & \mathrm{~mm}\end{array}$

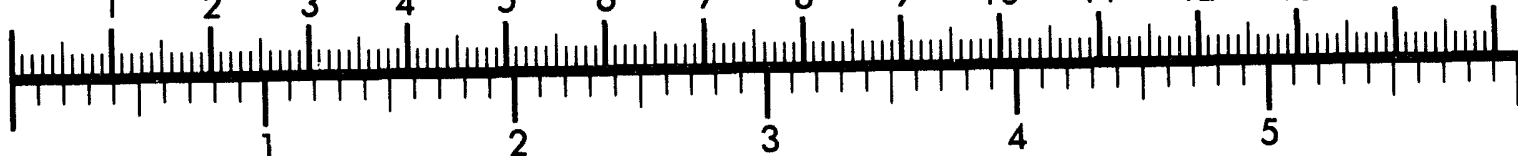
Inches
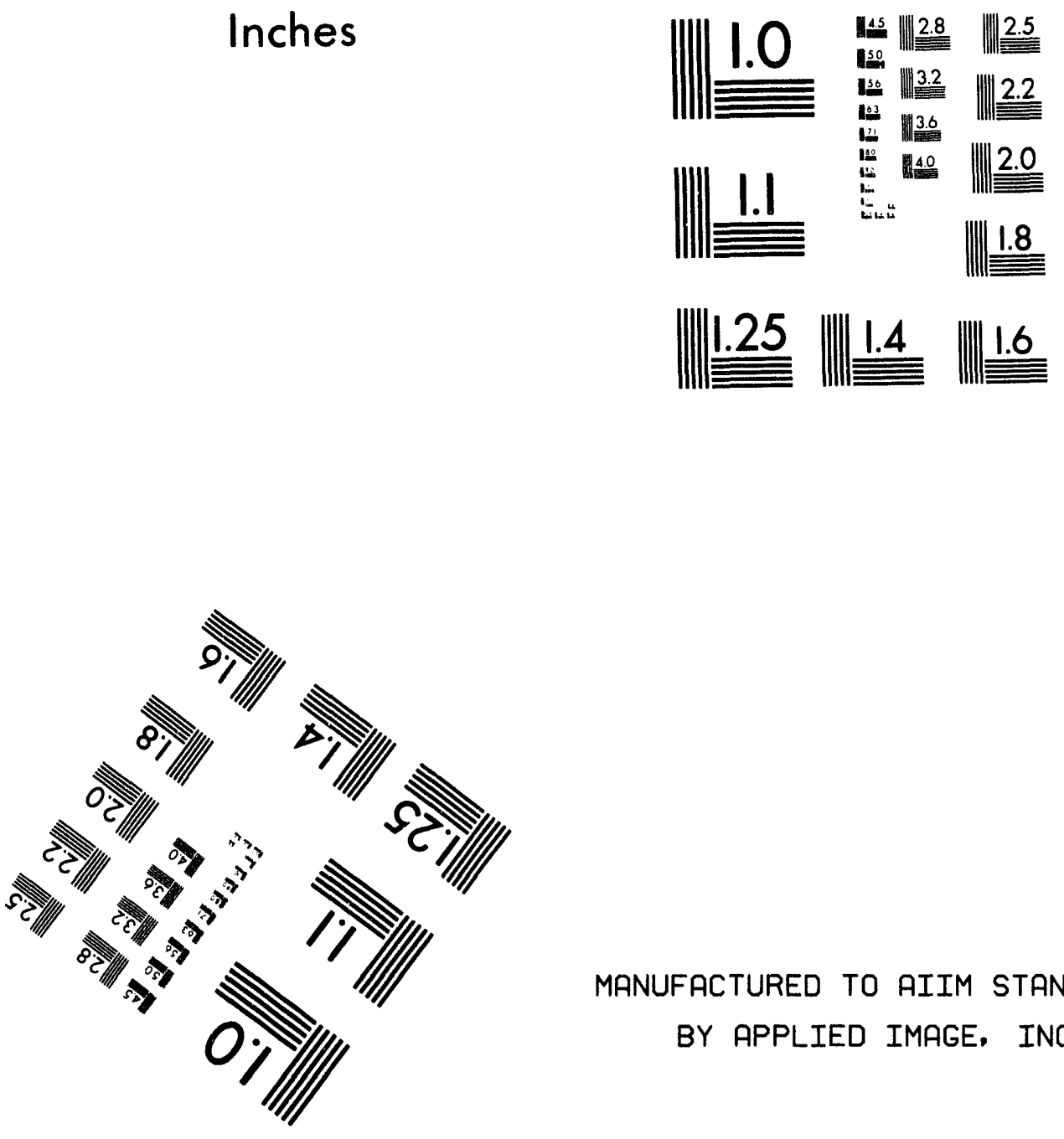

MANUFACTURED TO AIIM STANDARDS BY APPLIED IMAGE, INC.

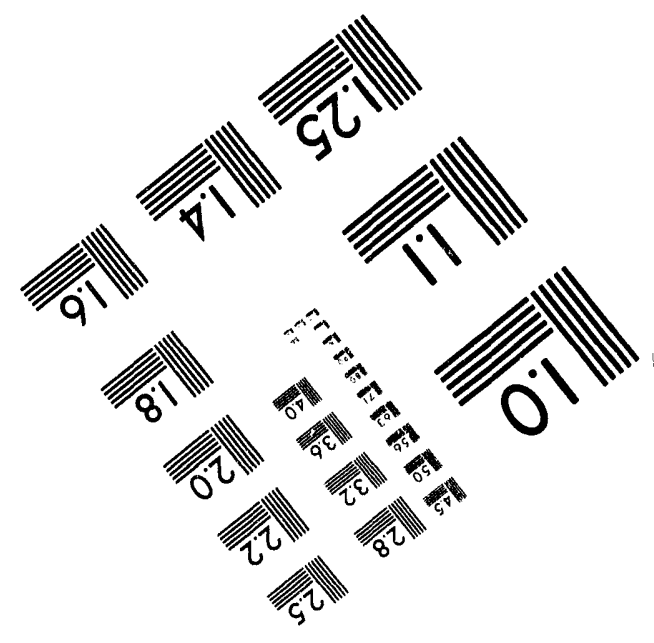



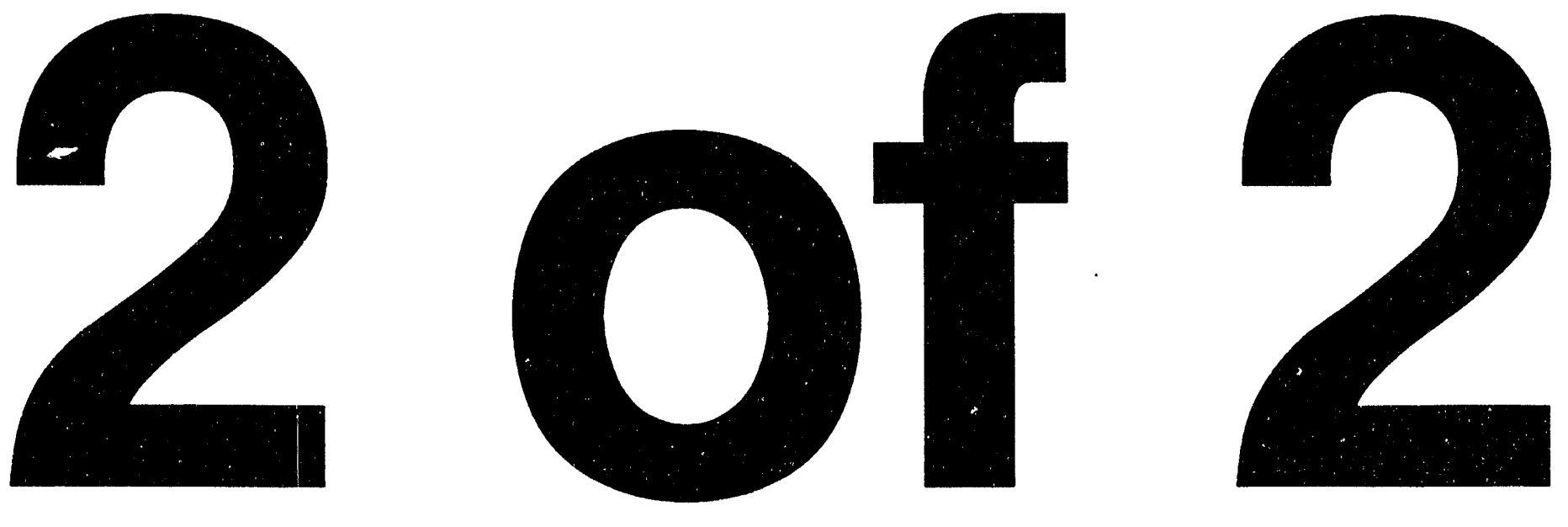


\title{
Worksheet 2 \\ Opportunity Descriptions - 080(1)(i)
}

\begin{abstract}
Briefly describe the reduction opportunities you have implemented during the past reporting year; or reference the section and page number where the opportunities are described in your Executive Summary for plan submitted in lieu of an Executive Summary). In either case, provide the following information:

- A short name and number for each opportunity. If you did this in your plan or Executive Summary, use the same name and number. Transfer the short name and/or code number to Worksheet 4.

- A discussion on any reduction opportunities that have changed from the original plan or prior progress reports.

- A description of any new opportunities you have identified and selected for implementation.
\end{abstract}

Facility name: Hanford

Reporting Year(s): October 1, 1992 - December 31, 1993

Number: PNL 5-1

Short name: Replace magnetic ballasts

Description: Replacement of magnetic ballasts with energy-efficient ballasts will result in the following waste reduction benefits:

First, according to literature provided by the Lighting Design Laboratory in Seattle, Washington, electronic ballasts operate with greater efficiency than magnetic ballasts because of their high operating frequency. This increased efficiency allows for decreased input power (watts) while increasing the overall efficiency of the lighting system.

Second, electronic ballasts have a greater life expectancy than magnetic ballasts, thus reducing ballast replacement and decreasing the ballasts waste stream.

Third, greater operating efficiency also lengthens the life expectancy of the fluorescent tubes, especially if effort has been taken to match appropriate ballasts and tubes. This decreases the fluorescent tube waste stream.

Fourth, electronic ballasts may not contain hazardous substances and may not require management at hazardous waste. This is being investigated. 


\section{Worksheet 3}

\section{Processes Impacted - 080(1)(a)(ii)}

Briefly describe the processes affected by your reduction opportunities; or reference the section and page number where they are described in your Executive Summary (or plan submitzed in lieu of an Executive Summary). In either case, provide the following information:

- A short name and number for each process. If you did this for your plan or Executive Summary, use the same name and number. Transfer the short name and/or code number to Worksheet 4.

- $\quad A$ discussion on the processes affected by your reduction opportunities.

Facility name: Hanford

Reporting Year(s): October 1, 1992 - December 31, 1993

Number: PNL-5

Short name: Light ballasts

Description: Ballasts are changed out lighting fixtures as they fail and are disposed of according to their type and constituents (PCB and non-PCB). 


\title{
Worksheet 2 \\ Opportunity Descriptions - 080(1)(i)
}

\begin{abstract}
Briefly describe the reduction opportunities you have implemented during the past reporting year; or reference the section and page number where the opportunities are described in your Executive Summary (or plan submitted in lieu of an Execurive Summary). In either case, provide the following information:

- A short name and number for each opportunity. If you did this in your plan or Executive Summary, use the same name and number. Transfer the shorn name and/or code number to Worksheet 4.

- A discussion on any reduction opportunities that have changed from the original plan or prior progress reports.

- A description of any new opportunities you have identified and selected for implementation.
\end{abstract}

Facility name: Hanford

Reporting Year(s): October 1, 1992 - December 31, 1993

Number: PUR 2-1

Short name: Recycle all toner cartridges

Description: Toner cartridges should be recycled. The cartridges are sent to a vendor who refurbishes cartridges so that they may be used again. The PUREX plant began recycling the toner cartridges in 1992. Recycling toner cartridges inside the PUREX facility is in progress. The locations for toner cartridge collection have been implemented.

Number: PUR 2-2

Short name: Procurement of recycled toner cartridges

Description: Procurement and Materials Management (PMM) orders office supply materials for the Hanford Site. PMM implemented a contract to have toner cartridges recycled. This contract has saved WHC approximately half the cost when new cartridges are purchased. Since the implementation of the refurbishing contract, WHC has been purchasing new and refurbished cartridges. The refurbished cartridges allow WHC to continue its effort in reducing the amount of waste created on site and saves space in the landfill. 


\section{Worksheet 3}

\section{Processes Impacted - 080(1)(a)(ii)}

Briefly describe the processes affected by your reduction opportunities; or reference the section and page number where they are described in your Executive Summary (or plan submitted in lieu of an Executive Summary). In either case, provide the following information:

- A short name and number for each process. If you did this for your plan or Executive Summary, use the same name and number. Transfer the shor name andlor code number to Worksheet 4.

- $A$ discussion on the processes affected by your reduction opportunities.

Facillty name: Hanford

Reporting Year(s): October 1, 1992 - December 31, 1993

Number: PUR-2

Short name: Printer/toner cartridges

Description: Generation of the waste stream is created by the daily office work. The cartridges limited life span causes a need for replacement when toner is low/empty. The spent cartridge is considered waste once the new cartridge has been installed. 


\section{Worksheet 2 \\ Opportunity Descriptions - 080(1)(i)}

Briefly describe the reduction opportunities you have implemented during the past reporting year; or reference the section and page number where the opportunities are described in your Executive Summary (or plan submitted in lieu of an Executive Summary). In either case, provide the following information:

- A short name and number for each opportunity. If you did this in your plan or Executive Summary, use the same name and number. Transfer the shor name and/or code number to Worksheet 4.

- $\quad A$ discussion on any reduction opportunities that have changed from the original plan or prior progress reports.

- $A$ description of any new opportunities you have identified and selected for implementation.

Facility name: Hanford

Reporting Year(s): October 1, 1992 - December 31, 1993

Number: PUR 3-1

Short name: Procure materials in bulk

Description: Materials can often be purchased in bulk. This option may be feasible for some of the maintenance and janitorial supplies. The material could then be transferred to reusable bottles. This would eliminate the amount of aerosol cans that are kept in inventory and must be disposed.

\section{Worksheet 3}

Processes Impacted - 080(1)(a)(ii)

Briefly describe the processes affected by your reduction opportunities; or reference the section and page number where they are described in your Executive Summary (or plan submitted in lieu of an Executive Summary). In either case, provide the following information:

- A short name and number for each process. If you did this for your plan or Executive Summary, use the same name and number. Transfer the short name and/or code number to Worksheet 4.

- $\quad A$ discussion on the processes affected by your reduction opportunities.

Facility name: Hanford

Reporting Year(s): October 1, 1992 - December 31, 1993

Number: PUR-3

Short name: Aerosol cans

Description: Solvents and some cleaning products are bought in aerosol form. They are then used for general plant maintenance. When the product can no longer be used, the aerosol can is placed in a drum in a satellite accumulation area. Disposal of the material is performed by certified waste shippers. 


\section{Worksheet 2 \\ Opportunity Descriptions - 080(1)(i)}

Briefly describe the reduction opportunities you have implemented during the past reporting year; or reference the section and page number where the opportunities are described in your Executive Summary (or plan submitted in lieu of an Executive Summary). In either case, provide the following information:

- A short name and number for each opportunity. If you did this in your plan or Executive Summary, use the same name and number. Transfer the short name and/or code number to Worksheet 4.

- $A$ discussion on any reduction opportunities that have changed from the original plan or prior progress reports.

- A description of any new opportunities you have identified and selected for implementation.

Facility name: Hanford

Reporting Year(s): October 1, 1992 - December 31, 1993

Number: PUR 4-1

Short name: Procure only nonregulated oils

Description: The current working level of 10 types of oil are all nonregulated products. The inventory of $\mathbf{3 5}$ to $\mathbf{4 0}$ types of oil was decreased to help minimize the amount of material held at the facility. The hazards of each product was evaluated during the reduction. The final 10 oils chosen to remain in the PUREX Plant inventory were all nonregulated products.

\section{Number: PUR 4-2}

Short name: Recycle as much oil as possible

Description: The PUREX facility has been recycling oil that is determined by sampling to be specification-used oil or nonspecification-used oil. The oil that is recycled is used for burning in shops and burned for heating in schools. Oil that is designated as hazardous waste cannot be recycled, but must be disposed of as hazardous waste.

The testing that is performed on the oil looks for PCB content, flashpoint, and halogenated hydrocarbons. If heavy metals are suspected, a toxicity characteristic leachate procedure (TCLP) analysis is performed on the sample. 


\section{Worksheet 3 \\ Processes Impacted - 080(1)(a)(ii)}

Briefty describe the processes affected by your reduction opportunities; or reference the section and page number where they are described in your Exerutive Summary (or plan submitted in lieu of an Executive Summary). In either case, provide the following information:

- A short name and number for each process. If you did this for your plan or Executive Summary, use the same name and number. Transfer the short name and/or code number to Worksheet 4.

- A discussion on the processes affected by your reduction opportunities.

Facility name: Hanford

Reporting Year(s): October 1, 1992 - December 31, 1993

Number: PUR-4

Short name: Process oil systems

Description: The PUREX Plant equipment is maintained through routine maintenance activities. The activities include lubing equipment, changing oil, and greasing bearings, etc. This maintenance of the equipment produces waste streams. Some of the oil that is placed into the equipment is burned up during equipment operation. During application of the oil/lubrication material, a possibility exists for spills.

Resultant streams from the routine maintenance of equipment are nonregulated, regulated waste, oil that is able to be recovered for recycling, leaks, and occasional spills. 


\section{Worksheet 2 \\ Opportunity Descriptions - 080(1)(i)}

Briefly describe the reduction opportunities you have implemented during the past reporting year; or reference the section and page number where the opportunities are described in your Executive Summary (or plan submitted in lieu of an Executive Summary). In either case, provide the following information:

- A shor name and numbe. jor each opportunity. If you did this in your plan or Executive Summary, use the same name and number. Transfer the short name and/or code number to Worksheet 4.

- A discussion on any reduction opportunities that have changed from the original plan or prior progress reports.

- A description of any new opportunities you have idensified and selected for implementation.

Facility name: Hanford

Reporting Year(s): October 1, 1992 - December 31, 1993

Number: PUR 5-1

Short name: Procure alkaline or general purpose batteries, but not both

Description: Procurement of either alkaline or general purpose batteries from an approved list of manufacturers would eliminate the need for multiple MSDSs and a more efficient means for tracking the product and managing the materials. Applications for the general purpose batteries and the alkaline batteries overlap, and in most cases either battery will perform the desired function with no harm to the equipment.

Benefits to using the alkaline or the general purpose batteries that are received from a designated manufacturer off of a list of accepted manufacturers would be the reduction in cost that occurs in handling and managing the wastes, disposal costs, procurement costs, and the cost required to handle each MSDS.

Number: PUR 5-2

Short name: Recycle lead acid batteries

Description: Lead acid batteries are currently under a recycling contract. The batteries are collected, surveyed, and shipped to the appropriate building to be sent to the recycling vendor.

Number: PUR 5-3

Short name: Begin recycling general purpose and alkaline batteries

Description: A recycling contract is being negotiated that would allow WHC to recycle all of the batteries used on the Hanford Site. This would allow for the reclamation of the material instead of it being disposed of as hazardous waste. 


\section{Worksheet 3 \\ Processes Impacted - 080(1)(a)(ii)}

Briefly describe the processes affected by your reduction opportunities; or reference the section and page number where they are described in your Executive Summary (or plan submitted in lieu of an Executive Summary). In either case, provide the following information:

- $\quad$ A short name and number for each process If you did this for your plan or Executive Summary, use the same name and number. Transfer the short nam nd/or code number to Worksheet 4.

- $\quad A$ discussion on the processes affected by your reduction opportunities.

Facility name: Hanford

Reporting Year(s): October 1, 1992 - December 31, 1993

Number: PUR-5

Short name: Spent batteries

Description: The general purpose and alkaline batteries are used in small equipment and maintenance items. Some of the items included are as follows: flashlights, adding machines, calculators, office equipment, pagers, etc. Lead acid batteries are used in the plant's emergency lighting and vehicles. 


\section{Worksheet 2}

Opportunity Descriptions - 080(1)(i)

Briefly describe the reduction opportunities you have implemented during the past reporting year; or reference the section and page number where the opportunities are described in your Executive Summary (or plan submitted in lieu of an Executive Summary). In either case, provide the following information: A shor name and number for each oppornunity. If you did this in your plan or Executive Summary, use the same name and number. Transfer the short name and/or code number to Worksheet 4.

- A discussion on any reduction opportunities that have changed from the original plan or prior progress reports.

- A description of any new opportunities you have identified and selected for implementation.

Facility name: Hanford

Reporting Year(s): October 1, 1992 - December 31, 1993

Number: $\quad$ PUR 6-1

Short name: Increased use of latex paints

Description: The PUREX facility is trying to reduce the amount of enamel paint used in jobs. Latex paints are being used more frequently by painters. Substitutes are used in as many areas as possible. There are some jobs where a latex has been tried as a substitute for the enamel, but did not hold up under the stress of the area where it was applied.

Evaluation of latex enamel products will continue as substitutes are sought for the enamel paints.

Number: $\quad$ PUR 6-2

Short name: Paint brush washing station

Description: A paint brush washing station is being considered for use at the PUREX facility. The station would allow brushes, that had been used with nonregulated latex paint, to be cleaned so that they could be reused. 
DOE/RL-94-96

\section{Worksheet 3}

\section{Processes Impacted - 080(1)(a)(ii)}

Briefly describe the processes affected by your reduction opportunities; or reference the section and page number where they are described in your Executive Summary (or plan submitted in lieu of an Executive Summary). In either case, provide the following information:

- A shorn name and number for each process. If you did this for your plan or Executive Summary, use the same name and number. Transfer the shor name and/or code number to Worksheet 4.

- $\quad A$ discussion on the processes affected by your reduction opportunities.

Facility name: Hanford

Reporting Year(s): October 1, 1992 - December 31, 1993

Number: PUR-6

Short name: Paint application

Description: Maintenance of the PUREX paint includes paint application. The application of paint often requires a clean surface. When a clean surface is required the area is sandblasted to remove old material and dirt. The sand used in sand blasting is reused until it isn't sharp enough to cut. The brushes that are used to apply paint are used until the job is completed and are then disposed as solid hazardous waste. Other materials used in the application of paint are drop cloths, rags, thinner, masks, etc. 


\section{Worksheet 2}

Opportunity Descriptions - 080(1)(i)

Briefty describe the reduction opportunities you have implemented during the past reporting year; or reference the section and page number where the opportunities are described in your Executive Summary (or plan submitted in lieu of an Executive Summary). In either case, provide the following information:

- A short name and number for each opportunity. If you did this in your plan or Executive Summary, use the same name and number. Transfer the shor name and/or code number to Worksheet 4.

- A discussion on any reduction opportunities that have changed from the original plan or prior progress reports.

- 1 description of any new opportunities you have identified and selected for implementation.

Facility name: Hantord

Reporting Year(s): October 1. 1992 - December 31, 1993

Number: PUR T $T-1$

Short name: Use only nonregulated oils

Description: Using nonregulated oils reduces the toxicity of the rags. The rags can be disposed of as nonregulated waste. Should a rag become contaminated with a regulated oil, caused by equipment failure or heavy metal contamination, it will be disposed of as regulated waste.

\section{Number: PUR 7-2}

Short name: Evaluate products to find less toxic substitutes

Description: Facility personnel evaluate the products used in the facility. Products that are nonregulated, or with the lowest toxicities are sought for use. Use of a substance with low toxicity, or none at all, protects the worker and environment.

Rags that are used with the products that are less toxic can be disposed as such. Use nonregulated oils. Any rag that is used with the nonregulated oil will be consiclered nonregulated waste. 


\section{Worksheet 3}

Processes Impacted - 080(1)(a)(ii)

Briefly describe the processes affected by your reduction opportunities; or reference the section and page number where they are described in your Executive Summany (or plan submitted in lieu of an Executive Summary). In either case, provide the following information: A short name and number for each process. If you did this for your plan or Executive Summary, use the same name and number. Transfer the short name and/or code number to Worksheet 4.

- $\quad A$ discussion on the processes affected by your reduction opportunities.

Facility name: Hanford

Reporting Year(s): October 1, 1992. - December 31, 1993

Number: PUR-7

Short name: Rags

Description: The PUREX Plant has routine and preventative maintenance performed. During the maintenance and upkeep activities, rags are generated that must be disposed of as waste. Routine maintenance activities consist of de-greasing, cleaning, etc.

The rags are used tc apply and absorb the oils and solvents. When the rags become saturated and are no longer able to be reused they are disposed of as waste. 


\title{
Worksheet 2 \\ Opportunity Descriptions - 080(1)(i)
}

\begin{abstract}
Briefly describe the reduction opportunities you have implemented during the past reporting year; or reference the section and page number where the opportunities are described in your Executive Summary (or plan submitted in lieu of an Executive Summary). In either case, provide the following information:

- A short name and number for each opportunity. If you did this in your plan or Executive Summary, use the same name and number. Transfer the shor name and/or code number to Worksheet 4.

- A discussion on any reduction opportunities that have changed from the original plan or prior progress reports.

- A description of any new opportunities you have identified and selected for implementation.
\end{abstract}

Facility name: Hanford

Reporting Year(s): October 1, 1992 - December 31, 1993

Number: PUR 8-1

Short name: Use standard for central point for ordering

Description: The packing constraints and requirements for chemicals that have been placed on the manufacturers makes it hard to receive chemicals in small quantities. The quantities chemicals are shipped in are often larger than what is required in analysis. If the analysis is not run on a frequent basis, the chemical could expire, becoming waste. To prevent unused chemicals from becoming waste, the 222SA standards laboratory is being used as a central point for ordering, storing, and distributing chemicals. Use of the 222SA standards laboratory for an ordering, storing, and distribution point reduces waste because all three analytical laboratories can use material from the same stock bottles, thereby reducing the quantity of material kept on site, and only the quantity that is requested can be delivered to the laboratories. The waste that comes from the 222SA facility is disposed of as hazardous waste, not radioactive or mixed waste.

Number: PUR 8-3

Short name: Replace regulated supplies with nonregulated materials

Description: Find nonregulated products to replace regulated ones.

Number: PUR 8-4

Short name: Find alternate users for laboratory chemicals and equipment

Description: As the mission of the PUREX laboratory changes, less support material is needed. Alternative users are sought for the excess material before it is declared a waste. 


\section{Worksheet 3 \\ Processes Impacted - 080(1)(a)(ii)}

Briefly describe the processes affected by your reduction opportunities; or reference the section and page number where they are described in your Executive Summary (or plan submitred in lieu of an Executive Summary). In either case, provide the following information:

- A shor name and number for each process. If you did this for your plan or Executive Summary, use the same name and number. Transfer the shor name and/or code number to Worksheet 4.

- $A$ discussion on the processes affected by your reduction opportunities.

Facility name: Hanford

Reporting Year(s): October 1, 1992 - December 31, 1993

Number: PUR-8

Short name: Laboratory waste

Description: The PUREX laboratory receives samples from PUREX operations, chemical engineering, 222SA laboratory, and other sources. Many different types of analyses are performed, such as acid/base titrations, uranium plutonium or total alpha/beta and gamma energy analysis (GEA) determinations. These analyses standards are furnished by the standards laboratory or chemists/technicians using the PUREX laboratory inventory. Shelf life of the reagents/standards and chemicals is taken into consideration; they are monitored so shelf life does not expire and as such, generate waste.

Laboratory equipment components may become waste because a component(s) is composed of hazardous materials, such as lithium batteries that are used in pipets or inductively coupled plasma (ICP) electron tubes that contain beryllium. Further, equipment may become contaminated with hazardous material or radioactive material during routine laboratory work; in such a case, the equipment will become waste if cleaning cannot sufficiently remove the hazardous or radioactive material. Laboratory procedures require the use of various safety horns, anticontamination clothing, and other materials that may become waste, dependent upon usage. In addition, laboratory maintenance may generate waste, such as paint, light ballasts, etc.

Aqueous wastes from the laboratory are sent to Tanks U3/U4. Liquid organic wastes and solid hazardous chemicals from the radiation zone are labpacked and sent to the central waste complex as mixed waste. 


\section{Worksheet 2 \\ Opportunity Descriptions - 080(1)(i)}

Briefty describe the reduction opportunities you have implemented during the past reporting year; or reference the section and page number where the opporturities are described in your Executive Summary (or plan submitted in lieu of an Executive Summary). In either case, provide the following information:

- A shor name and number for each opporrunity. If you did this in your plan or Executive Summary, use the same name and number. Transfer the shor name and/or code number to Worksheet 4.

- A discussion on any reduction opportunities that have changed from the original plan or prior progress reports.

- A description of any new opporturities you have identified and selected for implementation.

Facility name: Hanford

Reporting Year(s): October 1, 1992 - December 31, 1993

Number: UOX 2-1

Short name: Recycle all toner cartridges

Description: Toner cartridges should be recycled. The cartridges are sent to a vendor who refurbishes cartridges so that they may be used again.

The UO3 Plant began recycling the toner cartridges in late 1992. Recycling toner cartridges inside the $\mathrm{UO} 3$ fence is in progress. The location for toner cartridge collection has been implemented.

Number: UOX 2-2

Short name: Procurement of recycled toner cartridges

Description: Procurement and Materials Management (PMM) orders office supply materials for the Hanford Site. PMM implemented a contract to have toner cartridges recycled. This contract has saved WHC approximately half the cost when new cartridges are purchased.

Since the implementation of the refurbishing contract, WHC has been purchasing new and refurbished cartridges. The refurbished cartridges allow WHC to continue its effort in reducing the amount of waste created on site and saves space in the landfill. 


\section{Worksheet 3}

Processes Impacted - 080(1)(a)(ii)

Briefly describe the processes affected by your reduction opporiunities; or reference the section and page number where they are described in your Executive Summary (or plan submitted in lieu of an Executive Summary). In either case, provide the following information:

- A short name and number for each process. If you did this for your plan or Executive Summary, use the same name and number. Transfer the shor name andlor code number to Worksheet 4.

- A discussion on the processes affected by your reduction opportunities.

Facility name: Hanford

Reporting Year(s): October 1, 1992 - [lecember 31, 1993

Number: UOX-2

Short name: Printer/toner cartridges

Description: Generation of the waste stream is created by the daily office work. The cartridges limited life span causes a need for replacement when toner is low/empty. The spent cartridge is considered waste once the new cartridge has been installed. 


\title{
Worksheet 2 \\ Opportunity Descriptions - 080(1)(i)
}

\begin{abstract}
Briefly describe the reduction opportunities you have implemented during the past reporting year; or reference the section and page number where the opportunities are described in your Executive Summary (or plan submined in lieu of an Executive Summary). In either case, provide the following information:

- A short name and number for each opportunity. If you did this in your plan or Executive Summary, use the same name and number. Transfer the short name and/or code number to Worksheet 4.

- A discussion on any reduction opportunities that have changed from the original plan or prior progress reports.

- A description of any new opportunities you have identified and selected for implementation.
\end{abstract}

Facility name: Hanford

Reporting Year(s): October 1, 1992 - December 31, 1993

Number: UOX 3-1

Short name: Procure materials in bulk

Description: Materials can often be purchased in a bulk quantity. This option may be feasible for some of the maintenance and janitorial supplies. The material could then be transferred to reusable bottles. This would eliminate the amount of aerosol cans that are kept in the inventory and must be disposed.

\section{Worksheet 3 Processes Impacted - 080(1)(a)(ii)}

Briefly describe the processes affected by your reduction opportunities; or reference the section and page number where they are described in your Executive Summary (or plan submitted in lieu of an Executive Summary). In either case, provide the following information:

- A short name and number for each process. If you did this for your plan or Executive Summary, use the same name and number. Transfer the short name and/or code number to Worksheet 4.

- $\quad A$ discussion on the processes affected by your reduction opportunities.

Facility name: Hanford

Reporting Year(s): Ostober 1, 1992 - December 31, 1993

Number: UOX-3

Short name: Aerosol cans

Description: Solvents and some cleaning products are bought in aerosol form. They are then used for general plant maintenance. When the product can no longer be used, the aerosol can is placed in a drum in a satellite accumulation area. Disposal of the material is performed by certified waste shippers. 


\section{Worksheet 2}

Opportunity Descriptions - 080(1)(i)

Briefly describe the reduction opportunities you have implemented during the past reporting year; or reference the section and page number where the opportunities are described in your Executive Summary for plan submitred in lieu of an Executive Summary). In either case, provide the following information:

- A short name and number for each opportunity. If you did this in your plan or Executive Summary, use the same name and number. Transfer the short name and/or code number to Worksheet 4.

- A discussion on any reduction opportunities that have changed from the original plan or prior progress reports.

- A description of any new opportunities you have identified and selected for implementation.

Facility name: Hanford

Reporting Year(s): October 1, 1992 - December 31, 1993

Number: UOX 4-1

Short name: Procure only nonregulated oils

Description: The current working level inventory of 10 types of oil are all nonregulated products. The inventory of 35 to 40 types of oil was decreased in an effort to minimize the amount of material held at the facility. During the reduction of the number of types of oil held at the plant, the hazards of each product was evaluated. The final 10 oils chosen to remain in the UO3 Plant inventory were all nonregulated products.

Number: UOX 4-2

Short name: Recycle as much oil as possible

Description: The UO3 Plant has been recycling oil that is determined by sampling to be specification used oil or nonspecification used oil. The oil that is recycled is used for buming in shop and bumed for heating in schools. Oil that is designated as hazardous waste cannot be recycled, but must be disposed of as hazardous waste.

The testing that is performed on the oil looks for PCB content, flashpoint, and halogenated hydrocarbons. If heavy metals are suspected, a TCLP analysis is performed on the sample. 


\section{Worksheet 3}

Processes Impacted - 080(1)(a)(ii)

Briefly describe the processes affected by your reduction opportunities; or reference the section and page number where they are described in your Executive Summary (or plan submitied in lieu of an Executive Summary). In either case, provide the following information:

- A shor name and number for each process. If you did this for your plan or Executive Summary, use the same name and number. Transfer the shor name and/or code number 10 Worksheet 4.

- A discussion on the processes affected by your reduction opporturities.

Facility name: Hanford

Reporting Year(s): October 1, 1992 - December 31, 1993

Number: UOX-4

Short name: Process oil systems

Description: The UO3 Plant equipment is maintained through routine maintenance activities. The activities include lubing equipment, changing oil, greasing bearings, etc. This maintenance of the equipment produces waste streams. Some of the oil that is placed into the equipment is burned up during equipment operation. During application of the oil/lubrication material, a possibility exists for spills to the environment.

Resultant streams from the routine maintenance of equipment are nonregulated, regulated waste, oil that is able to be recovered for recycling, leaks, and occasional spills to the environment. 


\section{Worksheet 2}

\section{Opportunity Descriptions - 080(1)(i)}

Briefly describe the reduction opportunities you have implemented during the past reporting year; or reference the section and page number where the opportunities are described in your Executive Summary (or plan submitted in lieu of an Executive Sunmary). In either case, provide the following information:

- A short name and number for each opportunity. If you did this in your plan or Executive Summary, use the same name and number. Transfer the short name and/or code number to Worksheet 4.

- A discussion on any reduction opportunities that have changed from the original plan or prior progress reports.

- A description of any new opportunities you have identified and selected for implementation.

Facility name: Hanford

Reporting Year(s): October 1, 1992 - December 31, 1993

Number: UOX 5-1

Short name: Procure alkaline or general purpose batteries

Description: Procurement of either alkaline or general purpose batteries from an approved list of manufacturers would eliminate the need for multiple MSDSs and a more efficient means for tracking the product and managing the materials. Applications for the general purpose batteries and the alkaline batteries overlap, and in most cases either battery will perform the desired function with no harm to the equipment.

Benefits to using only the alkaline or the general purpose batteries that are received from a designated manufacturer off of a list of accepted manufacturers would be the reduction in cost that occurs in handling and managing the wastes, disposal costs, procurement costs, and the cost required to handle each MSDS.

Number: UOX 5-2

Short name: Recycle lead acid batteries

Description: Lead acid batteries are currently under a recycling contract. The batteries are collected, surveyed, and shipped to the appropriate building to be sent to the recycling vendor.

A recycling contract is being negotiated that would allow recycling of all batteries used on the Hanford Site. This would allow for the reclamation of the material instead of it being disposed of as a hazardous waste.

Number: UOX 5-3

Short name: Begin recycling general purpose and alkaline batteries

Description: Lead acid batteries are currently under a recycling contract. The batteries are collected, surveyed, and shipped to the appropriate building to be sent to the recycling vendor. 


\section{Worksheet 3}

\section{Processes Impacted - 080(1)(a)(ii)}

Briefly describe the processes affected by your reduction opportunities; or reference the section and page number where they are described in your Execurive Summary (or plan submitted in lieu of an Executive Summary). In either case, provide the following information:

- A shor name and number for each process. If you did this for your plan or Executive Summary, use the same name and number. Transfer the shon name and/or code number to Worksheet 4.

- $A$ discussion on the processes affected by your reduction opportunities.

Facility name: Hanford

Reporting Year(s): October 1, 1992 - December 31, 1993

Number: UOX-5

Short name: Spent batteries

Description: The general purpose and alkaline batteries are used in small equipment and maintenance items. Some of the item are as follows: flashlights, adding machines, calculators, office equipment, pagers, etc. Lead acid batteries are used in the plant's emergency lighting and vehicles. 


\section{Worksheet 2}

\section{Opportunity Descriptions - 080(1)(i)}

Briefly describe the reduction opportunities you have implemented during the past reporting year; or reference the section and page number where the opportunities are described in your Executive Summary (or plan submitred in lieu of an Executive Summary). In either case, provide the following information:

- A short name and number for each opportunity. If you did this in your plan or Execurive Summary, use the same name and number. Transfer the shor name and/or code number to Worksheet 4.

- A discussion on any reduction opportunities that have changed from the original plan or prior progress reports.

- $\quad A$ description of any new opportunities you have identified and selected for implementation.

Facility name: Hanford

Reporting Year(s): October 1, 1992 - December 31, 1993

Number: UOX 6-1

Short name: Increased use of latex paints

Description: The UO3 Plant is trying to reduce the amount of enamel paint used in jobs. Latex paints are being used more frequently by painters. Latex is less hazardous to the worker than the enamel paints. Substitutes are used in as many areas as possible. There are some jobs where a latex has been tried as a substitute for the enamel, but did not hold up under the stress of the area where it was applied.

Evaluation of latex enamel products will continue as substitutes are sought for the enamel paints.

Number: UOX 6-2

Short name: Paint brush washing station

Description: A paint brush washing station is being considered for use at the UO3 Plant. The station would allow brushes, that had been used with nonregulated latex paint, to be cleaned so that they could be reused. 


\section{Worksheet 3}

Processes Impacted - 080(1)(a)(ii)

Briefly describe the processes affected by your reduction opportunities; or reference the section and page number where they are described in your Executive Summary (or plan submitied in lieu of an Executive Summary). In either case, provide the following information:

- A shor name and number for each process. If you did this for your plan or Execurive Summary, use the same name and number. Transfer the shor name and/or code number to Worksheet 4.

- $\quad$ discussion on the processes affected by your reduction opportunities.

Facility name: Hanford

Reporting Year(s): October 1, 1992 - December 31, 1993

Number: UOX-6

Short name: Paint application

Description: Maintenance of the UO3 Plant includes paint application. The application of paint often requires a clean surface. When a clean surface is required, the area is sandblasted to remove old material and dirt. The sand used in sand blasting is reused until it isn't sharp enough to cut. The brushes that are used to apply paint are used until the job is completed and are then disposed as solid hazardous waste. Other materials used in the application of paint are drop cloths, rags, thinner, masks, etc. 


\section{Worksheet 2 \\ Opportunity Descriptions - 080(1)(i)}

Briefly describe the reduction opportunities you have implemented during the past reporting year; or reference the section and page number where the opportunities are described in your Executive Summany (or plan submitted in lieu of an Executive Summary). In either case, provide the following information:

- A short name and number for each opportunity. If you did this in your plan or Executive Summary, use the same name and number. Transfer the shor name and/or code number to Worksheet 4.

- A discussion on any reduction opportunities that have changed from the original plan or prior progress reports.

- A description of any new opportunities you have identified and selected for implementation.

Facility name: Hanford

Reporting Year(s): October 1, 1992 - December 31, 1993

Number: UOX 7-1

Short name: Use only nonregulated oils

Description: Using nonregulated oils reduces the toxicity of the rags. The rags can be disposed of as nonregulated waste. Should a rag become contaminated with a regulated oil, caused by equipment failure or heavy metal contamination, it will be disposed of as regulated waste.

Number: UOX 7-2

Short name: Evaluate products to find less toxic substitutes

Description: Facility personnel evaluate the products used in the facility. Products that are nonregulated, or with the lowest toxicities, are sought for use. Using a substance with low toxicity, or none at all, protects the worker and environment.

Rags that are used with the products that are less toxic can be disposed as such. Use nonregulated oils. Any rag that is used with the nonregulated oil will be considered nonregulated waste. 


\section{Worksheet 3}

\section{Processes limpacted - 080(1)(a)(ii)}

Briefly describe the pricesses affected by your reduction opportunities; or reference the section and page number where they are described in your lixecutive Summary (or plan submitted in lieu of an Executive Summary). In either case, provide the following information:

- A shor name and number for each process. If you did this for your plan or Executive Summary, use the same name oud number. Transfer the short name and/or code number to Worksheet 4.

- $\quad$ discusision on the processes affected by your reduction opportunities.

Facility name: Haniford

Reporting Year(s): Dctober 1, 1992 - December 311993

Number: UOX 7

Short name: Rags

Description: The UO3 Plant has routine and preventative maintenance performed. During the maintenance activities, rags are generated that must be disposed of as waste. Routine maintenance activities consist of painting, lubrication of equipment, changing oil in equipment, de-greasing, cleaning, etc.

The rags are used to apply and absorb the oils and solvents. When the rags become saturated and are no longer able to be reused they are disposed of as waste. 
DOE/RL-94-96

This page left intentionally blank.

C-72 
DOE/RL-94-96

SECTION D

PRODUCTION LEVELS, PROBLEMS, AND ESTIMATION TECHNIQUES 


\title{
Worksheet 5 \\ Production Levels, Problems
}

Facility name: Hanford

Reporting Year(s): October 1, 1992 - December 31, 1993

Production Levels - 080(1)(a)(iii)

Your progress needs to be reported in relation to changing production levels. This is done by comparing units of production during the reporting year with units of production in the base year, as listed in your plan. You only need to report a "production factor."

The production factor is salculated by dividing the level of production in the reporting year by the level of production in the base year. This will result in a production factor greater than 1.0 if production has increased, and less than 1.0 if production decreased.

\author{
1993 Year level $=\mathrm{n} / \mathrm{a}$ \\ Base Year level $(1991)=\mathrm{n} / \mathrm{a}$ \\ Production Factor (this reporting year): $\mathrm{n} / \mathrm{a}$
}

A production factor is difficult to characterize given the current nature of work processes at the Hanford Site. The Hanford Site mission is to clean up the Hanford Site, eliminate potential risks to the public and our workers, and serve as the DOE model in environmental restoration-the majority of which is remedial, and hazardous waste generated under such action is excluded from the pollution prevention progress measurement under WAC 173-307. As the recent work at the Hanford Site does not involve manufacturing products, no comparison of units of production can be made. If needed for this progress report, consider the production factor $=1.0$.

\section{Problems Encountered - 080(1)(b)}

Clearly identify any problems encountered in the implementation process specific to selected opportunities. Some examples might be: unexpected regulatory problems; capital andlor operating costs higher than expected; equipment and necessary debugging adjustments. Include in your discussion the following items:

- Specific problems encountered in implementing selected opportunities.

- Steps taken or proposed to resolve the problems.

- Update problems identified in previous reporting periods.

Discussion: The impediments discussed in the Executive Summary, Section 3.2 .5 continue to impact progress in implementing selected opportunities. Some steps taken to reduce the impediments include implementation of the Hazardous Materials Reduction Initiative project designed to review purchase requisitions for hazardous or toxic substances and offer lessor or nonhazardous product substitution alternatives. By controlling the quantity and type of chemicals and hazardous materials purchased through the Westinghouse Hanford Procurement system, we reduce the amount of hazardous and mixed waste disposed.

In conjunction with this activity, a small database of alternative chemicals and products has been developed. The database, compiled from internal and external sources, is being expanded as more information from product testing becomes available. Although much work has been done in this area by other companies and contractors, a single transportable database for use at all DOE facilities is not available. 
Most of the progress in implementing Pollution Prevention opportunities has occurred in facilities where there is a strong grassroots advocacy with a supportive middle management. The disincentives, though, are formidable based on the current regulatory and fiscal policies that drive priority resources. Some of the disincentives are as follows: (1) lack of priority; (2) lack of middle management accountability through performance measures; (3) lack of upper management attention; (4) absence of real economic incentives; (5) lack of funding; and (6) cultural inertia.

Nevertheless, Pollution Prevention projects continue to be developed and implemented. The greatest number of success stories relate to low cost, readily implemented opportunities. Opportunities could be advanced and better efficiencies obtained simply through more communication/cooperation among the facilities and in some cases coordination of "seed" monies. Regular meetings with the Site Pollution Prevention representatives have been instituted to facilitate the communication/cooperation among the facilities. A Hanford Site request for Pollution Prevention funds is being submitted to DOE-HQ for priority activities in Fiscal Year 1995 and 1996 to supplement the funding shortfalls projected. 


\section{Worksheet 6}

\section{Estimation Techniques, Conversions}

Facility name: Hanford

Reporting Year(s): October 1, 1992 - December 31, 1993

\section{Estimation Techniques and Assumptions - 080(1)(a)(iii) (if applicable)}

If the hazardous substances or waste reduction reported on Worksheet 4 are not actual amounts, describe the technique(s) and assumptions used to estimate the weight of the maserials.

Discussion: Most numbers on worksheet 4, when represented, are estimates. Estimates are arrived at primarily through process knowledge. This is based on knowing the previous year's waste generation for a given process/activity and calculating the effect of a reduction opportunity while holding variables constant.

Numbers on worksheet 1 are actual amounts taken from the Hanford Site tracking systems, HMID2 and SWITS.

\section{Conversion Methodology - 080(1)(a)(iv) (if applicable)}

If you have changed your measurement or estimation rechniques from prior reporting periods so that reductions are not additive for the five year planning period, describe a methodology for converting your prior reporied reductions and provide the recalculations.

Discussion: $\quad \mathrm{n} / \mathrm{a}$ 
DOE/RL-94-96

This page left intentionally blank.

D-5 
DOE/RL-94-96

This page left intentionally blank.

D-6 


\section{REFERENCES}

DOE/RL, 1992, Hanford Site Pollution Prevention Plan, RL-PPP-92-1, U.S. Department of Energy, Richland Operations Office, Richland, Washington. (NOT FOR PUBLIC RELEASE)

DOE/RL, 1992, Executive Summary, in "Hanford Site Pollution Prevention Plan, " DOE/RL-92-62, U.S. Department of Energy, Richland Operations Office, Richland, Washington.

Ecology, 1993, Pollution Prevention Planning Guidance Manual for Chapter 173-307 WAC, Publication 91-2, Washington State Department of Ecology, Olympia, Washington.

Ecology, 1994, Guidance for Reporting Progress in Pollution Prevention, Publication 93-38, Washington State Department of Ecology, Olympia, Washington. 
DOE/RL-94-96

This page left intentionally blank. 


\section{DISTRIBUTION}

Number of Copies

OFFSITE

ONSITE

1 Washington State Department of Ecology

Mark Benedict

Washington State Department of Ecology/Central Region Office

106 South Sixth Avenue

Yakima, WA 98902-3387

4 U.S. Department of Eneray. Richland Operations Office

E. B. Dagan

J. E. Rasmussen

A5-15

S. H. Wisness

A5-15

RL Public Reading Room

A5-15

A1-65

1 Bechtel Hanford Company

R. A. Lewis

H6-21

1 Hanford Environmental Health Foundation

T. W. Harrison

$\mathrm{H} 1.77$

$5 \quad$ ICF Kaiser
B. J. Dixon
G7-33
D. R. Herman (e)
S2-12
R. L. Lynne
G7-33
C. E. Marple (e)
$\$ 2-34$
A. D. Poor
L6-55

2 Pacific Northwest Laboratory
K. B. Selby
P7-79
H. T. Tilden
P7-79

39 Westinghouse Hanford Company
B. A. Austin
B2-30
C. S. Barr (e)
T5-54
T. G. Beam (e)
S6-70
H. L. Benny (e)
L5-64
F. J. Carvo (e)
N $1-41$
R. D. Clements (e)
S4-25
K. H. Cronin (e)
L. J. Estey
L6-36
D. J. Farquhar (e)
W. O. Greenhalgh (e)
T5-50
A1-05
D. E. Hare $(\theta)$
L5-31
N. O. Hinojosa (e)
S3-97
J. R. Hillard
X0-35
M. B. Jaeger (e)
S6-19
C. R. Joseph
L4-02
J. R. Kirkendall
B2-22
B2-22 
J. M. Kisielnicki (e)

L6-13

D. S. Merry (5)

B2-22

D. A. Moore

H6-21

R. R. Nielson (e)

T4-05

F. D. Schlien ( $\theta)$

T4-05

J. A. Seamans

N2-04

T. W. Seifert (e)

R1-51

J. B. Stec

R. W. Szelmeczka (e)

T3-28

M. R. Vasquez

L4-96

Central Files

Correspondence Control

T7-38

L8-04

Document Processing and

R1-03

Distribution (2)

L8-15

EDMC (2)

OSTI (2)

H6-08

L8-07

(e) - electronic copy 

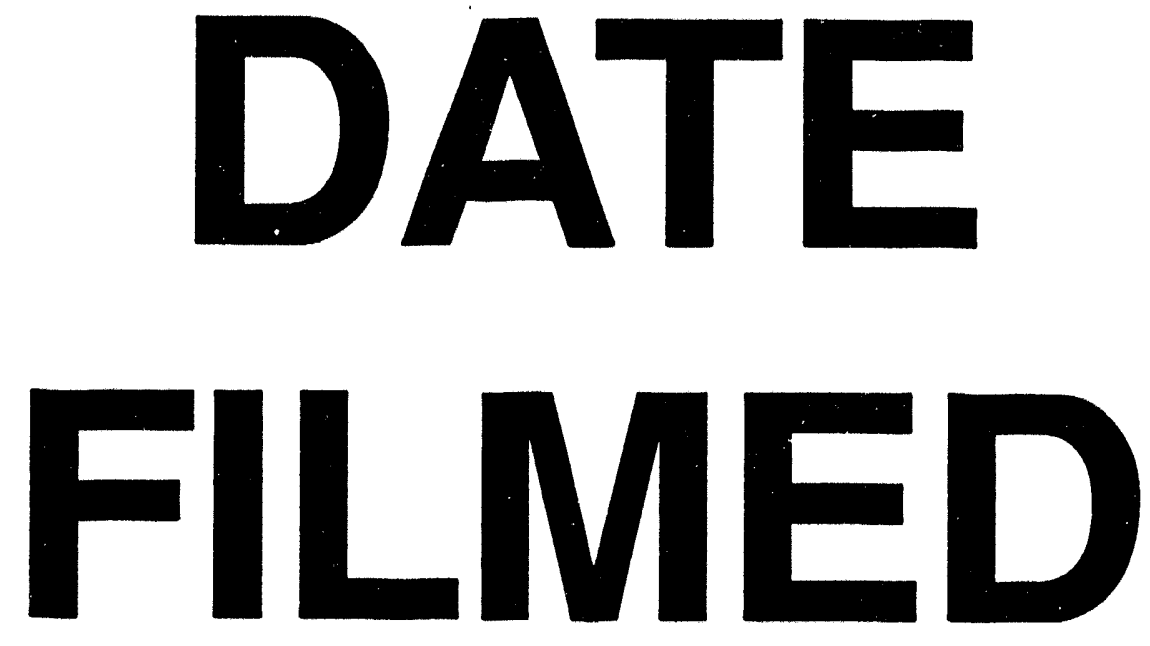

$10 / 05 / 94$
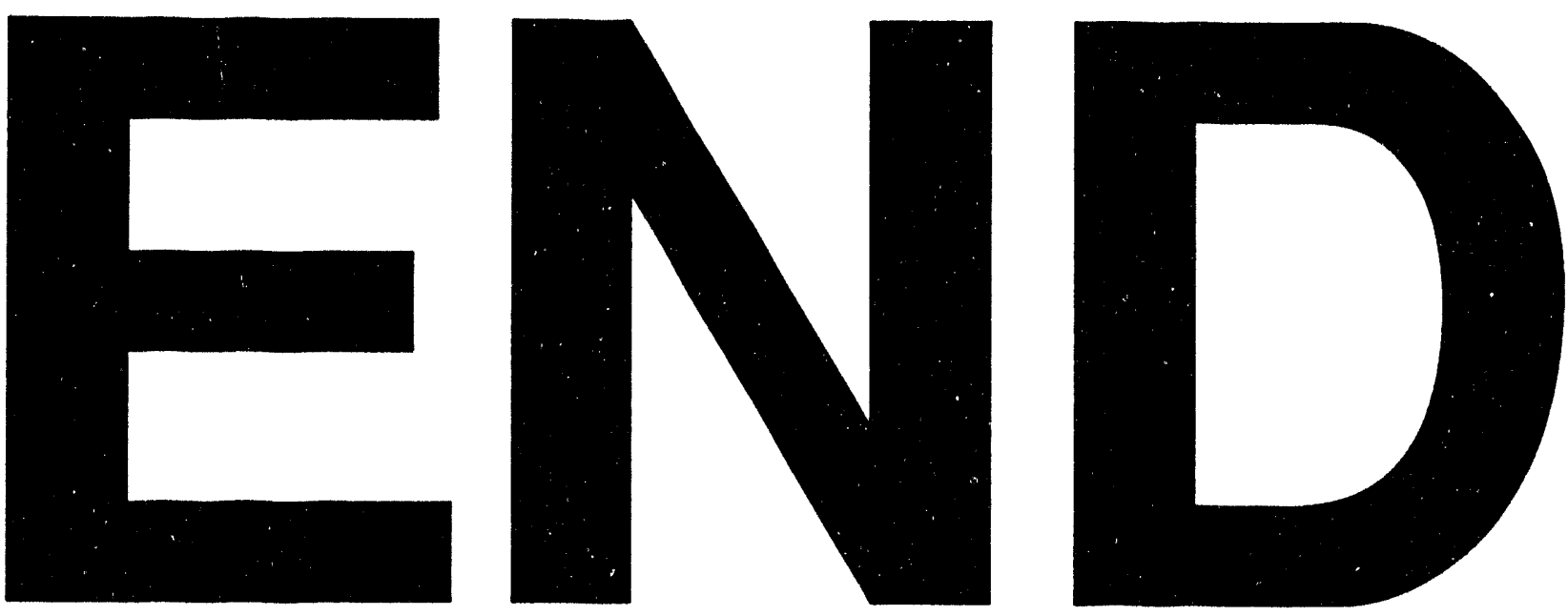
